\title{
Effects of Glass Powder as a Supplementary Cementitious Material on the Performance of High Strength Mortars
}

\section{Amir Reza Tarassoly}

Submitted to the

Institute of Graduate Studies and Research in partial fulfillment of the requirements for the degree of

\author{
Master of Science \\ in \\ Civil Engineering
}

Eastern Mediterranean University

November 2016

Gazimağusa, North Cyprus 


\begin{abstract}
Concrete, is the most widely used engineering material in construction. Since around 11 billion tons of concrete is used each year all over the world, considerable amount of cement is required for its production. This results in high production of carbon dioxide which is one of the main reasons of global warming. Therefore, in the last few years, there is a growing interest in using waste pozzolanic admixtures as a supplementary cementitious material. Using these kind of admixtures as a part of cement replacement reduces the air pollution, cost and also enhances some properties of mortars and concretes.
\end{abstract}

Among the other waste natural pozzolans, glass powder becomes important due to its high content of silica, availability and cost. These motivate lots of researchers to evaluate the effects of glass powder as a cement replacement material.

In this study, effects of three different types (colors) of glass powders with different quantities used as cement replacement on the workability and mechanical properties of high strength mortars were evaluated. For this purpose, the flow table test for workability, flexural and compressive strength tests, modulus of elasticity measurement, rapid chloride test for permeability were performed to determine the effects of water binder ratio on high strength mortars performance. Moreover, the effect of curing temperature on the performance of high strength mortars modified with glass powders was also investigated. Finally, comparison is done between the results of control, silica fume and glass powder specimens. It is important to note that glass powder addition as a pozzolanic material has a considerable influence on 
compressive strength and permeability at low water binder ratio specimens under high curing temperature.

Keywords: glass powder, curing temperature, water-binder ratio, workability, compressive and flexural strength, modulus of elasticity, permeability 


\section{ÖZ}

Beton, yapılarda en yaygın kullanılan yapı malzemesidir. Her yıl, dünya genelinde yaklaşık olarak 11 milyon ton beton üretilmektedir. Bu durumda ciddi miktarda çimento üretimi gerekmekte ve gerçekleştirilmektedir. Yüksek miktarda karbondioksit salınımına yol açan çimento üretimi, küresel ısınmaya yol açan en önemli sebeplerden birini oluşturmaktadır. Son yıllarda; çimento kullanımını azaltmak için, pozolanik özelik taşıyan atık malzemelerin çimentonun bir kısmının yerine kullanımı yoluna gidilmiştir. Bu tip katkı malzemelerinin kullanımı ile hem karbondioksit salınımının yol açtığg hava kirliliği azalmış olacak hem de daha az çimento kullanılacağından beton fiyatı düşecektir. Aynı zamanda, harç veya betonun bazı özeliklerinde de iyileşmeler olmacaktır.

Öğ̈̈tülmüş cam tozu, yüksek miktarda silis içerdiğinden, ucuz olduğundan ve de kolay bulunduğundan dolayı diğer pozolanik atık malzemelerin yanında en uygun olarak tercih edilmektedir. Atık cam tozunun bu olumlu özelikleri, araştırmacıların bu konuya ilgi duymalarına ve de cam tozunun kısmen çimentonun yerine kullanılması halinde betonun özeliklerinin nasıl değiştiği konusunda araştırma yapmalarına yol açmıştır.

$\mathrm{Bu}$ çalışmada; üç farklı tipte (renkte) öğütülmüş cam tozu farklı miktarlarda olmak üzere çimentonun yerine kullanılmış ve de üç farklı tipte üretilmiş olan yüksek dayanımlı harçların işlenebilirlik,ve de mekanik özeliklerinin nasıl etkilendiği incelenmiştir. Bu deneysel çalışmada, su - bağlayıcı malzeme oranı ve farklı tip ve miktarlardaki cam tozunun yüksek dayanımlı harçlar üzerindeki etkisini tesbit etmek için; akma tablası işlenebilirlik, eğilme ve basınç dayanımı, elastic modulus ve de 
geçirimlilik deneyleri tüm numuneler için gerçekleştirilmiştir. Bunların yanısıra, üç farklı kür sıcaklığının yüksek dayanımlı harçlar üzerindeki etkisi tüm numuneler için araştırılmıştır. Sonuç olarak, kontrol, silis dumanı ve de cam tozu numunelerinden elde edilen sonuçlar kıyaslanmıştır. Burada belirtilmelidir ki; düşük su - bağlayıcı malzeme oranı ve de yüksek kür sıcaklığında, cam tozunun pozolanik atık malzeme olarak çimentonun yerine (kısmi) kullanılması; harcın basınç dayanımı ve de geçirimliliğini önemli ölçüde etkilemiştir.

Anahtar Kelimeler: cam tozu, kür sıcaklığı, su/bağlayıcı, işlenebilirlik, eğilme ve basınç dayanımı, elastic modulus, geçirimlilik. 
To my family... 


\section{ACKNOWLEDGMENT}

I would like to express my deepest gratitude to my supervisor and lecturer of the Civil Engineering Department, Assist. Prof. Dr. Tülin Akçaoğlu. Her guidance, concern, patience and support has seen me through my academic endeavors and have constantly provided me with the inspiration and will to work on my research.

I am grateful to my best friend, Engineer. Ogün Kılıç for all his supports and helps with all the necessary facilities in the materials of construction laboratory that were instrumental for the research. Without his supports, experiences, and guidance during experiments, it would be impossible to finish this amount of lab work in an appropriate time.

Special thanks goes to all Civil Engineering Department staff members for sharing their expertise and creating a sociable environment, in which they were readily approachable for an academic discussion and one in which I was comfortable.

I would like to express my sincere gratitude to my parents, my mother, my father, and my lovely sister, for their supports and encouragements throughout my life.

Last but not least, I would like to appreciate and give a special thanks to my loyal friend and my true love, Elahe Kouhpaye, who stood beside me and motivated me with her great fortitude and supported me in every respect. 


\section{TABLE OF CONTENTS}

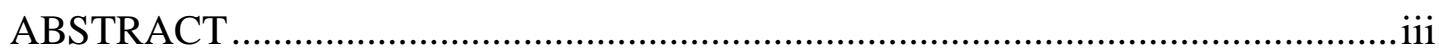

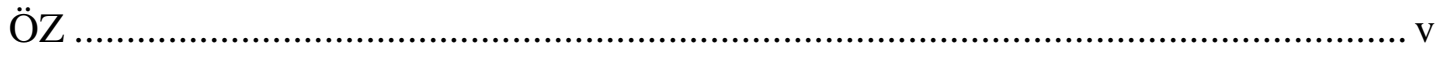

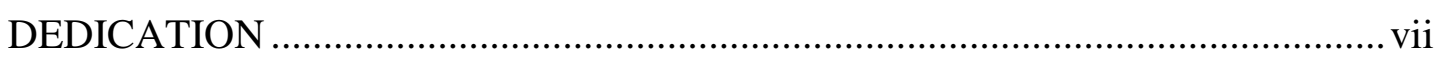

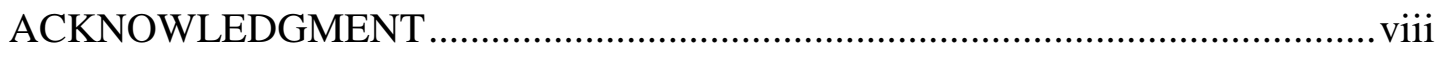

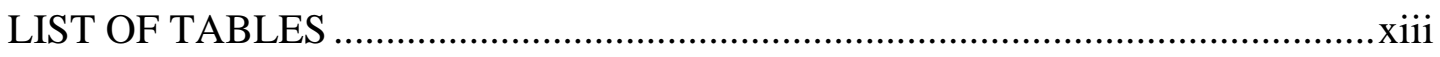

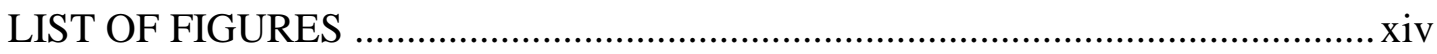

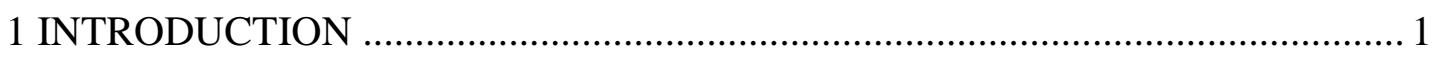

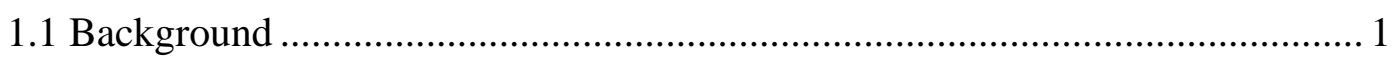

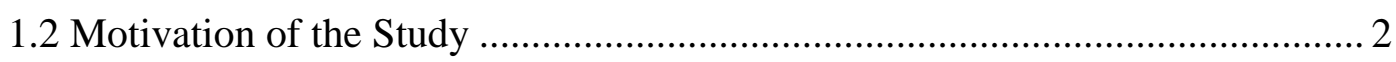

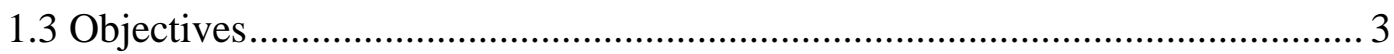

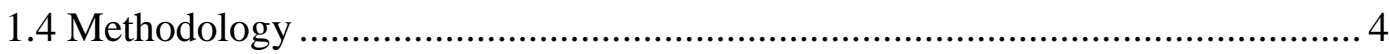

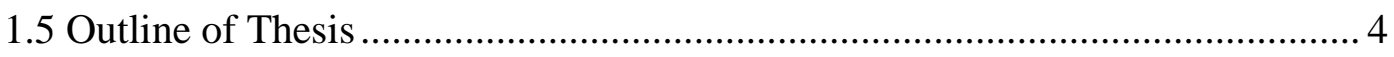

2 LITERATURE REVIEW: EFFECTS OF WASTE POZZOLANIC MATERIALS ON MORTARS AND CONCRETES PERFORMANCE .................................. 5

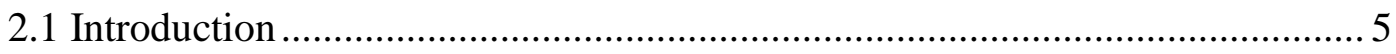

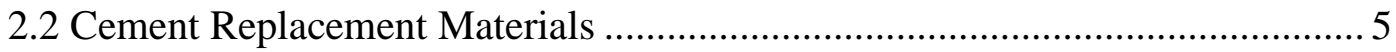

2.3 Glass Powder as a Pozzolanic Admixture...................................................... 7

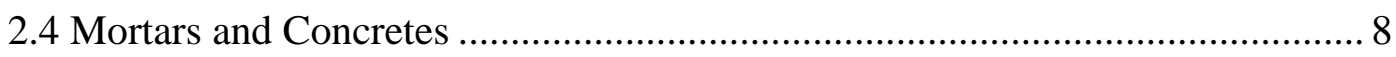

2.5 Workability of Mortars and Concretes........................................................ 9

2.5.1 Definitions, and Significance of Studying Workability of Concretes......... 9

2.5.2 Effect of Glass Powder on Workability of Mortars and Concretes .......... 10

2.6 Compressive Strength of Mortars and Concretes......................................... 12 
2.6.1 Significance of Studying Compressive Strength of Mortars and Concrete

2.6.2 Effect of Glass Powders on Compressive Strength of Concretes and Mortars

2.6.3 Effect of Different Curing Temperatures on Compressive Strength of Mortars and Concretes

2.6.4 Effects of Different w/b Ratios on Compressive Strength of Mortars and Concretes 19

2.7 Flexural Strength

2.7.1 Significance of Studying the Flexural Strength of Mortars and Concretes

2.7.2 Effect of Pozzolans and Glass Powder on Flexural Strength of Mortars and

Concretes 22

2.7.3 Effect of w/b and Curing Temperature on Flexural Strength of Mortars and

Concretes .22

2.8 Modulus of Elasticity 23

2.8.1 Significances of Studying Modulus of Elasticity 23

2.8.2 Effect of Pozzolans and Curing Temperature on Modulus of Elasticity of Mortars and Concretes 24

2.9 Chloride Resistance of Concrete and Mortars 25 2.9.1 Significance, and Determination of Chloride Resistance of Mortars and Concretes 25

2.9.2 Effect of Glass Powder and Pozzolans on Chloride Resistance of Mortars and Concretes . 26

2.10 Pozzolanic Activity Index Test 27 
3 MATERIALS AND EXPERIMENTAL PROGRAM ….......................................2 29

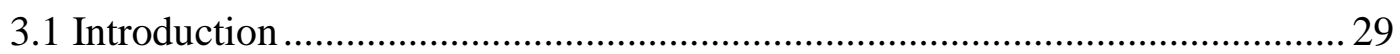

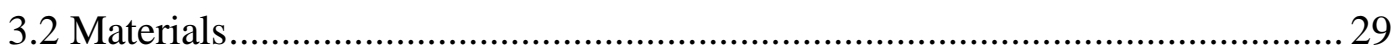

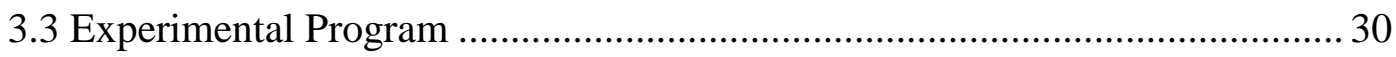

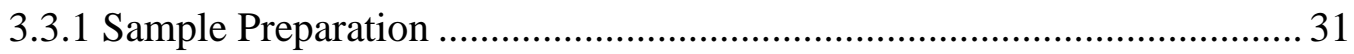

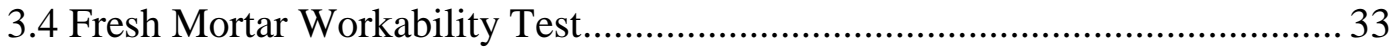

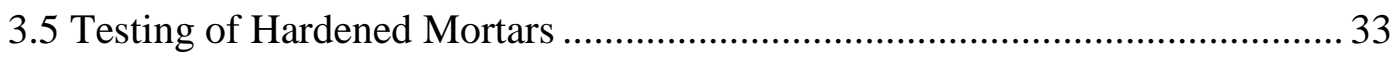

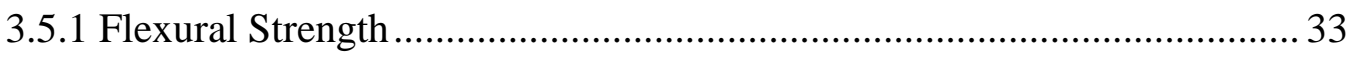

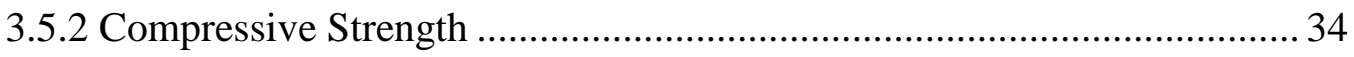

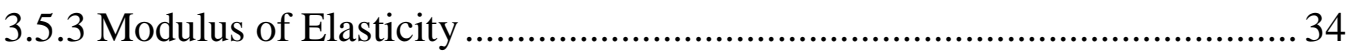

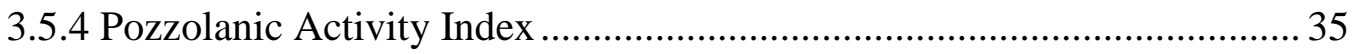

3.5.5 Rapid Chloride Permeability Test ...................................................... 35

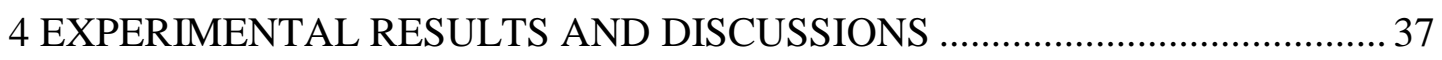

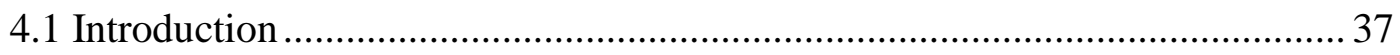

4.2 Effect of GP Type (Color) and Quantity on Workability of High Strength Mortars (HSM)

4.3 Effect of GP Type and Quantity, w/b Ratio, and Curing Temperature on Compressive Strength of HSM

4.4 Effects of GP Type and Quantity, w/b Ratio, and Curing Temperature on Flexural Strength of HSM 55

4.5 Effect of GP Type and Quantity, w/b Ratio, and Curing Temperature on

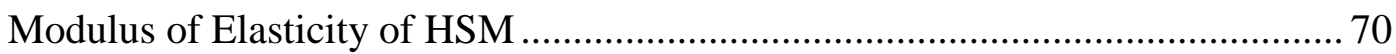

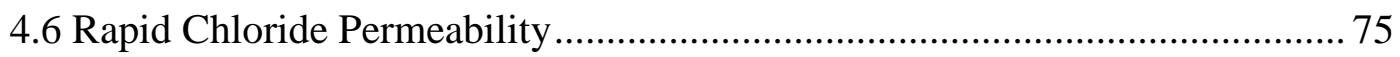

4.7 Pozzolanic Activity Index of Glass Powders ............................................. 75 
5.1 Conclusions

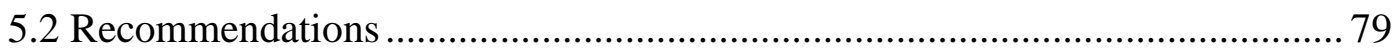

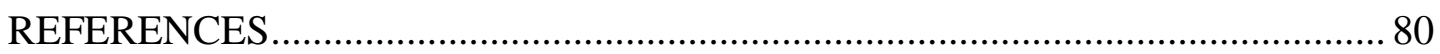

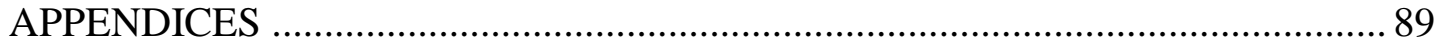

Appendix A: Effect of Different Gradients on Compressive Strength of mortars. 90

Appendix B: Effect of Different Gradients on Flexural Strength of Mortars ........ 91

Appendix C: Effect of Different Ingredients on Modulus of Elasticity of Mortars92 


\section{LIST OF TABLES}

Table 3.1: Mixing materials and proportion of mortar specimens $(\mathrm{w} / \mathrm{b}=0.35) \ldots \ldots . .31$

Table 3.2: Mixing materials and proportions of mortar specimens $(\mathrm{w} / \mathrm{b}=0.40) \ldots . . .32$

Table 3.3: Mixing materials and proportions of mortar specimens $(\mathrm{w} / \mathrm{b}=0.45) \ldots . .32$

Table 3.4: Effect of GP to pozzolanic activity index of mortar specimens

Table 4.1: Amount of charge passed from mortars at w/b of 0.45 and standard curing temperature .75 


\section{LIST OF FIGURES}

Figure 3.1: Fine Aggregate Gradation 30

Figure 4.1: Effect of Different Colors and Quantities of GPs on Workability Relative to Control and SF 38

Figure 4.2: Effect of Different Colors and Quantities of GPs on 7 and 28 Days Compressive Strengths for $\mathrm{w} / \mathrm{b} 0.35$ and $22^{\circ} \mathrm{C}$ Curing Temperature 39

Figure 4.3: Effect of Different Colors and Quantities of GPs on 7 and 28 Days Compressive Strengths for $\mathrm{w} / \mathrm{b} 0.35$ and $55^{\circ} \mathrm{C}$ Curing Temperature .40

Figure 4.4: Effect of Different Colors and Quantities of GPs on 7 and 28 Days Compressive Strengths for w/b 0.35 under $80^{\circ} \mathrm{C}$ Curing Temperature 41

Figure 4.5: Effect of Different Colors and Quantities of GPs and Curing Temperatures on 7-Days Compressive Strength for w/b 0.35 42

Figure 4.6: Effect of Different Colors and Quantities of GPs and Curing Temperatures on 28-Days Compressive Strength for w/b 0.35

Figure 4.7: Effect of Different Colors and Quantities of GPs on 7 and 28 Days Compressive Strengths for w/b 0.40 under $22^{\circ} \mathrm{C}$ Curing Temperature 43

Figure 4.8: Effect of Different Colors and Quantities of GPs on 7 And 28 Days Compressive Strengths for w/b 0.40 under $55^{\circ} \mathrm{C}$ Curing Temperature .44

Figure 4.9: Effect of Different Colors and Quantities of GPs on 7 and 28 Days Compressive Strengths for w/b 0.40 under $80^{\circ} \mathrm{C}$ Curing Temperature .45

Figure 4.10: Effect of Different Colors and Quantities of GPs and Curing Temperatures on 7-days Compressive Strength for w/b 0.40 .46

Figure 4.11: Effect of Different Colors and Quantities of GPs and Curing Temperatures on 28-Days Compressive Strength for w/b 0.40 .46 
Figure 4.12: Effect of Different Colors and Quantities of GPs on 7 and 28 Days Compressive Strengths for w/b 0.45 under $22^{\circ} \mathrm{C}$ Curing Temperature

Figure 4.13: Effect of Different Colors and Quantities of GPs on 7 and 28 Days Compressive Strengths for w/b 0.45 under $55^{\circ} \mathrm{C}$ Curing Temperature 48

Figure 4.14: Effect of Different Colors and Quantities of GPs on 7 and 28 Days Compressive Strengths for w/b 0.45 under $80^{\circ} \mathrm{C}$ Curing Temperature 49

Figure 4.15: Effect of Different Colors and Quantities of GPs and Curing Temperatures on 7-days Compressive Strength for w/b 0.45 50

Figure 4.16: Effect of Different Colors and Quantities of GPs and Curing Temperatures on 28-days Compressive Strength for w/b 0.45 50

Figure 4.17: Effect of Different Colors and Quantities of GPs and w/b Ratios on 7days Compressive Strength for Curing Temperature of $22^{\circ} \mathrm{C}$ 51

Figure 4.18: Effect of Different Colors and Quantities of GPs and w/b Ratios on 28days Compressive Strength for Curing Temperature of $22^{\circ} \mathrm{C}$ 52 Figure 4.19: Effect of Different Colors and Quantities of GPs and w/b Ratios on 7days Compressive Strength for Curing Temperature of $55^{\circ} \mathrm{C}$ 53

Figure 4.20: Effect of Different Colors and Quantities of GPs and w/b Ratios on 28days Compressive Strength for Curing Temperature of $55^{\circ} \mathrm{C}$ 53 Figure 4.21: Effect of Different Colors and Quantities of GPs and w/b Ratios on 7days Compressive Strength for Curing Temperature of $80^{\circ} \mathrm{C}$ 54 Figure 4.22: Effect of Different Colors and Quantities of GPs and w/b Ratios on 28days Compressive Strength for Curing Temperature of $80{ }^{\circ} \mathrm{C}$ 54 Figure 4.23: Effect of Different Colors and Quantities of GPs on 7 and 28 Days Flexural Strength for w/b 0.35 under $22^{\circ} \mathrm{C}$ Curing Temperature. 55 
Figure 4.24: Effect of Different Colors and Quantities of GPs on 7 and 28 Days Flexural Strength for w/b 0.35 under $55^{\circ} \mathrm{C}$ Curing Temperature. 56

Figure 4.25: Effect of Different Colors and Quantities of GPs on 7 and 28 Days Flexural Strength for w/b 0.35 under $80^{\circ} \mathrm{C}$ Curing Temperature. .57

Figure 4.26: Effect of Different Colors and Quantities of GPs and Curing Temperatures on 7-Days Flexural Strength for w/b 0.35 58

Figure 4.27: Effect of Different Colors and Quantities of GPs and Curing Temperatures on 28-Days Flexural Strength for w/b 0.35 58

Figure 4.28: Effect of Different Colors and Quantities of GPs and Curing Temperatures on 7 and 28-Days Flexural Strength for w/b 0.35 .59

Figure 4.29: Effect of Different Colors and Quantities of GPs on 7 And 28 Days Flexural Strength for w/b 0.40 under $22^{\circ} \mathrm{C}$ Curing Temperature. 60

Figure 4.30: Effect of Different Colors and Quantities of GPs on 7 and 28 Days Flexural Strength for w/b 0.40 under $55^{\circ} \mathrm{C}$ Curing Temperature 61

Figure 4.31: Effect of Different Colors and Quantities of GPs on 7 and 28 Days Flexural Strength for w/b 0.40 under $80^{\circ} \mathrm{C}$ Curing Temperature. 61

Figure 4.32: Effect of Different Colors and Quantities of GPs and Curing Temperatures on 7-Days Flexural Strength for w/b 0.40 62

Figure 4.33: Effect of Different Colors and Quantities of GPs and Curing Temperatures on 28-Days Flexural Strength for w/b 0.40 . 63

Figure 4.34: Effect of Different Colors and Quantities of GPs and Curing Temperatures on 7 and 28-Days Flexural Strength for w/b 0.40 ........ 63 Figure 4.35: Effect of Different Colors and Quantities of GPs on 7 and 28-Days Flexural Strength for w/b 0.45 under $22^{\circ} \mathrm{C}$ Curing Temperature 64 
Figure 4.36: Effect of Different Colors and Quantities of GPs on 7 and 28 Days Flexural Strength for w/b 0.45 under $55^{\circ} \mathrm{C}$ Curing Temperature 64

Figure 4.37: Effect of Different Colors and Quantities of GPs on 7 and 28 Days Flexural Strength for w/b 0.45 under $80^{\circ} \mathrm{C}$ Curing Temperature 65

Figure 4.38: Effect of Different Colors and Quantities of GPs and Curing Temperatures on 7and 28-Days Flexural Strength for w/b 0.45 66

Figure 4.39: Effect of Different Colors and Quantities of GPs and Curing Temperatures on 7-Days Flexural Strength for w/b 0.45 66

Figure 4.40: Effect of Different Colors and Quantities of GPs and Curing Temperatures on 28-Days Flexural Strength for w/b 0.45 67

Figure 4.41: Effect of Different Colors and Quantities of GPs and w/b Ratios on 7 and 28-Days Flexural Strength for Curing Temperature of $22^{\circ} \mathrm{C}$ 68

Figure 4.42: Effect of Different Colors and Quantities of GPs and w/b Ratios on 7 and 28-Days Flexural Strength for Curing Temperature of $55^{\circ} \mathrm{C}$ .68

Figure 4.43: Effect of Different Colors and Quantities of GPs and w/b Ratios on 7 and 28-Days Flexural Strength for Curing Temperature of $80^{\circ} \mathrm{C}$ 69

Figure 4.44: Effect of Different Colors and Quantities of GPs and Curing Temperatures on $\mathrm{E}$ for $\mathrm{w} / \mathrm{b} 0.35$ 70

Figure 4.45: Effect of Different Colors and Quantities of GPs and Curing Temperatures on $\mathrm{E}$ for $\mathrm{w} / \mathrm{b} 0.40$ .71

Figure 4.46: Effect of Different Colors and Quantities of GPs and Curing Temperatures on $\mathrm{E}$ for $\mathrm{w} / \mathrm{b} 0.45$ .72

Figure 4.47: Effect of Different Colors and Quantities of GPs and w/b Ratios on E at Curing Temperature of $22^{\circ} \mathrm{C}$ .73 
Figure 4.48: Effect of Different Colors and Quantities of GPs and w/b Ratios on E at Curing Temperature of $55^{\circ} \mathrm{C}$ 74

Figure 4.49: Effect of Different Colors and Quantities of GPs and w/b Ratios on E at

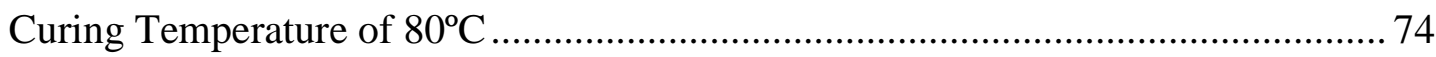

Figure 4.50: Strength Activity Index of GPs and SF at the Age of 28 Day .............. 76 


\section{LIST OF ABBREVIATIONS}

$\begin{array}{ll}\text { HSM } & \text { High strength mortar } \\ \text { HSC } & \text { High strength concrete } \\ \text { UHPC } & \text { Ultra-high performance concrete } \\ \text { GP } & \text { Glass powder } \\ \text { WGP } & \text { White glass powder } \\ \text { GGP } & \text { Green glass powder } \\ \text { BGP } & \text { Brown glass powder } \\ \text { SF } & \text { Silica fume } \\ \text { E } & \text { Modulus of elasticity } \\ \text { SCM } & \text { Supplementary cementitious material } \\ \sigma_{c} & \text { Compressive strength } \\ \sigma_{f} & \text { Flexural strength }\end{array}$




\section{Chapter1}

\section{INTRODUCTION}

\subsection{Background}

Concrete and mortar are the most widely used materials in construction all over the world. In the last few years, a growing appeal in using waste materials as a replacement of part of aggregates and/or cement in mortar and concrete productions has been seen. Using these kinds of objects as a part of cement replacement not only provides some benefits to its microstructure and performance, but also it gives an opportunity to reduce the amount of cement used and hence decrease the final cost of concrete manufacturing. From environmental point of view, this leads to reduction in the release of $\mathrm{CO}_{2}$ in the atmosphere, which is one of the main reasons for global warming (Siddique, Waste Materials and By-products in Concrete, 2008).

Around the world, million tons of waste glasses are dumped into the nature every year. In 2005, around 13 million tons of waste glass was produced and dumped only in America. Also, other sources showed that the United Kingdom produces 1.3 million tons of waste glass every year (Ansari Ismail, 2015).

The glass is a non-crystalline structure and it contains up to $70 \%$ of silica oxide, which can help to produce more C-S-H phases in cement pastes, mortars and therefore concrete. On the other hand, widespread availability of glass makes it cheaper and easier to produce when compared to other pozzolanic admixtures. This reality 
motivated lots of researchers to investigate the possibility of using waste glass as a natural pozzolan and also study the effects of using waste glass in concrete, as a cement replacement. Since 1970s, many researchers studied the effect of glass used as cement or aggregate replacement in concrete (Johnston, 1974), (Limbachiya, 2009), (Meyer, 1999).

One research showed that waste glass powder finer than $45 \mu \mathrm{m}$ has improved the durability of concrete (Schwarz N, 2008). Shi showed that fine glass powder with the fineness of $582 \mathrm{~m}^{2} / \mathrm{kg}$ has high pozzolanic activity index and as the fineness of waste glass increased, the pozzolanic strength activity index increased (Shi C, 2005). Shao Y. showed that, grounded waste glass with a particle size less than $38 \mu \mathrm{m}$ had high pozzolanic activity index (Shao Y L. T., 2000). As a general conclusion; higher compressive strength, lower expansion of alkali-silica reaction and higher strength activity could be the results of finer particles of waste ground glass powder. Idir also showed fine that ground glass with a specific surface area (more than $180 \mathrm{~m}^{2} / \mathrm{kg}$ ) can reduce mortars expansion due to exposure to alkali-silica reaction. Mortars containing fine ground glass, more than the specific surface area of $180 \mathrm{~m}^{2} / \mathrm{kg}$, which is exposed to alkali-silica reaction, had lower expansion when compared to mortars without this admixture (Idir R, 2010).

\subsection{Motivation of the Study}

Recently, many researchers investigated on pozzolanic admixtures, obtained from waste materials. Waste glass powder is one of these materials, which attracted lots of attentions due to its high content of silica and availability. In this study, it is tried to develop this studies and fill some gaps. Therefore motivation factors of this study are as listed below: 
1. Production of high-strength mortars and concretes needs a massive amount of cement, which makes it more expensive than normal concrete and mortars.

2. The interaction of different water-cement ratios and also different curing temperatures on mixtures made by this type of admixtures are not studied well.

3. The effects of different types (colors) of waste glass powders on the performance of high strength mortars and concretes is not studied well.

4. Effect of different types of glass powder on tensile strength of high strength mortars and concretes still requires further studies.

\subsection{Objectives}

The objectives of this study are as listed below:

1. Determining effects of three different types (colors) of glass powders with different quantities to cement replacement on workability and mechanical properties of high strength mortars produced by three different water binder ratios.

2. Obtaining the best type and the optimum quantity of glass powder, which is the most suitable supplementary cementitious material for high strength mortars performance.

3. Determining the effects of $w / b$ ratios on high strength mortars performance with different types and quantities of glass powders. 
4. Comparing the performances of high strength mortars with waste glass powders, silica fume and the control mortar specimens without any admixture.

5. Studying the effect of the curing temperature on the performance of high strength mortars made by using glass powders.

\subsection{Methodology}

The following experiments are performed based on ASTM standards in order to investigate the effects of glass powder on the performance of high strength mortars:

1. Workability test (flow table test)

2. Compressive strength test

3. Tensile strength test

4. Modulus of elasticity test

5. Rapid chloride permeability test

The results of tests are compared against each other and also with the control specimens for better evaluations.

\subsection{Outline of Thesis}

$1^{\text {st }}$ chapter is the introduction to this study. $2^{\text {nd }}$ chapter covers the wide literature review about effects of glass powder, water binder ratios, and curing temperature on the performance of mortars and concretes. $3^{\text {th }}$ chapter describes the materials and experimental procedures used in this study. In $4^{\text {th }}$ chapter, results and discussions are presented. Finally the $5^{\text {th }}$ chapter includes the derived conclusions. 


\section{Chapter 2}

\section{LITERATURE REVIEW: EFFECTS OF WASTE POZZOLANIC MATERIALS ON MORTARS AND CONCRETES PERFORMANCE}

\subsection{Introduction}

Concrete, the most used material in constructions, is the most man-made consumed material in the world. Near 700 million tons of concrete was used in the United States alone in 2007 and around 11 billion tons of concrete has been used all over the world in 2007. One of the most used materials in concrete is cement which is highly pollution and energy intensive process (Pade, 2007).

One of the most effective and environmentally friendly strategies to reduce the amount of Portland Cement used in concrete and mortar, is to replace it partially with waste material or industrial by-product materials, which does not only have improving effects on concrete, but also decreases the production cost of concrete without consuming energy or polluting the environment.

\subsection{Cement Replacement Materials}

There are many materials such as industrial wastes or natural material which could be used to replace the cement in any given mixture by percentage. These kinds of materials are called pozzolans, and they can increase durability of the cementitious mixtures and improve its mechanical properties. Among all pozzolans, some of the most widely known supplementary materials are briefly described below. 
Fly Ash: it is the most popular type of all supplementary cementitious materials (SCMs). It is a by-product of power units, and is produced by combustion of pulverized coal or from exhaust gasses of furnaces. Sulfate attack resistance, promoting hydration rate increase, and increasing the strength of cementitious mixture are among three most important advantages of fly ash.

Ground Granulated Blast-Furnace Slag (GGBS): it is a fine pozzolanic material, which contains aluminosilicate and silicate, and is created by rapidly cooling the molten steel blast furnace slag with water. This pozzolan contains low amounts of crystal formation, is extremely cementitious and when the fineness of particles is similar to that of cement, hydration may also resemble that of Portland cement (Dali, 2012). Making concrete mixtures by replacing PC partially by slag helps improving its consistency in numerous ways as follows:

- Better workability

- Higher flexural and/or compressive strength

- Easier finish ability

- Lower permeability

- Resistance to chemical attacks.

Silica fume (SF): it is made of very fine particles of silicon dioxide which is produced by using an electric arc furnace in melting process of ferrosilicon or metallic silicon in the alloy industry and contains very high amount of $\mathrm{SiO} 2$ whit the rate of 85 to $99 \%$ of amorphous silica (Dali, 2012). Particle size range of silica fume is defined between 500 to $20 \mathrm{~nm}$. 
Nowadays, a combination of Portland cement and silica fume is being used to produce high performance or ultra-high performance concrete. This is made possible through the significant co-operation of Portland cement and silica fume. The physical and chemical effects of silica fume on the microstructure of hardened cement paste in mixtures leads to a higher strength, higher durability and lower permeability (Miguel Ángel Sanjuán, 2015).

Waste glass powder: Another source of cement replacement is produced from waste glasses and called waste glass powder. Waste glass is said to have the desired chemical blend to use as a cementitious supplementary material in concrete due to its pozzolanic properties, and can improve hydration, mechanical properties, and the durability of mortars. However, to achieve this potential, the particles need to be graded to a micro size to be able to react with the cement particles (Aboshama, 2016).

\subsection{Glass Powder as a Pozzolanic Admixture}

As the amount of production of waste glass has been increased recently, many researchers started to study the effects of glass added to concrete either replaced as a part of aggregates or as an admixture which replaced by cement in concrete.

Glass is a shapeless solid, which has been made and used since 1300 BC up until today (Siddique, Waste Materials and By-products in Concrete, 2008). It also is one of the most utilizable materials on the planet with many applications in every aspect of human life from using clear colorless glass sheets in buildings to providing natural light or thousands of daily use to special applications in laboratories such as special lenses or magnifiers or heat resistance glasses (Pyrex glass) in some instruments. Millions of tons of glass waste is dumped into nature every year all over the world. As 
it was mentioned in (Ansari Ismail, 2015); in 2005, near 13 million tons of waste glass was produced and disposed just in America. Also, other sources showed that the United Kingdom produces 1.3 million ton of waste glass every year.

This raises the question why are these glasses being disposed, when glass is in fact a recyclable material?

One of the reasons is that it is important for glass production companies to produce high quality glass, which might be used as sheets or bottles. Therefore, there is a recommended proportion of raw material to produce glass to achieve this quality. Most of these instructions recommend at least $40 \%$ of glass cullet is good to be used as a part of raw materials for producing new glass in each batch. Nevertheless, they also recommend that cullet should not contain different colors of glass. In fact, if cullet contains even two different colors of glass, it becomes useless to produce new glass as it results in low quality glass with an undesired color (Ansari Ismail, 2015).

\subsection{Mortars and Concretes}

In construction, mortar is applicable for many functions such as filling the empty spaces and gaps between blocks and breaks. It is also used to cover walls, to prevent the insides of a structure from environmental conditions like rain. Mortar is simply made by mixing sand, water, and binder materials. It is possible to categorize mortars into three different groups according to the binder used in their preparation. These are:

\footnotetext{
- Gypsum mortar

- Portland cement mortar (cement mortar)

- Lime mortar
} 
Gypsum mortar is the oldest mortar known to the mankind, first utilized by the Egyptians. Lime mortar has been said to be used since 4000 BC in Egypt. It is produced by mixing of slaked lime, sand, and water. It is noticeable that more than 1900 famous ancient buildings all around the world are found to be made by using this kind of mortar. While this kind of mortar was so common to use due to its significant properties, and wide availability, it was replaced by cement based mortars introduced to the world in 19th century due to its faster setting time, and higher level of strength it could gain. It can be said that cement mortars are the basis of cement concretes.

Compared to concrete, the amount of cement used in mortar is higher, and nowadays many researchers try to find a way to reduce the amount of cement used in concrete and mortar without decreasing the performances of cementitious mixtures. This is because of environmental reasons, as cement industries are the second biggest producers of $\mathrm{CO}_{2}$ in the world after iron and steel production with the total amount of $8 \%$ of total $\mathrm{CO}_{2}$ emission (Jos Olivier, 2015). Until today, one of the best ways to decrease the amount of cement in mixtures is to replace it partially with pozzolanic materials, which may be natural, artificial, or even waste products.

\subsection{Workability of Mortars and Concretes}

In this section, the importance of factors affecting the workability of fresh mortars and concretes are investigated. Therefore, fresh properties of mortars and concretes, which modified with glass powder is tested and compared with control.

\subsubsection{Definitions, and Significance of Studying Workability of Concretes}

Glanville was the first to develop the best definition of workability for mortars and concretes. He said "Workability is the amount of suitable inner work needed to make full compaction in mortars and concretes" (William Henry glanville, 1947). ASTM 
C125-93 describes workability as the property which defines the work required to handle fresh concrete and mortars with minimum loss of homogeneity. ACI 116R standard defines workability of mortars and concretes as the property of a fresh mixture of mortars or concrete which describes the ease and homogeneity which it could be mixed, placed, consolidated, and finished.

Workability is defined as flowability of mortar and concrete in a fresh state. If the workability is lower than desired, it might need more labor and time for compaction, which increases the final cost of finished concrete job. On the other hand, if the flowability increases more than the normal, level segregation might take place and, the strength of concrete might be decreased.

The water content of mixtures is the most important factor in decreasing or increasing the amount of workability. Increasing the amount of water might help increase the workability but it also might decrease the final strength of hardened concrete. This is due to the high number of initial micro-cracks caused by evaporation of excess water. Workability test can make a balance between desired workability and strength of concrete. It can give the best amount of water to use as a lubricant in the mixture, which has the less negative effects on hardened mechanical properties of concrete.

Workability test is used in this study to see the effects of different types of glass powders on mortar when it partially replaces cement in the mixture.

\subsubsection{Effect of Glass Powder on Workability of Mortars and Concretes}

For fresh phase of concrete, some researchers demonstrated that replacement of glass powder up to $40 \%$ to cement with a particle size less than $300 \mu \mathrm{m}$ could increase the slump from $40 \mathrm{~mm}$ up to $160 \mathrm{~mm}$ (Kumarappan, 2013). Another research also showed 
that by increasing the amount of glass powder in concrete, the amount of slump is also increased, however the particle size of the glass was not mentioned in the study (Khatib, 2012) . Chikhalikar also found an increase in the slump of concrete, using glass powder with particle size of $600 \mu \mathrm{m}$, up to $40 \%$ replacement of cement (Chikhalikar, 2012). Shayan investigated the effect of glass powder on workability of mortars. He concluded from his research that the increase in workability of mortar by replacing the glass powder is due to the surface structure of glass powder, which is crystal - like, and subsequently too little amount of water is absorbed by glass powder compared to cement particles (Shayan, 2006). Another study showed that replacing 13 $\mu \mathrm{m}$ glass powder with cement in mortars increased the amount of slump (Soroushian, 2012). On the other hand, Vandhiyan showed that replacing $75 \mu \mathrm{m}$ green glass powder with cement up to $15 \%$ could reduce the workability of mortars due to angular shape of particles and also, increase in surface area of glass powder which absorbs more water (Vandhiyan, 2013).

Soliman developed UHPC in his study by replacing glass powder with cement in different percentages. Sulfate-resistance cement was used in his experiments and it was replaced by glass powder with the maximum size of $12 \mu \mathrm{m}$ at different levels $(0 \%$, $10 \%, 20 \%, 40 \%$, and 50\%). He found that; the workability of UHPC increased with increasing amount of glass powder as a cement substitution, due to its lower water absorption rates. Soliman also reported that by increasing the amount of glass powder in the mixture, the amount of cement hydration production within the first minutes of mixing is reduced, which provides a better workability for concrete. Also in this case, the amount of water required as lubricant between particles of binder will be decreased because the specific surface area of glass powder used in the study above $\left(380 \mathrm{~m}^{2} / \mathrm{kg}\right)$ 
was smaller than that of cement $\left(430 \mathrm{~m}^{2} / \mathrm{kg}\right)$ and with fixed water-cement ratio, the workability of mixture is automatically increased (Soliman, 2016).

\subsection{Compressive Strength of Mortars and Concretes}

In this section, the significance of studying and performing compressive strength tests on mortars and concretes are explained. In addition, general information on the effects of independent variables such as glass powder types, quantities, w/b ratios and curing temperatures are gathered from previous studies.

\subsubsection{Significance of Studying Compressive Strength of Mortars and Concrete}

The compressive strength of concrete is always considered as the most important property of concrete among other parameters, and it defines the quality of concrete (A.M.neville, 1995). In some cases, characteristics, like durability and permeability of concrete are considered as important properties but compressive strength is the main describe for quality of concrete, since it is always related directly to the structure of hydrated and hardened cement paste (A.M Neville, 1987).

There were many researchers worked on this field to find connections between every phenomenon related to the strength of concrete. Many connections were found between raw material, the proportion of selection of raw material, aggregate sizes and shapes, water cement/binder ratio, the temperature of curing of concrete, the age of concrete, and many other things, which have effects on compressive strength, with compressive strength of the cementitious mixture (Ansari Ismail, 2015).

Among this wide range of study, some researchers studied on compressive strength of mortars, which are developed by pozzolanic admixtures. These pozzolanic admixtures can be replaced by percentage of cement in concrete for special purposes, but it has 
always seen that these pozzolanic admixtures always develop other parameters of concrete like compressive strength. On the other hand, recently, to decrease the cost of concrete and more practical to make and use everywhere, another new branch of research started to grow in case of studying properties of waste materials which are produced everywhere and can improve the properties of concrete. Compressive strength test results can strongly give the researcher the idea about using that kind of new materials (Ansari Ismail, 2015) (Kamali, 2016) (Mirzahosseini, Influence of different particle size on reactivity of finely ground glass as supplementary cementitious material (SCM), 2015).

\subsubsection{Effect of Glass Powders on Compressive Strength of Concretes and Mortars}

On the contrary of the effects of GP on the workability; effects of glass powder on development of compressive strength is quite clear. All researchers agreed that the glass powder increases the compressive strength between the range of 5\% and $30 \%$ in different situations.

Khatib showed in his studies that $10 \%$ replacement of glass powder with cement had some improvements on compressive strength of concrete without mentioning which type of cement was used in experimental (Khatib, 2012). Vandhiyan showed that replacing $15 \%$ of WGP with cement in mortars, which was optimum, increased the compressive strength of mortar up to $29 \%$ for 7 days and also, increased the compressive strength of 28 days samples by $23 \%$ comparing to control mix. He mentioned that the particle size of WGP was $75 \mu \mathrm{m}$ but the type of cement used in that experiment was not determined (Vandhiyan, 2013). Dali showed that glass powder with particle size passed from $600-\mu \mathrm{m}$ sieve can improve the compressive strength of mortars and the optimum percentage of replacement said to be $20 \%$ by the weight of cement (Dali, 2012). Patil concluded 10\% of replacement of WGP with cement had 
the best improvement in compressive strength of concrete while he used $90 \mu \mathrm{m}$ WGP in his studies (Patil, 2013). Vijayakumar studied the compressive strength of concrete, which was modified by replacing $40 \%$ of glass powder by Portland cement. Particle size of glass powder he used in his study was $150 \mu \mathrm{m}$. He observed that replacing the glass powder with cement increased the compressive strength of concrete up to 20\%comparing to control (Vijayakumar, 2013).

Soliman reported that among different levels of replacement of glass powder with cement UHPC, specimens containing $10 \%$ and $20 \%$ of glass powder had higher values of compressive strength comparing with control mix. He also found that mixtures with glass powder had higher compressive strength in later ages in 56 and 91 days. He concluded that C-S-H can be made, densifies the microstructure of concrete. The newly produced C-S-H fills the pores in the structure of concrete so it can improve the mechanical properties of mixture significantly but it takes place at a long time later due to the slow reaction of pozzolans than hydration of cement (Soliman, 2016).

To be able to study more accurate about effects of glass powder on strength of concrete or mortar, it is possible to categorize them by the size of particles or even by different colors.

\subsubsection{Effect of the Size of Glass Powder on Compressive Strength of Mortars and Concretes}

Ground glass powder with very small particle sizes can improve the hydration of concrete and directly affects the compressive strength of mixture due to its pozzolanic activity while used as supplementary cementitious material in concrete and mortar or even cement paste. According to previous literature, waste glass powder contains a high amount of active silica, which can complete the hydration of mixture and leads 
to improve the compressive strength of mixture when it is ground well. When the particle size of glass powder takes place between ranges of 30 to $300 \mu \mathrm{m}$, it has more chance to react with hydration gel and produce more C-S-H. In addition, the amount of alkali reaction of big particles reduces in the mixture, which gives concrete more strength, and durability (Mirzahosseini, Influence of different particle size on reactivity of finely ground glass as supplementary cementitious material (SCM), 2015).

Mirza Hosseini, who investigated the effect of different particle sizes on compressive strength of mortar, found that as the particle size of glass powder decreases, the amount of hydration and production of C-S-H increased, which finally lead to increase in compressive strength of mortar. He mentioned that the highest amount of strength obtained in his study by using waste glass powder with particle size less than $25 \mu \mathrm{m}$ comparing with other bigger particles and control mix. He concluded that the ions in fineness glass powder particles between 0 to $25 \mu \mathrm{m}$ had the highest tendency to dissolve in hydration gel. That must take place before glass particles can react and produce C-S-H, as an explanation for higher activity index of small particles and compressive strength of mortars (Mirzahosseini, Influence of different particle size on reactivity of finely ground glass as supplementary cementitious material (SCM), 2015). Pereira also studied the effect of different particle sizes of glass powder on strength of concrete. He selected three different ranges for GP particle sizes as below:

- Between $150 \mu \mathrm{m}$ to $75 \mu \mathrm{m}$

- Between 75 to $45 \mu \mathrm{m}$

- Particle sizes less than $45 \mu \mathrm{m}$ 
He found the amount of compressive strength decreased by replacing more glass powder with cement, with a particle size of $150 \mu \mathrm{m}$ to $75 \mu \mathrm{m}$, while he observed replacing the glass powder with a particle size smaller than $75 \mu \mathrm{m}$ increased the amount of compressive strength in later ages (Pereira de Oliveira, 2005).

It was seen that if glass particles were ground up to $300 \mu \mathrm{m}$ in particle size or smaller, alkali-silica reaction could be reduced (Meyer C, 1999). Actually, investigations showed that if glass particles become smaller than $75 \mu \mathrm{m}$, in size, alkali-silica reaction does not take place and mortar and concrete durability will be increased (Shao Y L. T., 2000).

\subsubsection{Effect of Different Types of Glass Powder on Compressive Strength of Mortars and Concretes}

Glass has been used in mortar and concrete as supplementary cementitious material (SCM) or fine aggregate. Glass reaction changes with both glass composition and curing temperature. Uniform composition, high content of silica, and amorphous structure of glass make it perfect for investigating effects of different types of glasses on reactivity.

Mirza Hosseini studied different effects of green and white glass powder on mechanical and chemical properties of mortars. Analyzing of Chemical components of glass powder showed however amount of $\mathrm{SiO}_{2}, \mathrm{CaO}$, and $\mathrm{Na}_{2} \mathrm{O}$ were nearly the same in green and white glass powders, but $\mathrm{Al}_{2} \mathrm{O}_{3}, \mathrm{~K}_{2} \mathrm{O}$, and $\mathrm{Cr}_{2} \mathrm{O}_{3}$ were found more, in green glass powder rather than white one (Mirzahosseini, Effect of curing temperature and glass type on the pozzolanic reactivity of glass powder, 2014). Mirza Hosseini replaced 0.35 of green and clear glass powder with Portland cement in mortars. The particle size of glass powder was selected as $25 \mu \mathrm{m}$ to make glass powder 
particles close to cement powder particle sizes and to make sure most of the glass powder participates into pozzolanic reaction in the mortar. By testing compressive strength of samples and comparing them together, and with control mix, he found a higher pozzolanic activity for green glass powder rather than clear one. Because high $\mathrm{pH}$ of mixture breaks down the silica arrangement of glass powder, and aluminum and silica could dissolve more and contribute in pozzolanic reaction. During bottle leaching, the amount of aluminum was found 27 times more than clear glass powder. Aluminum and silica can dissolve in pore hydration gel more easily at $\mathrm{PH}$ near to what exist in concrete, which may be the cause of higher activity of green glass powder than clear glass powder (Mirzahosseini, Effect of curing temperature and glass type on the pozzolanic reactivity of glass powder, 2014).

\subsubsection{Effect of Different Curing Temperatures on Compressive Strength of Mortars and Concretes}

Temperature is one of the essential factors in hydration of cementitious materials. The temperature of the mortar or concrete might change due to the heat of hydration, curing, and weather. High temperature can rise the rate of hydration and pozzolanic activity may be accelerated. It can also change the formed hydration products, and its density (Elkhadiri, 2009) . However, in some cases, it can increase the permeability or decrease the ultimate strength of mortar or concrete, because as the temperature increases, drying shrinkage also increases, which causes some internal cracks (Chini, 2003).

There are some methods to accelerate the presses of hydration by increasing the curing temperature the first two days of curing, and this method called heat treatment. This acceleration in strength gain is the main aim of this procedure, especially in pre-cast industries. However, there are also some disadvantages of this method, stated by 
several authors. While this method increases the amount of strength in early ages, but sometimes it decreases the amount of compressive strength in later times, around 180 days (Bingol, 2013).

However elevated temperature might increase the hydration rate and pozzolanic reactivity of binder, but it can lead to the production of large pores, thus increasing the pore volume, which might affect the mechanical properties and compressive strength or hardened mortar in later ages (Lothenbach, 2007) (Boubekeur, 2014).

On the other hand, heat treatment accelerates the pozzolanic reaction in binder, and changes microstructures of hydrates by changing the chain length of $\mathrm{C}-\mathrm{S}-\mathrm{H}$ to pentamer from trimer (Cwirzen, 2007).

Derabla (2014) investigated the incorporation of different temperatures for heat treatment and mineral admixtures (fine limestone, crystallized slag, and granulated slag) on mechanical properties of SCCH is method consisted of putting specimens in $60^{\circ} \mathrm{C}$ water for the first 24 hours of curing and then transferring them to normal temperatures cure, up to the day of testing (28 and 180 days). He revealed that in early ages, the amount of compressive strength of concrete containing pozzolanic admixtures with heat treatment increased 2-4 times more than specimens cured under normal temperature, while at later ages (on 28th day), concrete with heat treatment exhibited $7 \%$ lower compressive strength compared to the rest without heat treatment. At the later age of 180th-day, it dropped by $14 \%$ in strength compared to mixtures without heat treatment. However, for mixtures containing admixtures, the drop in strength was 5\% compared to the specimens containing admixtures without heat treatment. He concluded that the presence of pozzolanic admixtures in concrete while 
using heat treatment has improving effects on strength of concrete, not only at early ages after casting but also at later ages. (Derabla, 2014) .

Mirza Hosseini also concluded that temperature is an important factor affecting the pozzolanic activity of glass powder. The results of apparent activation energy calculation showed that glass, especially green one, is more temperature sensitive and has a higher tendency to participate in pozzolanic reaction (Mirzahosseini, Effect of curing temperature and glass type on the pozzolanic reactivity of glass powder, 2014).

\subsubsection{Effects of Different w/b Ratios on Compressive Strength of Mortars and Concretes.}

Water cement ratio or water binder ratio is one of the most important factors in concrete because not only it traces the workability, but also it has an important influence on compressive strength of the cement-based mixture. Therefore, the consideration on the amount of water in the mixture is very important. From hydration point of view, lack of water for completing hydration become evident, and lower compressive strength exhibits at water-cement ratios lower than $24 \%$, as stoichiometric calculation demonstrates that the amount of water needed for complete hydration of 1 gram of cement is $0.24 \mathrm{~g}$ (Larrard, 1999). Another phenomenon, occurring at low water-cement ratios in mortar or concrete, is called higher autogenous shrinkage which causes the production of some cracks independent of loading within the first few days of casting, which results in a decrease in the compressive strength of concrete. Also if w/b increases more than normal, segregation may occur while placing the concrete, and aggregates will be settled in the base, which strongly decreases the strength of concrete (Paillère, 1989). 
In high-performance mortars and concretes, usually the water/cement ratio is less than 0.40, which causes some unhydrated cement particles in the mixture (Yanzhou, 2015). Rehydration is another phenomenon, which indicates the amount of hydration of unhydrated particles, in later ages in concrete when exterior water enters inside of hardened specimens and meets these particles. Rehydration leads concrete to gain more strength in later ages especially, in low w/b ratios (Yue Wang, 2016).

Schwarz studied cement paste hydration that was modified by waste glass powders. His study showed that waste glass powders improved the hydration of cement (Schwarz, 2008). Another study by Neithalath investigated the hydration of cement modified by calcium aluminosilicate, which is a byproduct of fiberglass. He concluded calcium vitreous aluminosilicate enhanced the hydration up to 7days, and after that, it showed pozzolanic reactivity (Neithalath, 2009).

To find the amount of hydration, researchers can use Non-evaporable water content measurement widely in cement-based mixtures (P. Richard, 1995). When supplementary cementitious materials replaced or mixed with cement, the explanation for the degree of hydration becomes complicated. Because the pozzolanic reaction which arises from the presence of these SCMs shifts C-H to low water C-S-H. Kamali investigated the rate of hydration of cement paste modified with two types of glass powder and fly ash and compared with cement paste without any pozzolanic admixture in constant W/C ratio (Kamali, 2016). She used non-evaporable water content measurements and noted that non-evaporable water content per binder mass of all modified pastes was below than that of the control paste at 28 and 91 days of testing. He concluded that tendency indicated the higher effectiveness of glass powder in hydration enhancement and pozzolanic reactivity at later ages compared to FA. 
Generally, it could be concluded that the strength of cementitious mixture after setting enhances by reducing w/b while hydration product contents reduce. At the same time, homogeneity of hydration products leads to growth and the amount of crystalline hydrates diminutions. At lower water/cement ratios, higher calcium Figures of the CS-H are interspersed arises at lower water-cement ratios. Crystalline production, $\mathrm{Ca}(\mathrm{OH})_{2}$, which grows by increasing the W/C values, and is the weakest part of the mixture, creates conditions for lowering the strength of mixture (Mesbah H, 2002).

\subsection{Flexural Strength}

In this section, the significance of tensile strength on mortars and concretes are explained. Additionally, studies on the effects of independent variables, such as glass powder types, quantities, w/b ratios, and curing temperatures, on flexural strength of mortars and concretes are gathered from previous studies.

\subsubsection{Significance of Studying the Flexural Strength of Mortars and Concretes}

Concrete and mortars are generally used in structures to endure against compressive stress and obtain low resistance against tension. Steel bars are commonly used to modify tensile strength of concrete structures. However, to prevent cracks in concrete pavement, runways, or dams that are caused due to the shear force, concrete should have enough resistance against tension stress. Therefore, engineers should investigate the effects of various conditions and parameters on the tensile strength of concrete (A.M.neville, 1995). According to the standards, there are several direct and indirect tests performed to determine and measure the amount of tensile strength of cementitious mixtures. Direct measurements of tensile strength of concrete or mortar is often difficult and complicated, thus researchers tend to prefer indirect tests such as splitting test or bending tests. Three point bending test is an indirect method to measure 
the tensile strength of concrete and mortar to investigate the parameters which effect the tensile strength (A.M Neville, 1987).

\subsubsection{Effect of Pozzolans and Glass Powder on Flexural Strength of Mortars and Concretes}

Nishikawa (1995) investigated the effect of glass powder when used as pozzolanic admixture on flexural strength of mortars. He found that mortars modified with glass powder, showed slight increases in bending, and thus an increase in flexural strength (Nishikawa, 1995).

\subsubsection{Effect of w/b and Curing Temperature on Flexural Strength of Mortars and Concretes}

There is a gap in literature measuring the flexural strength and also studying the effect of elevated temperatures on flexural strength of mortars. Instead of directly measuring the flexural strength, some indirect tests like splitting tensile test are performed in general.

Boubekeur (2014) investigated the effects of high temperatures on flexural strength of concrete after exposing the samples to very high temperatures, and found that by increasing the temperature, the rate of hydration also increases, and the pozzolanic reaction of SF and GP accelerates, which leads the hardened mortar to exhibit higher flexural strength in early ages (Boubekeur, 2014). However, another research showed that specimens, produced by substituting fly ash as a pozzolanic admixture and are exposed to elevated temperature showed decrement in flexural strength compared to the control mix. The main reason of this is the accelerated rate of cement hydration which results in a larger size and number of micro cracks combining and propagating easier when compared with the mortar samples cured under normal temperature. Therefore more brittle microstructure of hydrated paste is obtained (Serdar, 2007). 


\subsection{Modulus of Elasticity}

In this section, of the significance of E-modulus of mortars and concretes are explained along with studies on the effects of independent variables such as glass powder types, quantities, w/b ratios, and curing temperatures on E-modulus of mortars and concretes gathered from the literature.

\subsubsection{Significances of Studying Modulus of Elasticity}

Modulus of elasticity test is performed generally to describe and find the limits and ranges of the elastic behaviour of materials under stress (joseph F.lamond, 2006). Modulus of elasticity (E) is described as the relationship between longitudinal compressive stress to strain of material below relative limits, according to ASTM C 469, and it is employed to measure instant elastic deformation (A.M.neville, 1995). Since there is no direct test to evaluate the elastic modulus of mortar or concrete, a comparative limit is assessed first, and this estimate is used to verify limits employed for curves in replicated purposes of loading. The E-modulus is then determined by defining the slope of the straight line in stress-strain graph (Haranki, 2009) .When concrete or mortar is exposed to loading within the elastic range, it shows a linear stress-strain correlation. The slope of that linear part of the stress-strain curve is called modulus of elasticity. As Hooke's law says, "the greatest stress which a material is capable of sustaining without any deviation from proportionality of stress to strain." The value of modulus of elasticity is important because it characterizes rigidity of materials and the load at which concrete will exhibit deformation when exceeded (Haranki, 2009). 


\subsubsection{Effect of Pozzolans and Curing Temperature on Modulus of Elasticity of Mortars and Concretes}

Some researchers studied the effects of pozzolans on modulus of elasticity of concrete. Many researchers also investigated the effect of fly ash and results showed that addition of fly ash reduced the Modulus of elasticity of high-performance concrete compared to control mixes without fly ash (Bouzoubaa, 2002). Sarıdemir investigated the compressive strength and modulus of elasticity of concrete modified with silica fume, and noted that with the addition of silica fume the sample showed higher compressive strength and modulus of elasticity compared to control mix (Saridemir, 2013).

Hani H. Nassif also studied the effects of pozzolans on the elastic modulus of highperformance concrete. By adding silica fume, fly ash, granulated blast furnace slag (GBFS) to concrete, cured specimens under different conditions, and found that addition of silica fume to concrete reduced the growth rate of $\mathrm{E}$ with increasing the age, due to a higher rate of hydration. The elastic modulus of HPC containing SF at an early age was higher with a continuing decrease over time (Hani H. Nassif, 2005).

Some researchers investigated the effects of curing. Nassif H, Suksawang N. studied the effects of curing methods on durability and modulus of elasticity of HPC in different curing conditions. They found that at elevated curing temperatures, the modulus of elasticity was increased at early ages due to an increase in rate of hydration, but at later ages, the modulus of elasticity of HPC decreased due to micro cracks, which was propagated in concrete because of high temperature (Nassif H., 2002). 


\subsection{Chloride Resistance of Concrete and Mortars}

In this section, definitions and significances of rapid chloride permeability test and chloride resistance of cementitious materials are explained. Later, results of effects of glass powder type and quantities, curing temperatures, and w/b ratios from other studies are presented.

2.9.1 Significance, and Determination of Chloride Resistance of Mortars and Concretes

Portland Cement Association established chloride resistance test, under a study by the Federal Highway Administration. Since its establishment, it has been adjusted and modified by various organizations, including ASTM International. This test is about calculating the amount of electric charge passing from a100mm in diameter of a cylindrical specimen in 6 hours, which defines the amount of Resistance of Concretes or mortar to Chloride Ion Penetration (Grace, 2006) .

Many researchers studied the relationship of this phenomenon with some parameters, like raw materials, the microstructure of concrete, curing conditions, and age. It can be concluded from all researches that, factors that might have some effects on this test, are:

- Cement type

- Water/Cement ratio

- Air content

- Age

- Aggregate type

-Admixtures which might be added to mixture 
Some admixtures, mostly used as accelerators, might have ionic salts like Calcium Nitrate, Sodium Thiocyanate, Calcium Nitrite, and Calcium Chloride, and this results in a higher level of charge passing with the assistance of ionic salts, even though the permeability of concrete has not changed (Ansari Ismail, 2015) (Lothenbach, 2007) (Serdar, 2007)(Grace, 2006).

Generally, this test is not to measure concrete permeability, but to measure mortar or concrete resistance to ion penetration. However, it has been seen that there are some relations between permeability and resistance of concrete (Grace, 2006).

\subsubsection{Effect of Glass Powder and Pozzolans on Chloride Resistance of Mortars and Concretes}

As mentioned above, pozzolans, especially those that contain ionic salts, have some effects on the amount of charge passed in this test, which related to the amount of penetration of chloric ions into the depth of concrete or mortar (Wang, 2009). There is another group of pozzolans, which might decrease the amount of charge passed by decreasing the amount of permeability of concrete. Kamali (2015) used rapid chloride permeability test, as porosity measurement of mortars in accordance with ASTM C1202, to study the effects of glass powder on durability of mortars, where it was replaced by certain percent of cement as pozzolanic supplementary cementitious materials. Kamali replaced 5\%, 10\%, 15, and 20\% of cement with glass powder, by weight. Kamali reported that using glass powder decreased the chloride permeability of mortars, compared to control mix, except for $5 \%$, where the chloride penetration amount was higher than control mix, at 28 days of testing. Kamali concluded that the reduction observed in chloride permeability amounts can be explained by microstructural development in mortar due to pozzolanic reactions, and better hydration from existence of glass powders in mortars. It is observed that mortars with 
$10 \%, 15 \%$, and $20 \%$ of glass powder showed decreases in chloride permeability compared to mortar modified with $20 \%$ of Fly Ash, which indicated the effectiveness of glass powder in reducing chloride permeability in mortars (Kamali, 2016).

\subsection{Pozzolanic Activity Index Test}

This test is performed to determine whether natural pozzolans or fly ash develop an acceptable level of strength development or not, when used by cement in mortars and concretes. It should be noted that because this test is developed by mortar, results might not offer a direct relation on how they support the strength to develop in concrete, according to ASTM C311.

This test is performed by comparing the compressive strengths of two different samples, one modified by replacing $20 \%$ of cement with the testing material by mass, and another mortar without any additive materials as cement replacement. The amount of compressive strength developed in control mix and test mixture at 28 days represents the amount of pozzolanic activity index of the material.

ASTM C311 developed an equation to calculate the amount of strength activity index of materials, which is suspected to have pozzolanic activity in reaction with Portland cement.

strength activity index with portland cement $=(A / B) \times 100$

Where: $\mathrm{A}=$ compressive strength of testing mixture, and $\mathrm{B}=$ compressive strength of control mixture. 


\subsubsection{Pozzolanic (or Strength) Activity Index of Glass Powder}

Due to the increasing number of studies on effects of different types and particle sizes of glass powders on properties of mortars and concretes, many researchers investigate the pozzolanic activity index of glass powder.

Caijun Shia studied the effects of particle size on strength activity index of glass powder. Caijun used 4 different particle sizes of glass powder to produce mortar with, and compared the compressive strength of specimens on 28 days mortars with control mix, and also with one mortar which prepared by $20 \%$ replacement of fly ash with cement. Caijun Shia found that the glass powder with biggest particle size showed the lowest reactivity index and as the fineness of glass increased, the strength activity index increased respectively. Caijun also observed that glass powder smaller than 30 $\mu \mathrm{m}$ exhibited pozzolanic activity index similar or slightly higher than fly ash in the $28^{\text {th }}$ day of testing (Caijun Shia, 2005). Also showed that glass powders with a particle size less than $38 \mu \mathrm{m}$ exhibited a pozzolanic behavior. 


\section{Chapter 3}

\section{MATERIALS AND EXPERIMENTAL PROGRAM}

\subsection{Introduction}

The chapter presents the material proportions and mixes, investigated in this study. Moreover, it includes explanation on preparation, curing and testing methods. Terms of ASTM standards are also appended for testing methods throughout each experiment.

\subsection{Materials}

The details of materials used in high strength mortar production are explained in this section.

Cement: CEM II Portland sulfate resistance slag cement of $42.5 \mathrm{~N}$, compelling with the European standard EN 197-1 (2002) cement composition, was used.

Glass powder: In this study, three different colors of glass powders were prepared from waste bottles dumped in the nature. After collecting the bottles, they were washed to remove paper labels, dust, or any undesired particles from the surface. They were classified according to their colors, which were brown (amber), green, and transparent (colorless). Subsequently, they were broken to pieces to be prepared for grinding with a rotary grinder machine and were pulverized up to $63 \mu \mathrm{m}$ in particle size. 
Fine aggregate: Fine aggregates used in this study was mining sand with a maximum size of $5 \mathrm{~mm}$. Sieve analysis was performed to find gradations based on ASTM standard, C136M-14 and was controlled by ASTM standard C33M-16 as shown in Fig 3-1.

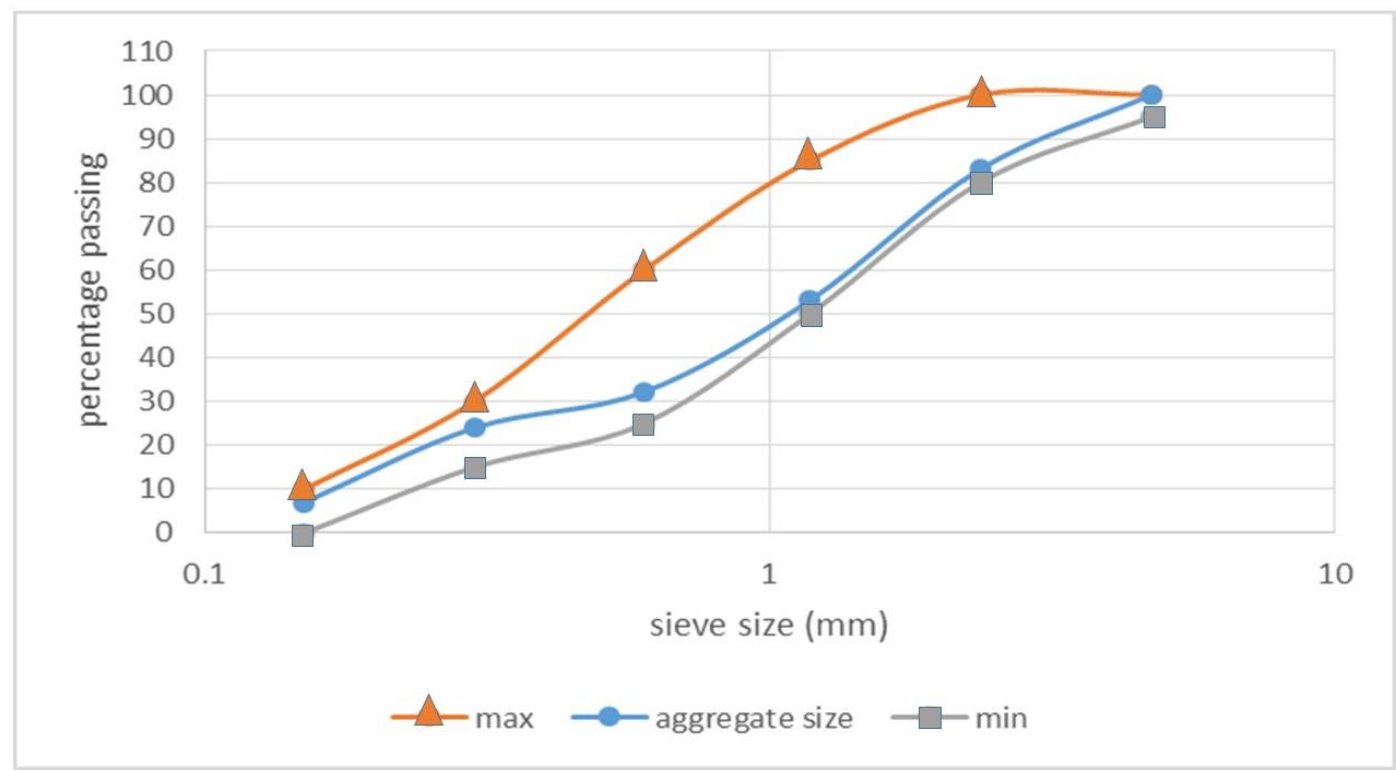

Figure3.1: Fine Aggregate Gradation

Mixing water: Normal pure tap water was used in mixing.

Superplasticizer: MasterGlenium 27 (commonly known as Glenium 27) was used as a polycarboxylic ether based, high range water reducing admixture, consistent with the ASTM standard C494-16 as type F; water-reducing, high range admixtures.

Silica fume: Undensified white silica fume with particle size of 0.1 to $1 \mu \mathrm{m}$ with $95 \%$ of silicon dioxide was used as pozzolanic material.

\subsection{Experimental Program}

The mechanical properties and the permeability of high strength mortar modified by glass powder were investigated. In total, 72 batches of mortar with different 
proportions of ingredients were prepared. Effects of different types of glass powders with different proportions water-cement ratio and curing temperature on high strength mortars were investigated.

\subsubsection{Sample Preparation}

In this section, materials, proportions and curing procedures used in order to prepare the samples are explained.

\subsubsection{Definitions and proportions of materials used in mortars production}

Three different types of glass powder with particle sizes less than $63 \mu \mathrm{m}$ were replaced at two levels as $10 \%$ and $20 \%$ with cement, by weight. In addition, control mix without any admixtures, and one mix with $20 \%$ of silica fume, replacing cement were prepared for later comparisons. Types of glass powders were white glass powder (WGP), green glass powder (GGP), and brown glass powder (BGP) which are expected to have different effects on mechanical properties due to differences in ingredients as explained in chapter 2 . In addition, three different $\mathrm{w} / \mathrm{b}$ ratios as $0.35,0.40$ and 0.45 were selected and used in this study to investigate the effects of pozzolanic reaction of glass powders with differing w/b ratios. Tables 3.1 to 3.3 illustrate the mix proportions of mortars.

Table 3.1: Mixing materials and proportion of mortar specimens $(\mathrm{w} / \mathrm{b}=0.35)$

\begin{tabular}{|c|c|c|c|c|c|c|c|}
\hline \multirow[t]{2}{*}{ Name } & \multirow{2}{*}{$\begin{array}{c}\text { Type } \\
\text { of } \\
\text { Admixture }\end{array}$} & \multicolumn{3}{|c|}{ Quantity } & \multirow{2}{*}{$\begin{array}{c}w / b \\
\text { Ratio }\end{array}$} & \multirow{2}{*}{$\begin{array}{c}\text { Fine } \\
\text { Aggregat } \\
e(g r)\end{array}$} & \multirow{2}{*}{$\begin{array}{c}\text { Super } \\
\text { plastici } \\
\text { zer } \\
(\mathrm{gr})\end{array}$} \\
\hline & & $\begin{array}{c}\text { Admixture } \\
(\%-g r)\end{array}$ & $\begin{array}{c}\text { Cement } \\
(\mathrm{gr})\end{array}$ & $\begin{array}{c}\text { Water } \\
(\mathrm{gr})\end{array}$ & & & \\
\hline Control & - & - & 1550 & 542 & 0.35 & 5580 & 30 \\
\hline$W 20$ & WGP & $20-310$ & 1240 & 542 & 0.35 & 5580 & 30 \\
\hline W10 & WGP & $10-155$ & 1395 & 542 & 0.35 & 5580 & 30 \\
\hline$G 20$ & GGP & $20-310$ & 1240 & 542 & 0.35 & 5580 & 30 \\
\hline G10 & GGP & $10-155$ & 1395 & 542 & 0.35 & 5580 & 30 \\
\hline B2O & BGP & $20-310$ & 1240 & 542 & 0.35 & 5580 & 30 \\
\hline B10 & BGP & $10-155$ & 1395 & 542 & 0.35 & 5580 & 30 \\
\hline$S F 20$ & SF & $20-310$ & 1240 & 542 & 0.35 & 5580 & 30 \\
\hline
\end{tabular}


Table 3.2: Mixing materials and proportions of mortar specimens $(\mathrm{w} / \mathrm{b}=0.40)$

\begin{tabular}{cccccccc}
\hline Name & $\begin{array}{c}\text { Type } \\
\text { of } \\
\text { Admixture }\end{array}$ & $\begin{array}{c}\text { Quantity } \\
\text { Admixture } \\
(\%-g r)\end{array}$ & $\begin{array}{c}\text { Cement } \\
(\mathrm{gr})\end{array}$ & $\begin{array}{c}\text { Water } \\
(\mathrm{gr})\end{array}$ & $\begin{array}{c}\text { Ratio } \\
\text { Ratio }\end{array}$ & $\begin{array}{c}\text { Fine } \\
\text { Aggregate } \\
(\mathrm{gr})\end{array}$ & $\begin{array}{c}\text { Super } \\
\text { plastici } \\
\text { zer } \\
(\mathrm{gr})\end{array}$ \\
\hline $\begin{array}{c}\text { Control } \\
\text { W20 }\end{array}$ & WGP & $20-310$ & 1240 & 620 & 0.40 & 5580 & 18 \\
W10 & WGP & $10-155$ & 1395 & 620 & 0.40 & 5580 & 18 \\
G20 & GGP & $20-310$ & 1240 & 620 & 0.40 & 5580 & 18 \\
G10 & GGP & $10-155$ & 1395 & 620 & 0.40 & 5580 & 18 \\
B20 & BGP & $20-310$ & 1240 & 620 & 0.40 & 5580 & 18 \\
B10 & BGP & $10-155$ & 1395 & 620 & 0.40 & 5580 & 18 \\
SF20 & SF & $20-310$ & 1240 & 620 & 0.40 & 5580 & 18 \\
\hline
\end{tabular}

Table 3.3: Mixing materials and proportions of mortar specimens $(\mathrm{w} / \mathrm{b}=0.45)$

\begin{tabular}{cccccccc}
\hline Name & $\begin{array}{c}\text { Type } \\
\text { of } \\
\text { Admixture }\end{array}$ & $\begin{array}{c}\text { Quantity of } \\
\text { Admixture } \\
(\%-g r)\end{array}$ & $\begin{array}{c}\text { Cement } \\
(\mathrm{gr})\end{array}$ & $\begin{array}{c}\text { Water } \\
(\mathrm{gr})\end{array}$ & $\begin{array}{c}\text { Fatio } \\
\text { Ratio }\end{array}$ & $\begin{array}{c}\text { Super } \\
\text { Agregate } \\
(\mathrm{gr})\end{array}$ & $\begin{array}{c}\text { plastici } \\
\text { zer } \\
(\mathrm{gr})\end{array}$ \\
\hline Control & - & - & 1550 & 698 & 0.45 & 5580 & 12 \\
W20 & WGP & $20-310$ & 1240 & 698 & 0.45 & 5580 & 12 \\
W10 & WGP & $10-155$ & 1395 & 698 & 0.45 & 5580 & 12 \\
G20 & GGP & $20-310$ & 1240 & 698 & 0.45 & 5580 & 12 \\
G10 & GGP & $10-155$ & 1395 & 698 & 0.45 & 5580 & 12 \\
B20 & BGP & $20-310$ & 1240 & 698 & 0.45 & 5580 & 12 \\
B10 & BGP & $10-155$ & 1395 & 698 & 0.45 & 5580 & 12 \\
SF20 & SF & $20-310$ & 1240 & 698 & 0.45 & 5580 & 12 \\
\hline
\end{tabular}

Every single batch was prepared to fill one cylinder with a diameter of $100 \mathrm{~mm}$ and a height of $200 \mathrm{~mm}$, and six beams with diameters of $160 \times 40 \times 40 \mathrm{~mm}$ size. Specimens which produced, cured at different temperatures $\left(22{ }^{\circ} \mathrm{C}, 55^{\circ} \mathrm{C}\right.$, and $\left.80{ }^{\circ} \mathrm{C}\right)$.

\subsubsection{Mixing, Molding and Compacting of Samples}

Mixing of each batch was done by a mixer as per ASTM C305-14. Mixing procedure was also carried out as per the requirements of ASTM C305-14. After this procedure, the fresh mixture was molded and compacted according to standard ASTM C109-16 and cured in a curing room with a relative humidity of $99 \%$ for 24 hours. 


\subsubsection{Curing of Specimens}

After remolding the specimens, according to the curing temperature, they were put into normal water or were cured in high-temperature water for $48 \mathrm{hrs}$ after remolding. Specimens cured in normal room temperature were transferred to $22{ }^{\circ} \mathrm{C}$ directly after remolding to cure in water up to the test day. Specimens subjected to high-temperature curing were put into high-temperature water curing tank $\left(55^{\circ} \mathrm{C}\right.$, or $\left.80^{\circ} \mathrm{C}\right)$ for the first $48 \mathrm{hrs}$ after remolding and then transferred to normal curing tank with $25^{\circ} \mathrm{C}$ until the day of testing.

\subsection{Fresh Mortar Workability Test}

Immediately after the mixing procedure was finished, a small amount of fresh mortar was collected to perform the flow table test for investigating the workability of fresh mortar for each batch. The mold was placed in the center, on the top of the flow table and was filled with two layers of mortar. Each layer was compacted with tamping rod, with 20 blows. 1 minute after the surface of mold became flat, the mold has been removed and 25 hits implied to the table in 15 seconds. The amount of propagation of fresh mortar on the table was measured at four different points on the diameter, and the average of 4 readings was reported. This test was performed according to ASTM C1437-15 standard test method. Standard ASTM C230-14 authenticated flow table Apparatus.

\subsection{Testing of Hardened Mortars}

In this section, the tests performed on hardened mortars were described. In addition, relevant ASTM standards used for these tests were presented.

\subsubsection{Flexural Strength}

Tensile strength test provides a method for defining the flexural strength of mortars. This test was performed according to ASTM C348-14. It was done with 
$40 \times 40 \times 160 \mathrm{~mm}$ prisms at $7^{\text {th }}$, and $28^{\text {th }}$ day of curing, and 3 specimens were used in each test. It should be noticed that specimens were kept under water until the test date. Center Point loading method was used in flexure test on specimens. After recording the load measured by a machine, the following formula was used to calculate the flexural strength of mortars:

$s_{f}=0.0028 P$

Where: $\mathrm{P}=$ total maximum load $(\mathrm{N})$

$\mathrm{S}_{\mathrm{f}}=$ flexural strength of specimen

\subsubsection{Compressive Strength}

This test was performed to investigate the amount of compressive strength of mortars at 7 and 28 days. Specimens, used for compressive strength test were broken prisms, which were used for flexural strength of mortars with diameters of $40 \mathrm{~mm}$ by $40 \mathrm{~mm}$ by 40mm cubes, according to standard test method ASTM C349-14. In addition, each compressive strength test was done on three specimens and the average of three was reported as the compressive strength.

\subsubsection{Modulus of Elasticity}

Effects of types of glass powder, different amounts of replacement, water/binder ratios, and curing temperature on Young's modulus of elasticity was investigated by cylindrical specimens with $100 \mathrm{~mm}$ diameter and $200 \mathrm{~mm}$ height. After curing samples for 28 days, capping was applied to make both surface of samples flat and paralleled to each other. Two sensors were placed in a manner to measure the middle third displacement of the specimen. After two cycles of loading and unloading, the specimen was loaded up to $40 \%$ of total strength. After normalizing the last cycle of the graph, the tangent was calculated and reported as the young's elastic modulus of mortar. All these procedures were done according to ASTM C496-14 standard test. 


\subsubsection{Pozzolanic Activity Index}

Pozzolanic activity index cover methods for testing fly ash or other natural pozzolans to be used in mortars and concretes with Portland cement. The test was performed according to ASTM C311- 13. The proportion of raw material is listed in table 3.4. Portland cement type II, 42.5 was used in this test. Normal standard sand, and normal tap water was used to prepare the mixtures.

Table 3.4: Effect of GP to pozzolanic activity index of mortar specimens

\begin{tabular}{lllll}
\hline Name & Cement $(\mathrm{g})$ & Sand $(\mathrm{g})$ & Water $(\mathrm{ml})$ & GP $(\mathrm{g}) /$ type \\
\hline Control mix & 500 & 1375 & 242 & - \\
WGP-PC & 400 & 1375 & 242 & $100 \mathrm{~W}$ \\
BGP-PC & 400 & 1375 & 242 & $100 \mathrm{~B}$ \\
GGP-PC & 400 & 1375 & 242 & $100 \mathrm{G}$ \\
\hline
\end{tabular}

After preparation of specimens, according to ASTM C618, compressive strength of control and test specimens were tested at $28^{\text {th }}$ day of curing under water with normal temperature, and then compared together as below:

strength activity index with Portland cement $=\left(\frac{A}{B}\right) \times 100$

Where; A: compressive strength of test mixtures, $\mathrm{MPa}$

$\mathrm{B}$ : compressive strength of control mixture, $\mathrm{MPa}$

\subsubsection{Rapid Chloride Permeability Test}

This test was performed to evaluate the effect of SF and BGP on resistance of mortar toward chloride ion penetration and the procedures satisfied the standard ASTM C1201. Rapid chloride permeability test was performed on the $56^{\text {th }}$ day of curing of cylindrical specimens and was applied on 6 samples. This test includes observing total electrical current passing through 50-mm pieces of cores, or cylinders with nominal 
diameter of $100-\mathrm{mm}$ during a period of 6hours. A potential variation of $60 \mathrm{~V}$ dc is provided at each end of the slices, with one end submerged in a solution of sodium chloride, and the other in a sodium hydroxide liquid.

After finishing each test, total charge passed from each sample is measured and compared with each other. 


\section{Chapter 4}

\section{EXPERIMENTAL RESULTS AND DISCUSSIONS}

\subsection{Introduction}

Effects of four independent variables such as w/b ratio, temperature, quantity and types of glass powder on mechanical properties of high-performance mortars were investigated experimentally. To evaluate the beneficial or detrimental effects at different curing temperatures and w/b ratios, samples, which modified with glass powder were compared with control mixes. Compressive strength, flexural strength and modulus of elasticity test were employed to evaluate effects of glass powder on mechanical properties. In addition, rapid chloride permeability test performed to evaluate resistance of mortars, which modified brown glass powder against chloride ions attack. Finally, results are illustrated by various graphs, enabling the comparison in different aspects.

\subsection{Effect of GP Type (Color) and Quantity on Workability of High Strength Mortars (HSM)}

Effect of silica fume and glass powder on the workability of mortars at different w/b ratios were investigated and results were illustrated in Fig 4.1. As results depicted, replacement of silica fume decreased the workability of fresh mortar, however glass powder increased it. In addition, comparisons revealed that the type of glass powder has no effect on the workability, while the amount of glass powder replaced is efficient; increased workability of mortars by replacing the glass powder is because of its particle surface. The surface of glass powder particles is smoother than cement 
particles so less water is required to cover the whole surface of glass particles. As replacement of GP increases, free water in fresh mortar increases consequently and it leads to higher workability.

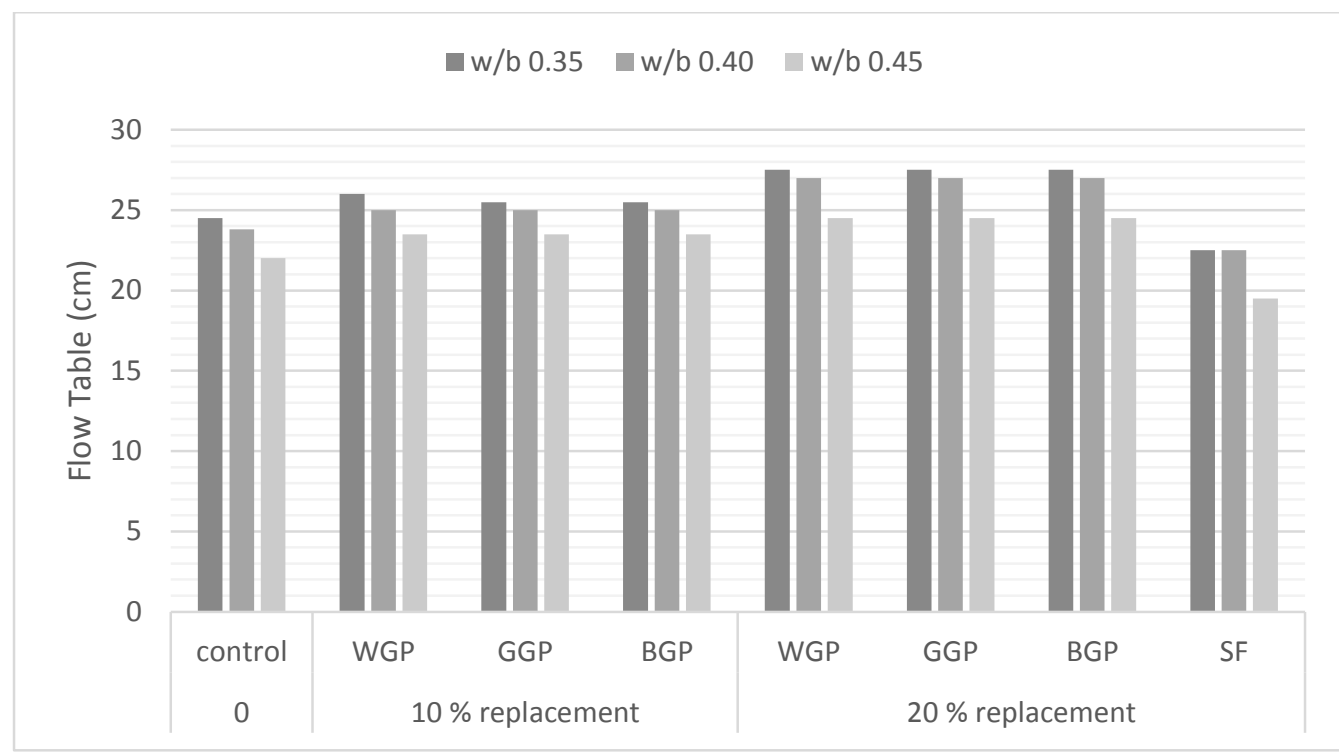

Figure 4.1: Effect of Different Colors and Quantities of GPs on Workability Relative to Control and SF

\subsection{Effect of GP Type and Quantity, w/b Ratio, and Curing Temperature on Compressive Strength of HSM}

The following charts illustrate the compressive strength of mortars prepared at different $\mathrm{w} / \mathrm{b}$ ratios and different temperatures. The compressive strength of samples prepared in each condition is compared together and with control mix to evaluate the effect of glass powder in different situations.

As it has been shown in Fig 4.2, at standard temperature and w/b of 0.35, mortars that modified with different types of glass powder expressed lower compressive strength at the early age, comparing to control mix. 


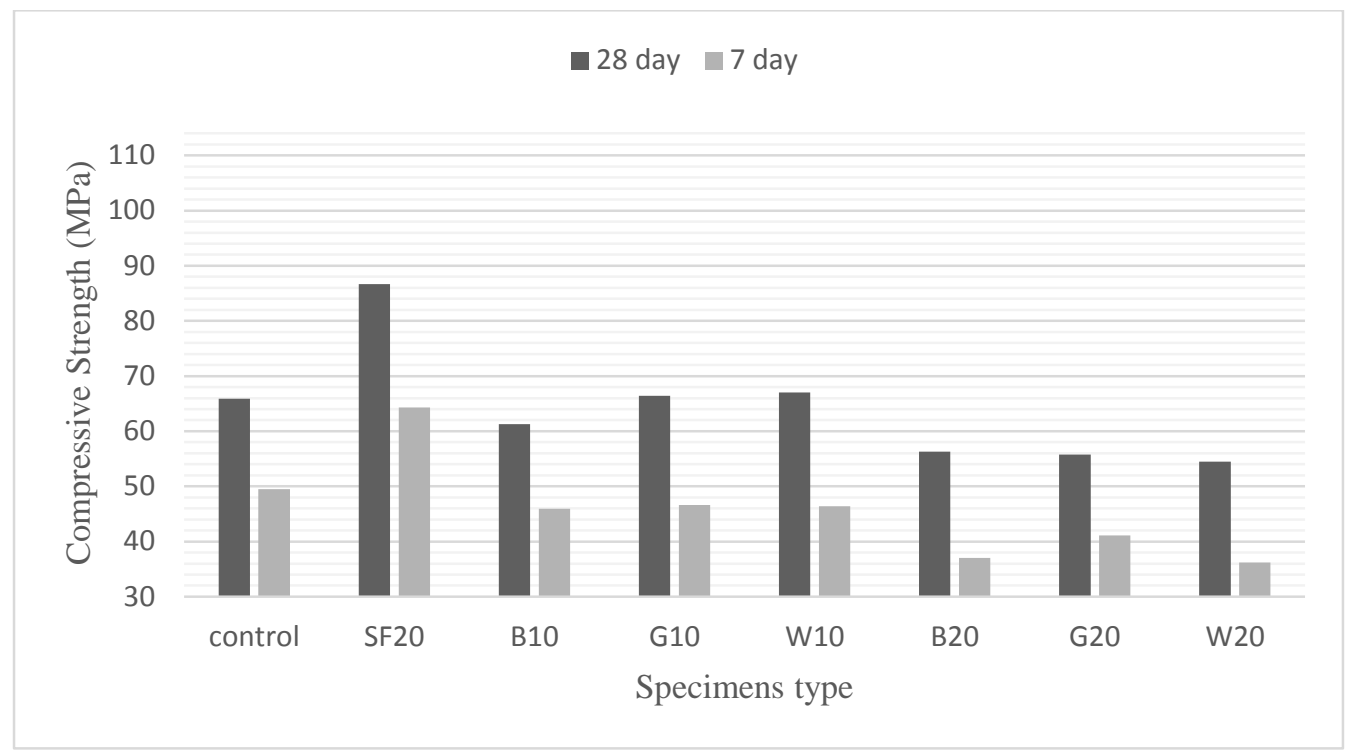

Figure 4.2: Effect of Different Colors and Quantities of GPs on 7 and 28 Days Compressive Strengths for w/b 0.35 and $22^{\circ} \mathrm{C}$ Curing Temperature

Nevertheless, replacement of white and green glass powder (WGP and GGP) by $10 \%$ made the compressive strength equal or even slightly higher than control mixture in the later age of curing. Totally, replacement of GP by $10 \%$ rather than $20 \%$ is more effective to enhance more compressive strength either in $7^{\text {th }}$ or $28^{\text {th }}$ days of curing. Comparing with control mix, replacement of GP decreased the rate of hydration and caused mortars to show lower compressive strength at early age. However, the compressive strength increased at the later age, especially with WGP, GGP replacement. Generally, it is because of pozzolanic reactivity of glass powder with unhydrated cement particles and production of C-S-H substances in the mortar at later ages. 


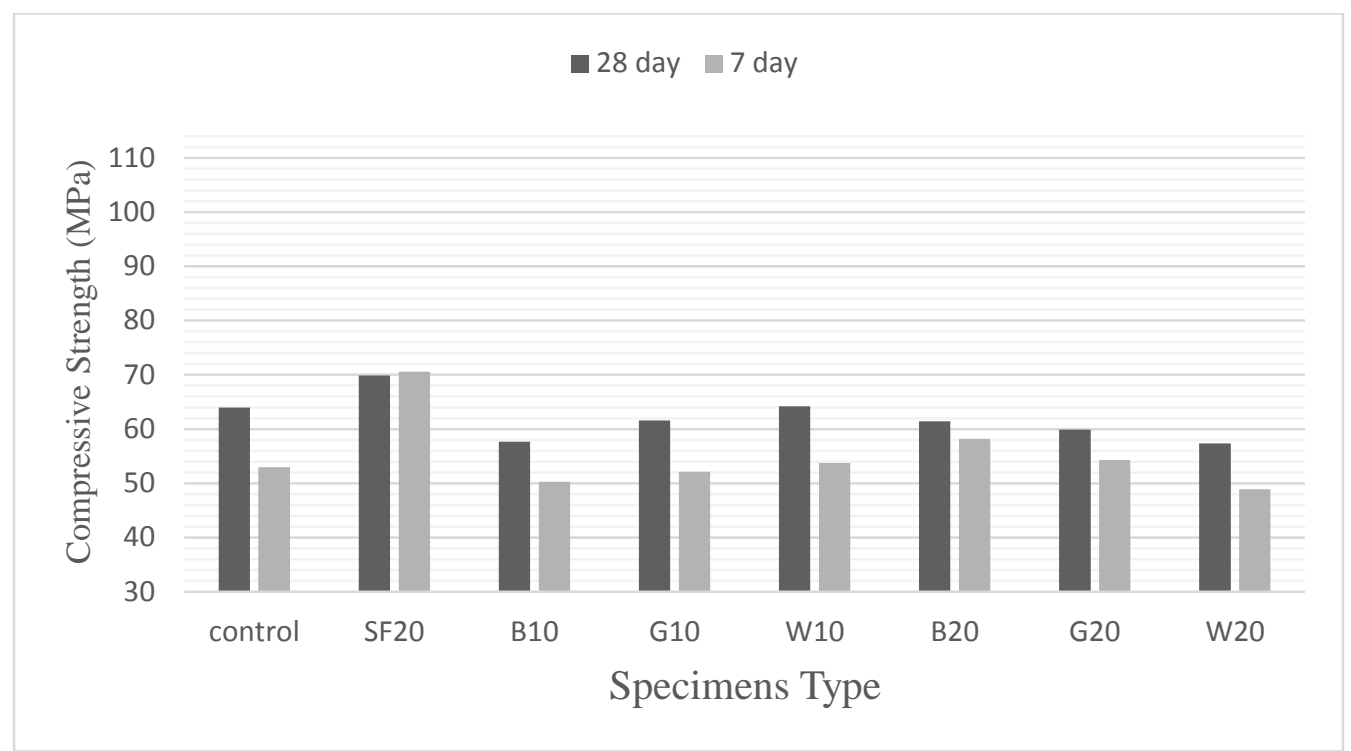

Figure4.3: Effect of Different Colors and Quantities of GPs on 7 and 28 Days Compressive Strengths for w/b 0.35 and $55^{\circ} \mathrm{C}$ Curing Temperature

Figure 4.3 illustrates the compressive strength of mortars at $7^{\text {th }}$ and $28^{\text {th }}$ days with $\mathrm{w} / \mathrm{b}$ of 0.35 and curing temperature of $55^{\circ} \mathrm{C}$. Results have shown that $\mathrm{B} 20, \mathrm{G} 20$, and $\mathrm{W} 10$ exhibited higher compressive strength at $7^{\text {th }}$ day of curing. However, only the mortar modified with $10 \%$ of WGP showed higher compressive strength comparing to control mix at the later age. It can be noted that, the compressive strength of SF20, not only did not increase at later ages, but also decreased negligibly.

The compressive strength of mortars modified with silica fume and glass powder at w/b of 0.35 and curing temperature of $80^{\circ} \mathrm{C}$ is depicted in Fig 4.4. Compressive strength of mortars, which contained GP, except the one with $20 \%$ of GGP, were near the compressive strength of control at the early age, while the compressive strength of B20, B10, and W20 were even higher than control mix. Meanwhile, only the compressive strength of B10 exhibited higher value than control mix at the later age. 


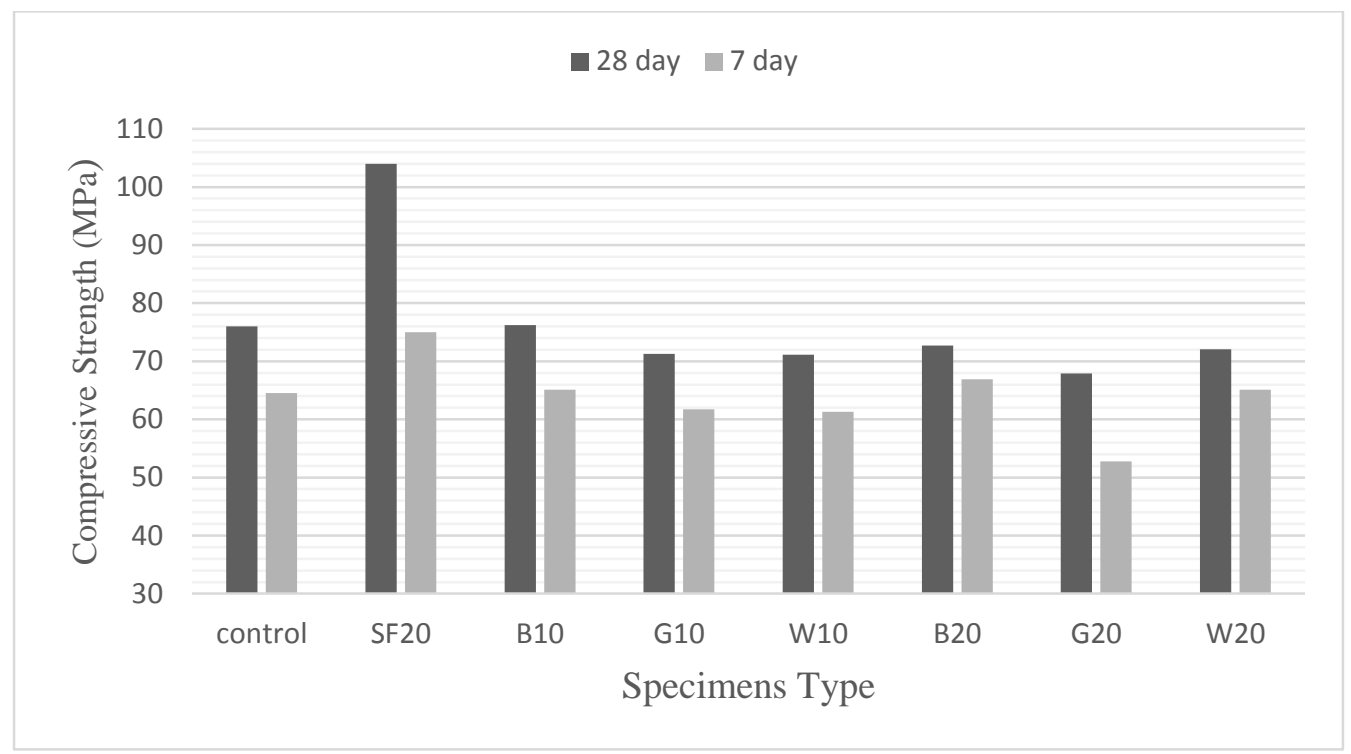

Figure 4.4: Effect of Different Colors and Quantities of GPs on 7 and 28 Days Compressive Strengths for w/b 0.35 under $80^{\circ} \mathrm{C}$ Curing Temperature

The SF20 at $80^{\circ} \mathrm{C}$ curing temperature and $w / b$ of 0.35 exhibited the highest compressive strength among all specimens and it is true even at other $\mathrm{W} / \mathrm{b}$ ratios and temperatures. As shown in Fig 4.5 and Fig 4.6, the pozzolanic activity of not only silica fume but also all types of GPs increase as the curing temperature increased.

As it is shown in Fig 4.5 and 4.6, the compressive strength of mortars modified with glass powder increases by increasing the curing temperature. Concluding all, elevated curing temperature increases the rate of pozzolanic reactivity of glass powders and decreases the retarder tendency of GP. 


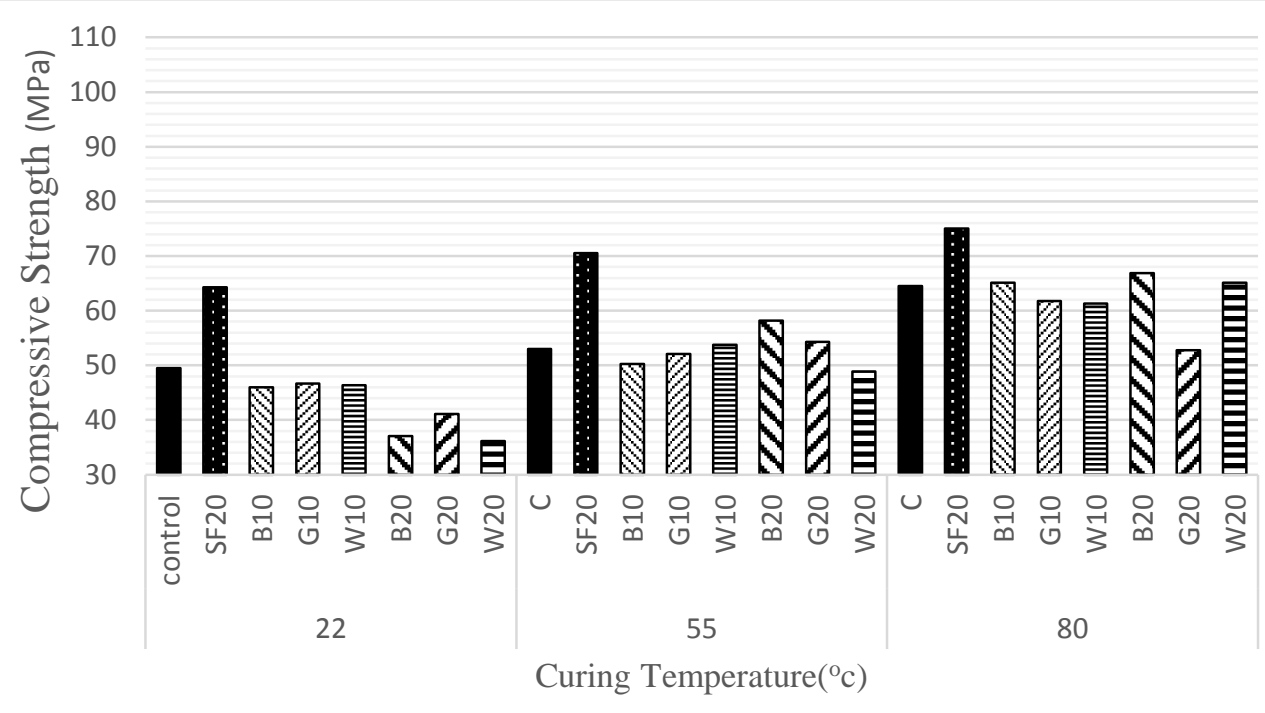

Figure 4.5: Effect of Different Colors and Quantities of GPs and Curing Temperatures on 7-Days Compressive Strength for w/b 0.35

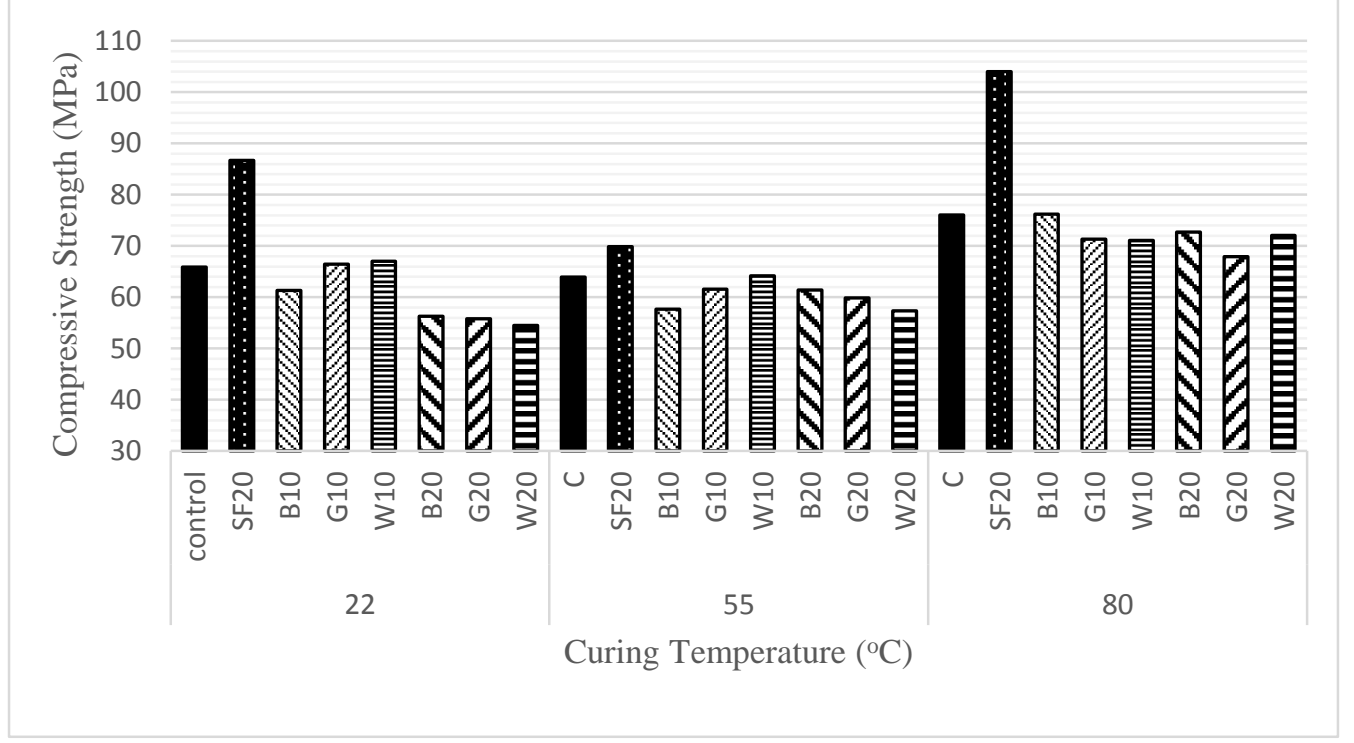

Figure 4.6: Effect of Different Colors and Quantities of GPs and Curing Temperatures on 28-Days Compressive Strength for w/b 0.35

Fig 4.5 and 4.6 give better vision about the effect of curing temperature on the compressive strength of mortars at w/b of 0.35 . The increase in compressive strength of mortars, which is done due to the increased temperature of curing, can be explained by the pozzolanic reactivity of glass powders, which is amplified by elevating the temperature. As the temperature increases, the propensity of GPs to react with cement 
particles and to produce $\mathrm{C}-\mathrm{S}-\mathrm{H}$ increases. Experimentally, the compressive strength of SF20, B10, G10, and W10 decreased at temperature of $55^{\circ} \mathrm{C}$, while it increased in $80^{\circ} \mathrm{C}$ at $28^{\text {th }}$ day. Comparisons between Fig 4.5 and 4.6 specifies that, the effect of temperature is more significant at early ages which can be attributed to a phenomenon sating that, increase in curing temperature will decrease the retard-ability of glass powder and increases the pozzolanic reactivity of binder. It is obvious that, the compressive strength of control increase at elevated temperatures in early ages, which is caused by acceleration in hydration due to the raising of curing temperature. On the other hand, mortars that modified with glass powder depict higher compressive strength in comparison with control mix at higher temperatures, which can attributed to the higher pozzolanic reactivity of glass powder at elevated curing temperatures.

Figure 4.7 illustrates the compressive strength of mortars with w/b of 0.40 and standard curing temperature.

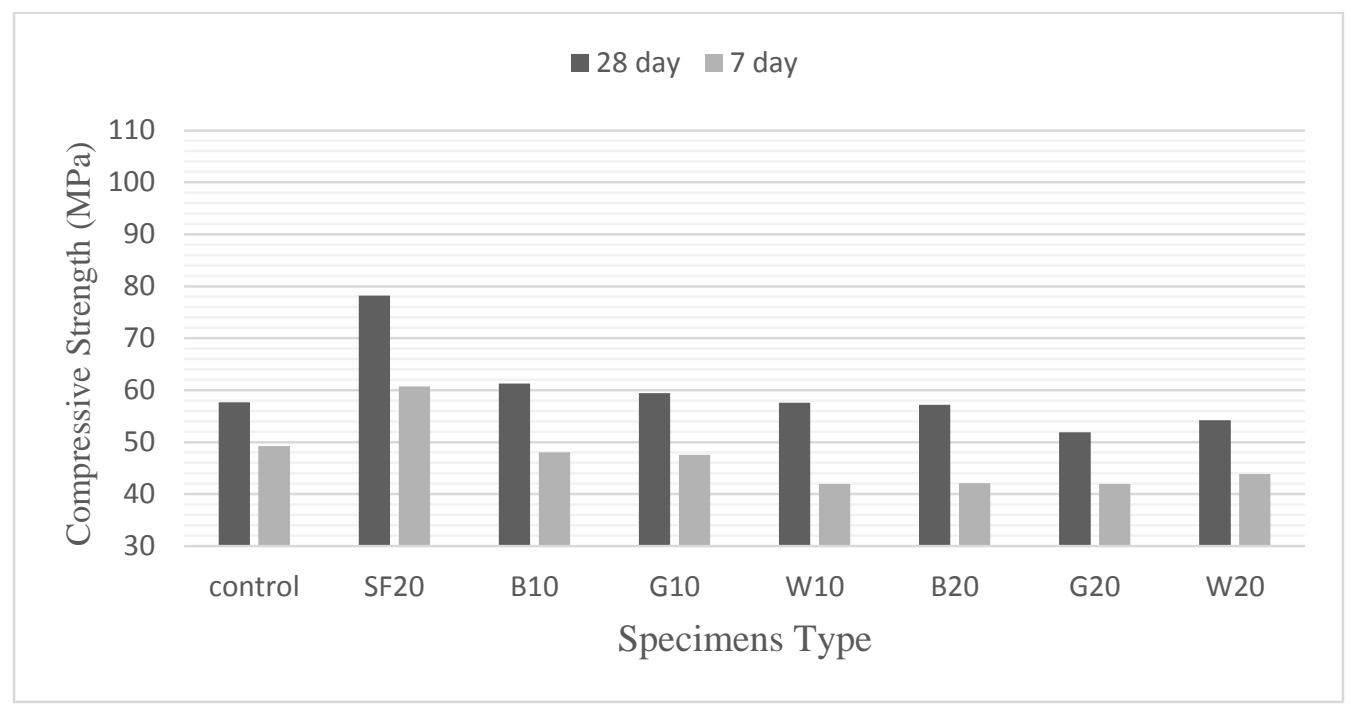

Figure 4.7: Effect of Different Colors and Quantities of GPs on 7 and 28 Days Compressive Strengths for w/b 0.40 under $22^{\circ} \mathrm{C}$ Curing Temperature 
At early ages, the compressive strength of all mortars except SF20 was lower than control, while the compressive strength of B10, G10 and W10 become slightly higher. In conclusion, the replacement of glass powders decreased the rate of hydration at normal curing temperature.

As it is illustrated in Fig 4.8, the compressive strength is almost the same for control mix and other mixtures, which are modified by GP at curing temperature of $55^{\circ} \mathrm{C}$ in early ages. However, W10 showed slightly higher compressive strength, but the rest of mortars modified with glass powder depicted lower amount in compressive strength at later ages. It can be seen that, SF20 did not obtain higher compressive strength after the $7^{\text {th }}$ day.

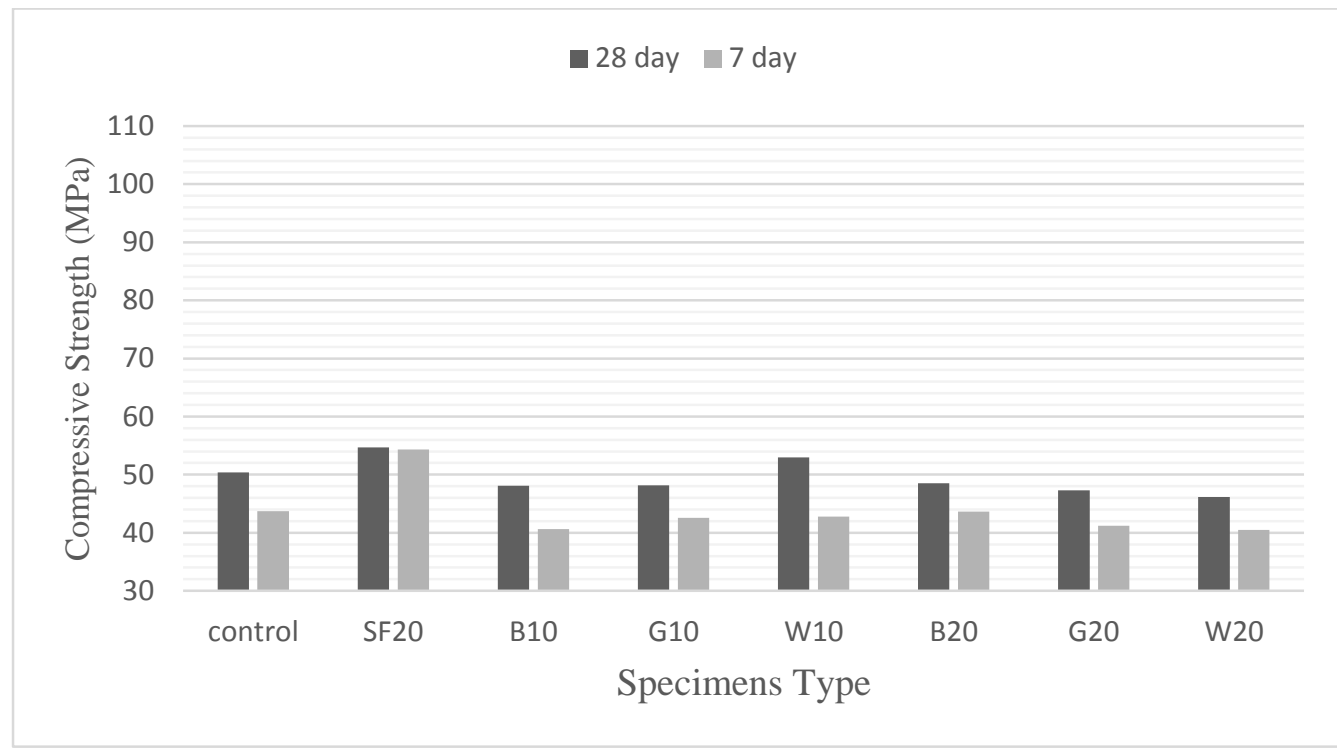

Figure 4.8: Effect of Different Colors and Quantities of GPs on 7 And 28 Days Compressive Strengths for w/b 0.40 under $55^{\circ} \mathrm{C}$ Curing Temperature

The compressive strength of mortars at w/b of 0.40 and curing temperature of $80^{\circ} \mathrm{C}$, was compared at $7^{\text {th }}$ and $28^{\text {th }}$ day. As it is shown in Fig 4.9, all mixtures, except B20 and G20, showed higher compressive strength than control at both $7^{\text {th }}$ and $28^{\text {th }}$ days. The difference between early and later ages' compressive strength of mortars was 
lower than other temperatures. However, this difference for control mixture was the same as it was at other temperatures. This phenomenon is because of the higher rate of hydration and higher pozzolanic activity of glass powders at high temperatures.

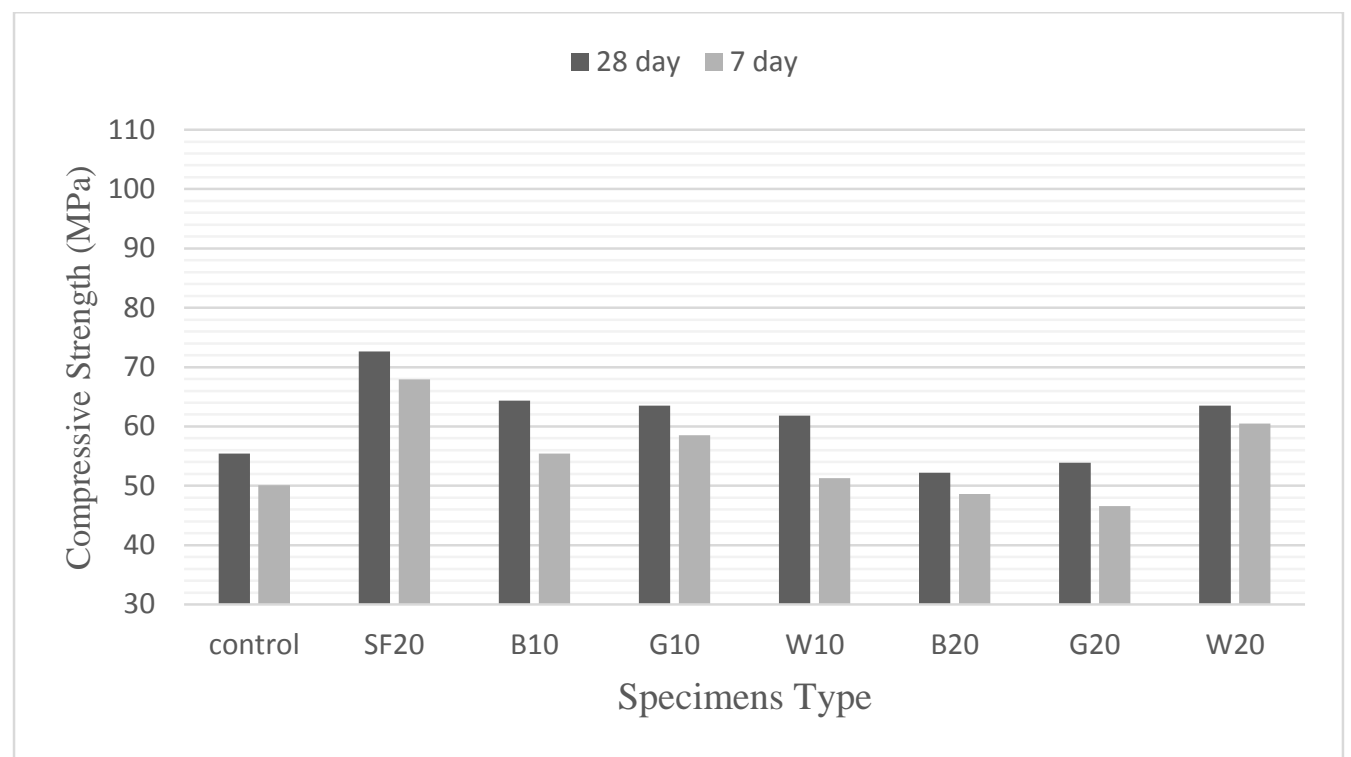

Figure 4.9: Effect of Different Colors and Quantities of GPs on 7 and 28 Days Compressive Strengths for w/b 0.40 under $80^{\circ} \mathrm{C}$ Curing Temperature

The comparison between all specimens that prepared at $\mathrm{w} / \mathrm{b}$ of 0.40 and different curing temperatures showed that, early compressive strength of control mixture decreases as the temperature increases to $55^{\circ} \mathrm{C}$ then increases when the temperature raises again to $80^{\circ} \mathrm{C}$. This process is valid for SF20, B10, G10, G20, and W20. But the Compressive strength of B20 and W10 increased as the temperature increased without any drop at $55^{\circ} \mathrm{C}$ as it is illustrated in Fig 4.10. In this range, the increase in rate of compressive strength related to samples modified with glass powder due to elevated temperatures was more than control mixes. 


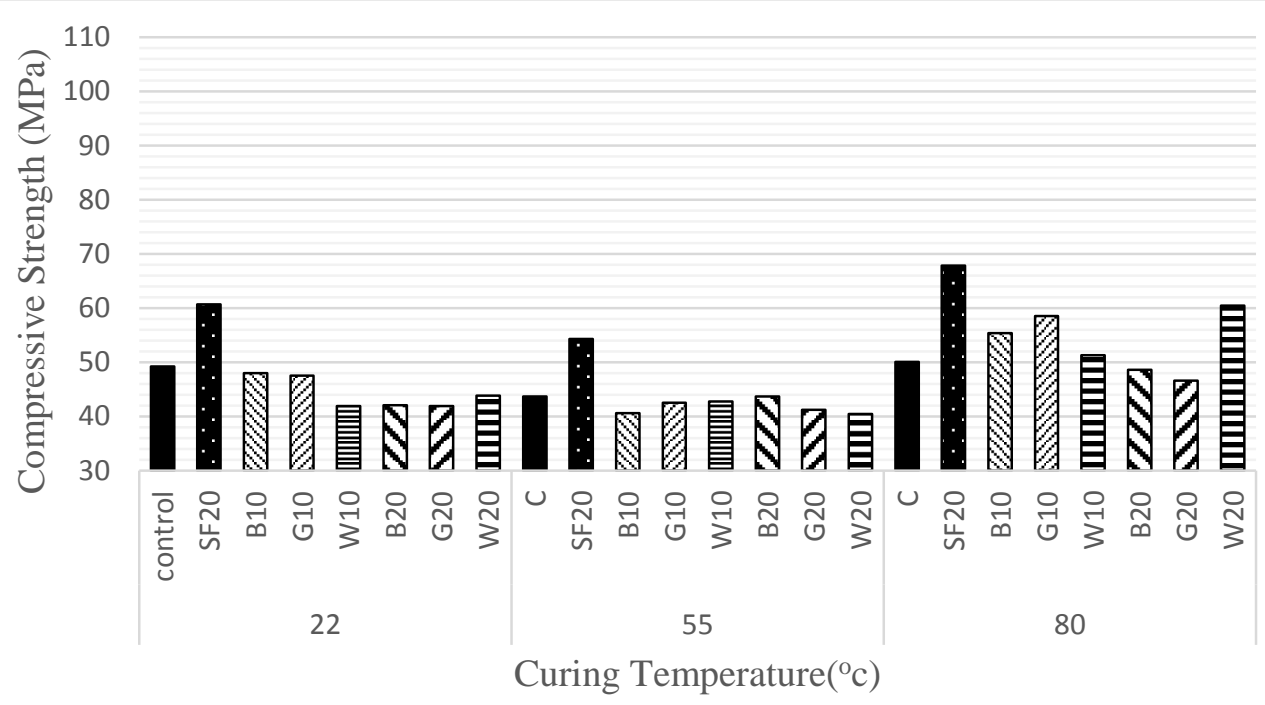

Figure 4.10: Effect of Different Colors and Quantities of GPs and Curing Temperatures on 7-days Compressive Strength for w/b 0.40

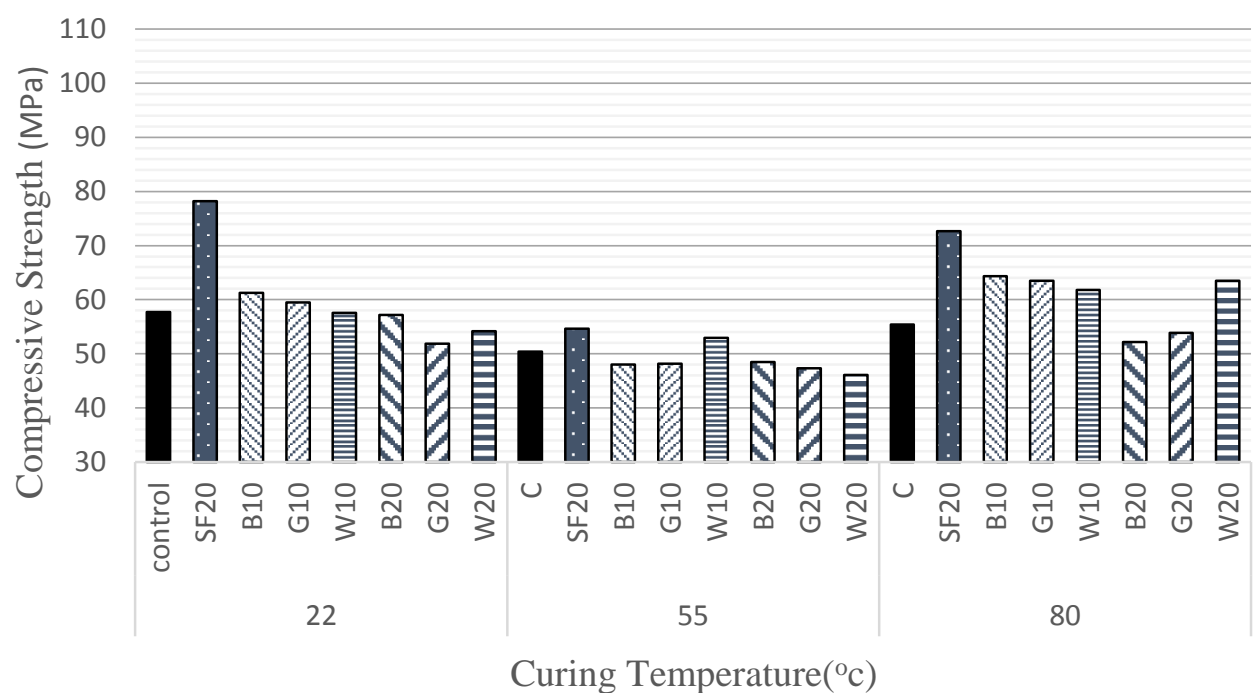

Figure 4.11: Effect of Different Colors and Quantities of GPs and Curing Temperatures on 28-Days Compressive Strength for w/b 0.40

The $28^{\text {th }}$ day's compressive strength of each sample with w/b of 0.40 at different temperatures was compared and results are shown in Fig 4.11. Comparison between specimens showed that compressive strength decreased as the temperature increased, while the highest decrease rate happened at the $55^{\circ} \mathrm{C}$ for all specimens. Additionally, Comparisons between B10, G10, G20, W10, and W20, which cured in standard 
temperature and samples that cured in $80^{\circ} \mathrm{C}$, showed that the compressive strength increased at the temperature of $80^{\circ} \mathrm{C}$. As the matter of the fact, mortars, which are modified with GP, had a higher hydration rate at $80^{\circ} \mathrm{C}$ than others, which are cured in normal temperature (Fig 4.11).

Comparison between all mixtures made at w/b of 0.45 and cured at standard temperature showed that, mortars modified with GP exhibited higher compressive strength than control mixture both at the $7^{\text {th }}$ and $28^{\text {th }}$ days except for G20 (Fig4.12).

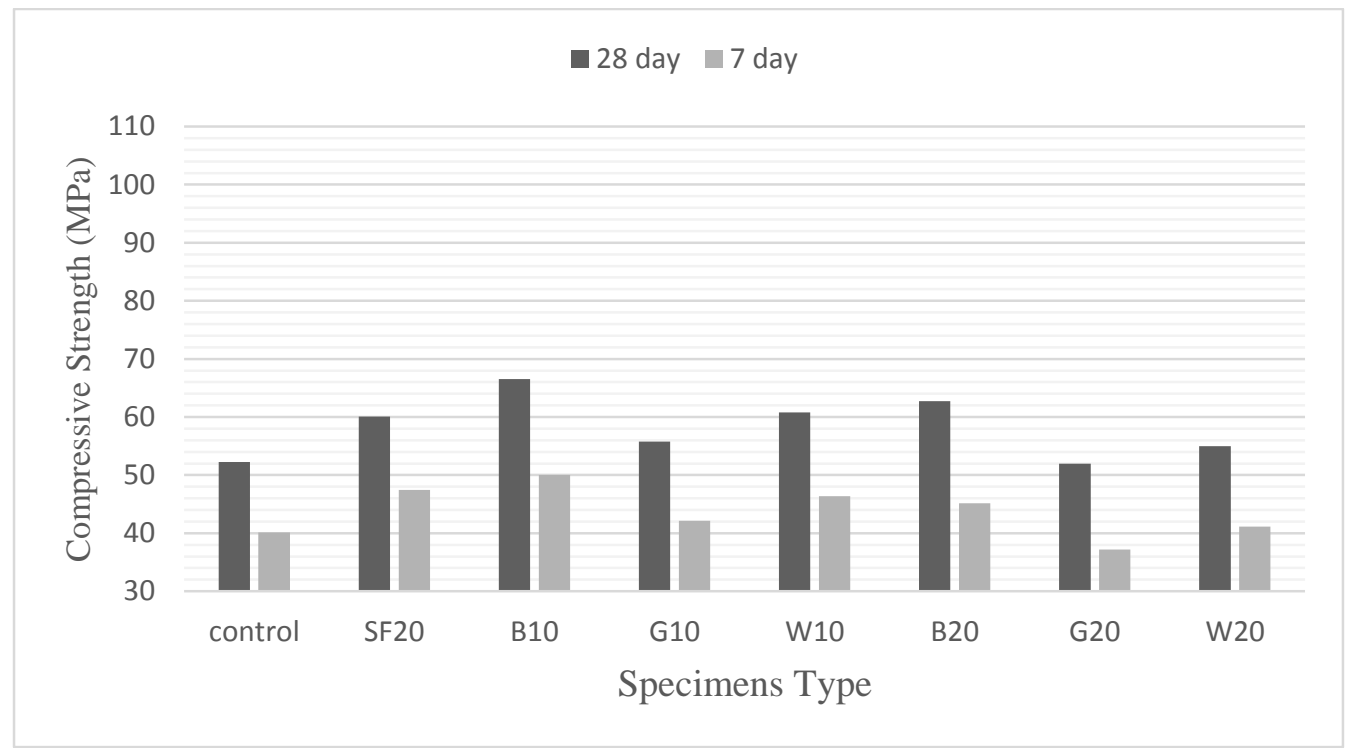

Figure 4.12: Effect of Different Colors and Quantities of GPs on 7 and 28 Days Compressive Strengths for w/b 0.45 under $22^{\circ} \mathrm{C}$ Curing Temperature

It can be noted that, B10, B20 and W10 exhibited higher compressive strength than not only control mix but also SF20. All in all, replacement of BGP and WGP were carried out better hydration rate than silica fume within this condition (Fig4.12).

The comparison between the control mix and mixtures modified with glass powder showed that, B10, W10, and B20 exhibited higher compressive strength than control mix at w/b of 0.45 and curing temperature of 55 in early ages. It demonstrates that, the 
rate of hydration of these samples were higher than control mix. Comparing to others, the minimum compressive strength attributed to G20 in both early and later ages, which may happen due to the lower pozzolanic reaction of GGP. W10 and B20 showed higher compressive strength than control and SF20 in later age, while B10 exhibited the highest at $28^{\text {th }}$ day (Fig 4.13).

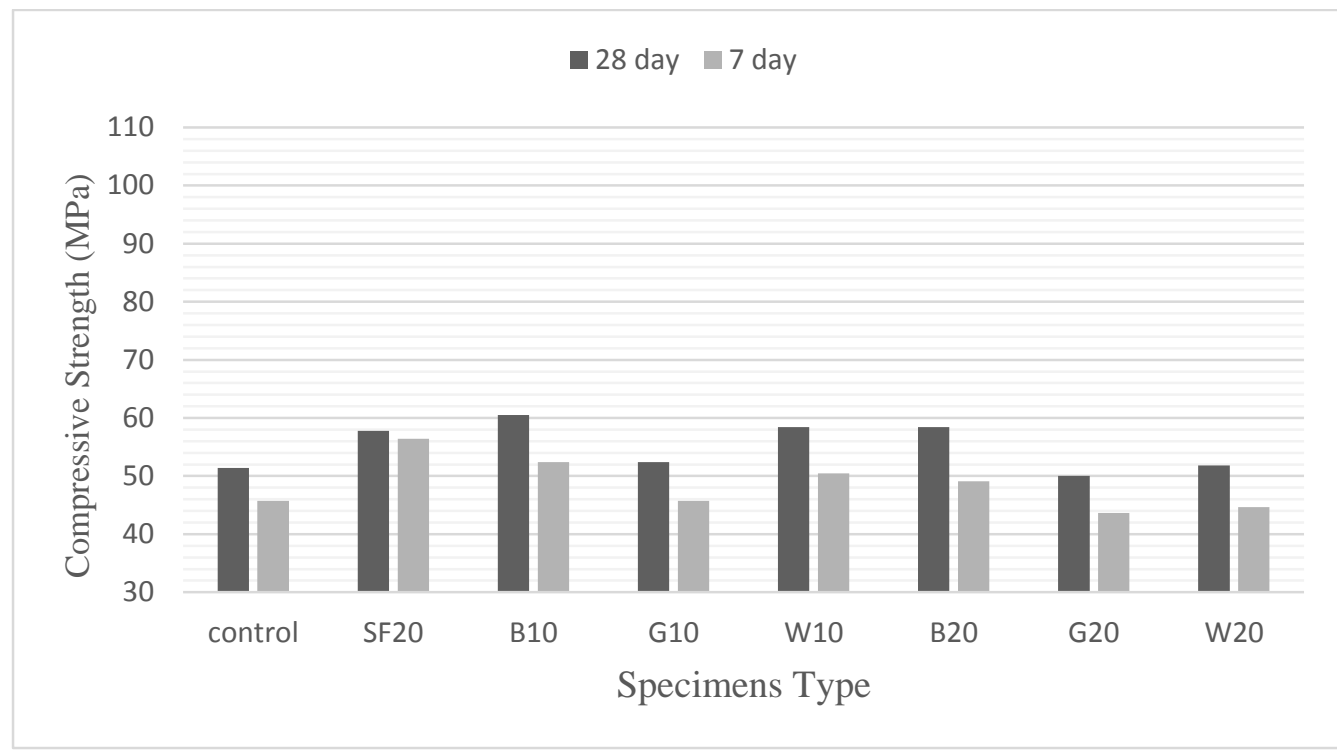

Figure 4.13: Effect of Different Colors and Quantities of GPs on 7 and 28 Days Compressive Strengths for w/b 0.45 under $55^{\circ} \mathrm{C}$ Curing Temperature

The comparison between mixtures, which are prepared at w/b of 0.45 and curing temperature of $80^{\circ} \mathrm{C}$ showed that, the compressive strength of all specimens modified with glass powder and silica fume exhibited higher compressive strength than control mixture. It shows that, the pozzolanic reaction of all glass powders in these conditions was higher than other conditions and the rate of hydration increased as amount of water and also temperature increased. The later compressive strength of SF20 decreased in comparison to the early ages. However, high temperature might increase the hydration rate and pozzolanic reactivity of binder. Besides, it can lead to production of large pores. Consequently, total pore volume might increase. This process may affect the 
mechanical properties and compressive strength of hardened mortars in later ages (Fig 4.14).

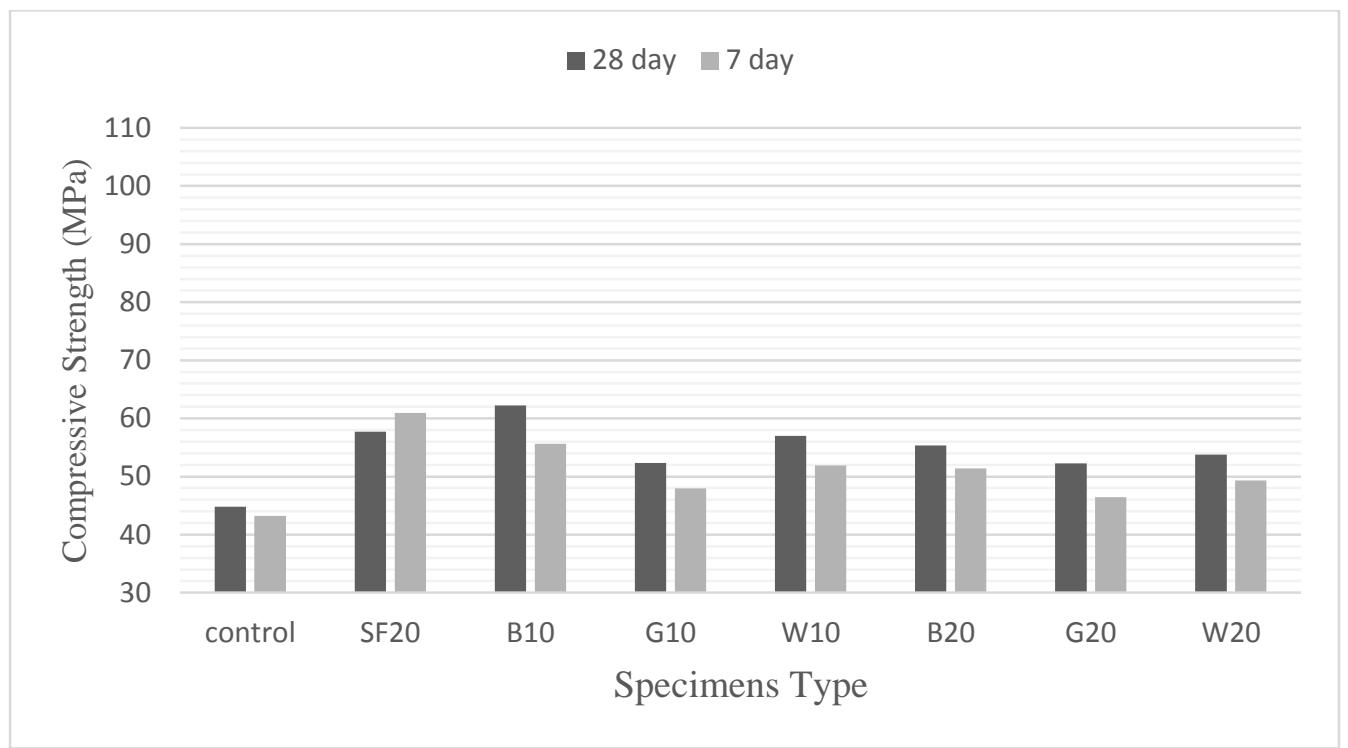

Figure 4.14: Effect of Different Colors and Quantities of GPs on 7 and 28 Days Compressive Strengths for w/b 0.45 under $80^{\circ} \mathrm{C}$ Curing Temperature

Compressive strength of All mortars with w/b of 0.45 at different curing temperatures were compared together and control mix to investigate the effect of temperature on pozzolanic reactivity of GP and SF in this w/b level (Fig.4.15, and Fig 4.16).

Fig 4.15 illustrates early age compressive strength of all mortars at w/b of 0.45 . The comparison between three control mixes shows that the compressive strength was at peak at curing temperature of 55 and the compressive strength of control in standard temperature was the lowest among two other samples. However, the early age compressive strength of SF20 increased as the temperature increased to 55 and 80 degrees, constantly. This condition is valid for other mixtures, which are modified with GP and consequently the highest amount of early-age compressive strength of each sample (SF20, B10, G10, W10, B20, G20, and W20) belonging to the curing temperature of 80 . 


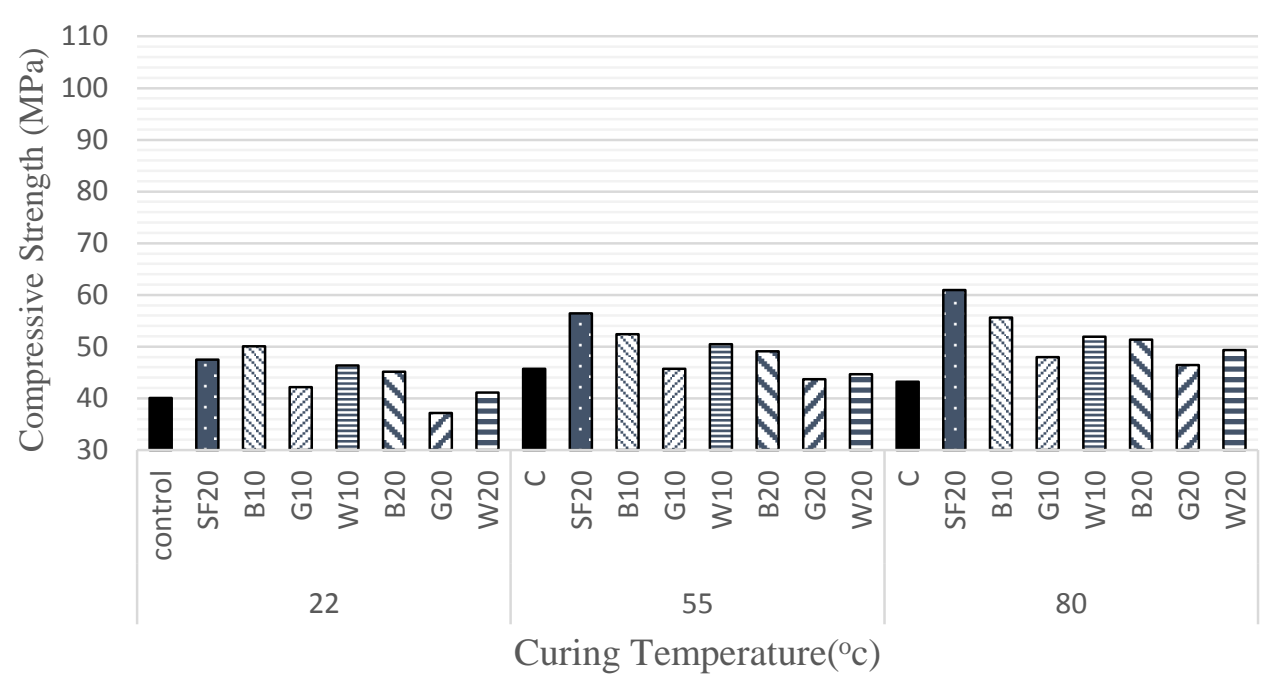

Figure 4.15: Effect of Different Colors and Quantities of GPs and Curing Temperatures on 7-days Compressive Strength for w/b 0.45

The later age compressive strength of samples, with w/b of 0.45 and different curing temperatures is illustrated in Fig 4.16. The compressive strength at the age of 28 decreased for control, SF20, G10, W10 and B20 as the temperature increased to 55 and 80 degrees.

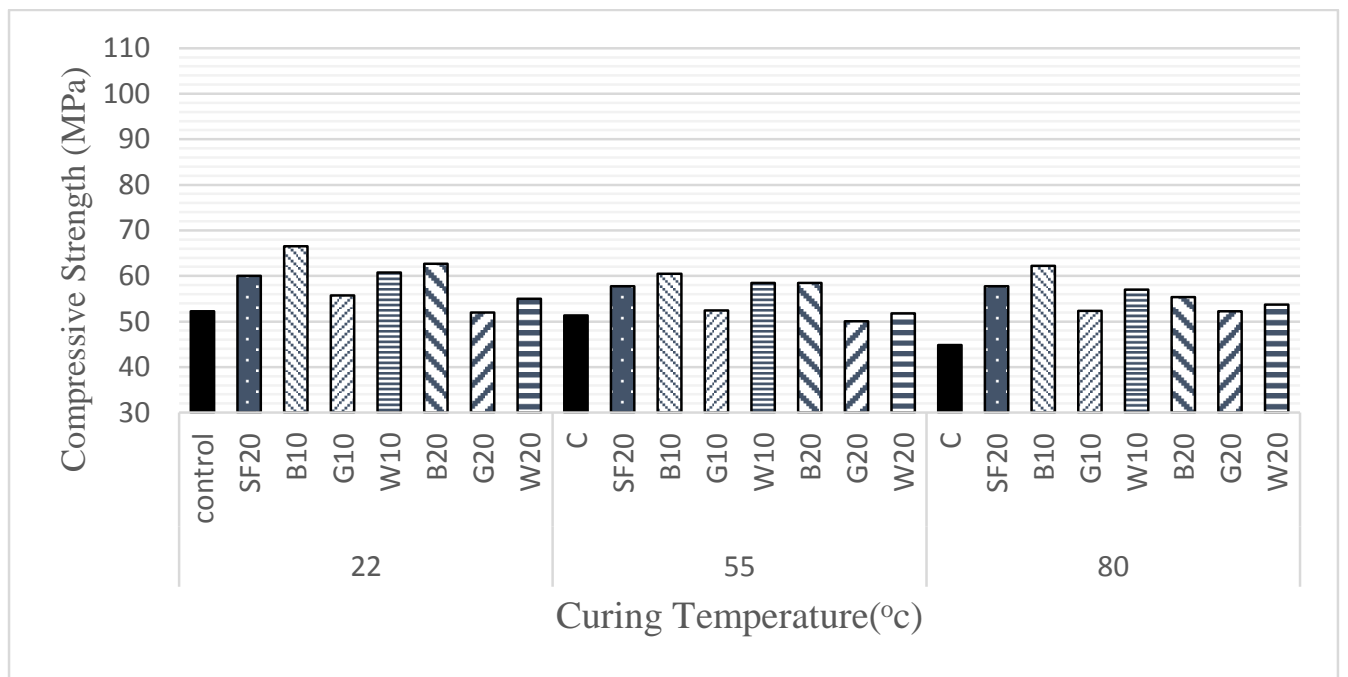

Figure 4.16: Effect of Different Colors and Quantities of GPs and Curing Temperatures on 28-days Compressive Strength for w/b 0.45 
Study the effect of amount of water, requires a comparison between each sample at different $w / b$ and temperatures. Figures below, illustrate the effect of different waterbinder ratios $(0.35,0.40$, and 0.45$)$ and temperature on compressive strength for all samples.

At standard curing temperature, compressive strength of control mix and SF20 decreased at early and later ages by increasing the w/b ratio from 0.35 to 0.40 and 0.45 , which is common for ordinary concretes and mortars. However, the early and later compressive strength of B10, and B20 increased by increasing the water content, which means that the amount of water required for complete hydration for BGP is higher than cement and silica fume (Fig 4.17, Fig 4.18). The comparison between B10 and B20 at each level of w/b ratio also showed that, the B20's compressive strength increase rate was higher than B10. In addition, Comparison between controls and mortars modified with glass powder at w/b of 0.35 and 0.45 also showed that, all mortars containing glass powder, except G20, have higher compressive strength than control mix in 0.45 (Fig 4.17).

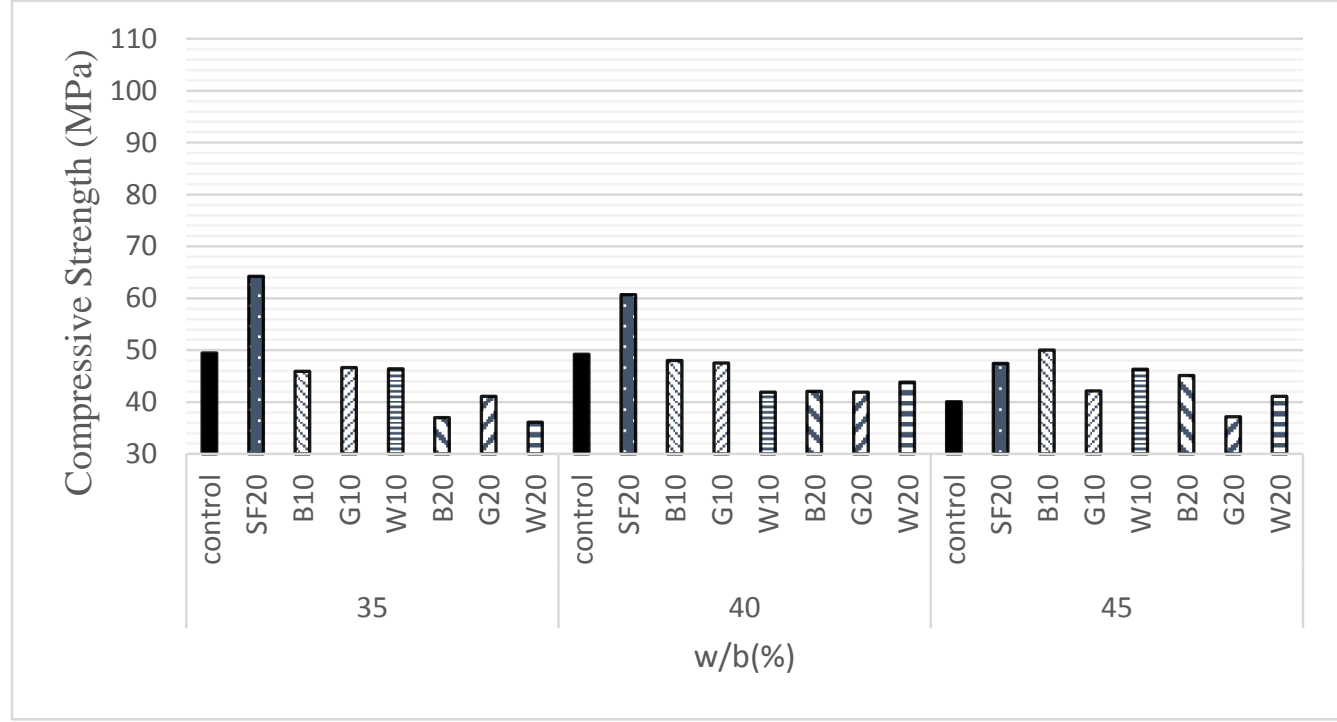

Figure 4.17: Effect of Different Colors and Quantities of GPs and w/b Ratios on 7-days Compressive Strength for Curing Temperature of $22^{\circ} \mathrm{C}$ 
Fig 4.17 shows that, compressive strength of G10, G20 and W20 increased by increasing the $\mathrm{w} / \mathrm{b}$ from 0.35 to 0.40 . However, it decreased insignificantly by increasing the water content from 0.40 to 0.45 .

At later ages, the compressive strength of G10 and G20 decreased with increasing the amount of water. W20 showed almost the same compressive strength for each $\mathrm{w} / \mathrm{b}$ in standard temperature. In addition, later compressive strength of W10 decreased by increasing the w/b. The comparison between $\mathrm{W} 10$ at 0.40 and 0.45 showed that, increasing the water increase the compressive strength (Fig4.18).

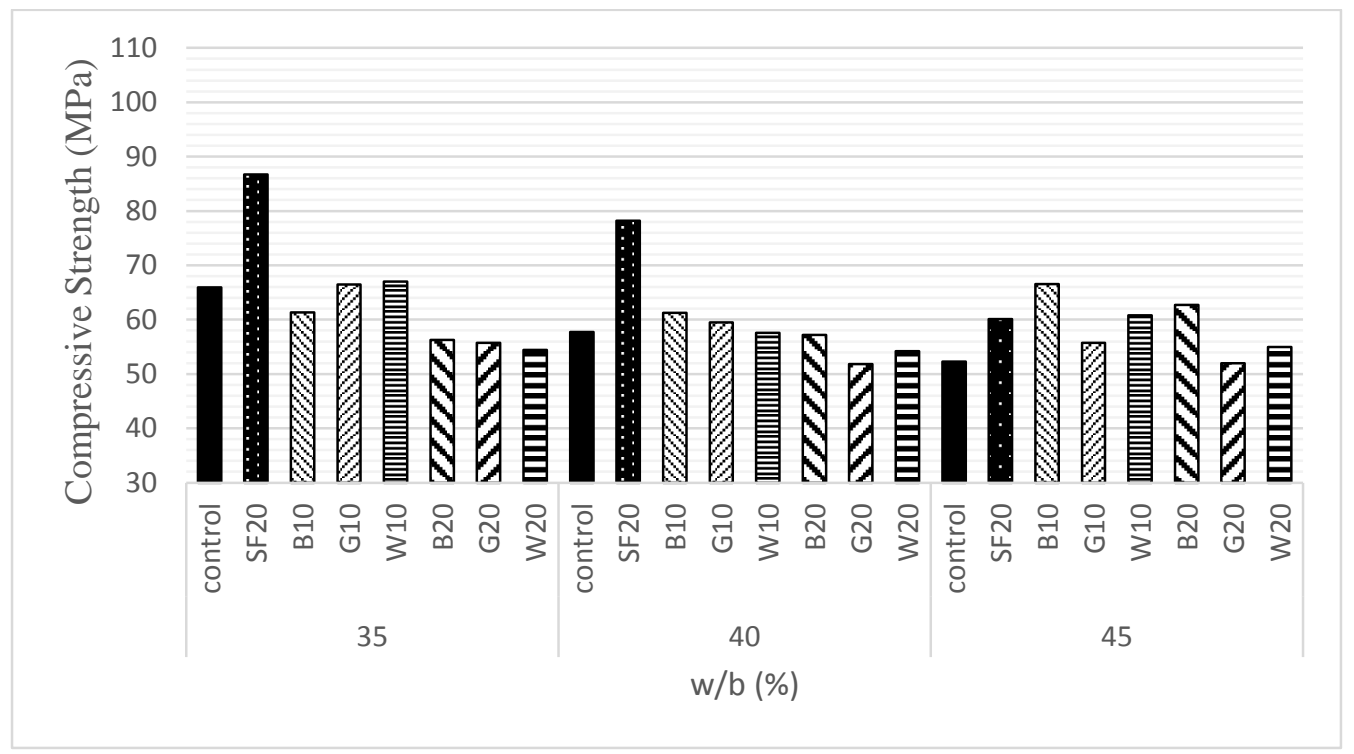

Figure 4.18: Effect of Different Colors and Quantities of GPs and w/b Ratios on 28-days Compressive Strength for Curing Temperature of $22^{\circ} \mathrm{C}$

The relation between compressive strength and w/b have completely changed in $55^{\circ} \mathrm{C}$. The compressive strength of all samples decreased as w/b increased from 0.35 to 0.40 . However, it increased by increasing the w/b from 0.40 to 0.45 at early and later ages as it can be seen in Fig4.19 and 4.20. 


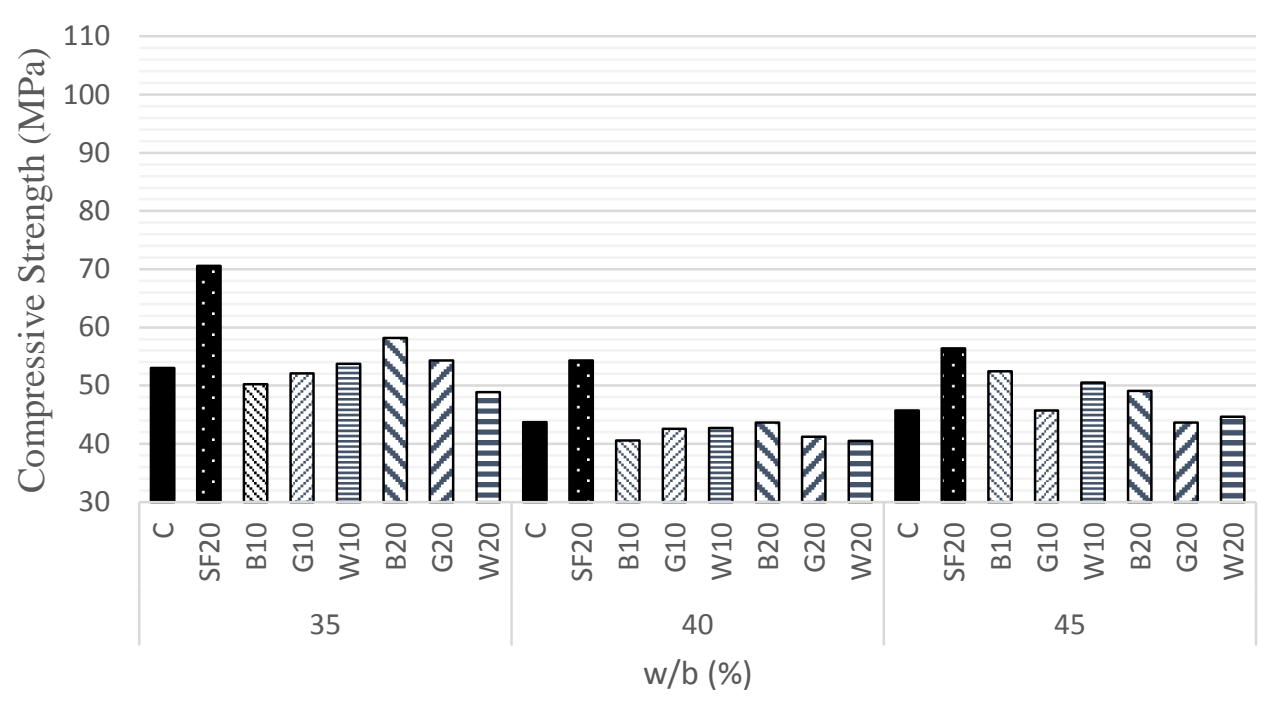

Figure 4.19: Effect of Different Colors and Quantities of GPs and w/b Ratios on 7-days Compressive Strength for Curing Temperature of $55^{\circ} \mathrm{C}$

Samples, except for B10 showed the highest compressive strength at w/b of 0.35 and the curing temperature of $55^{\circ} \mathrm{C}$ in early and later ages. Moreover, B10 showed highest compressive strength at w/b of 0.45 (Fig4.19 and 4.20).

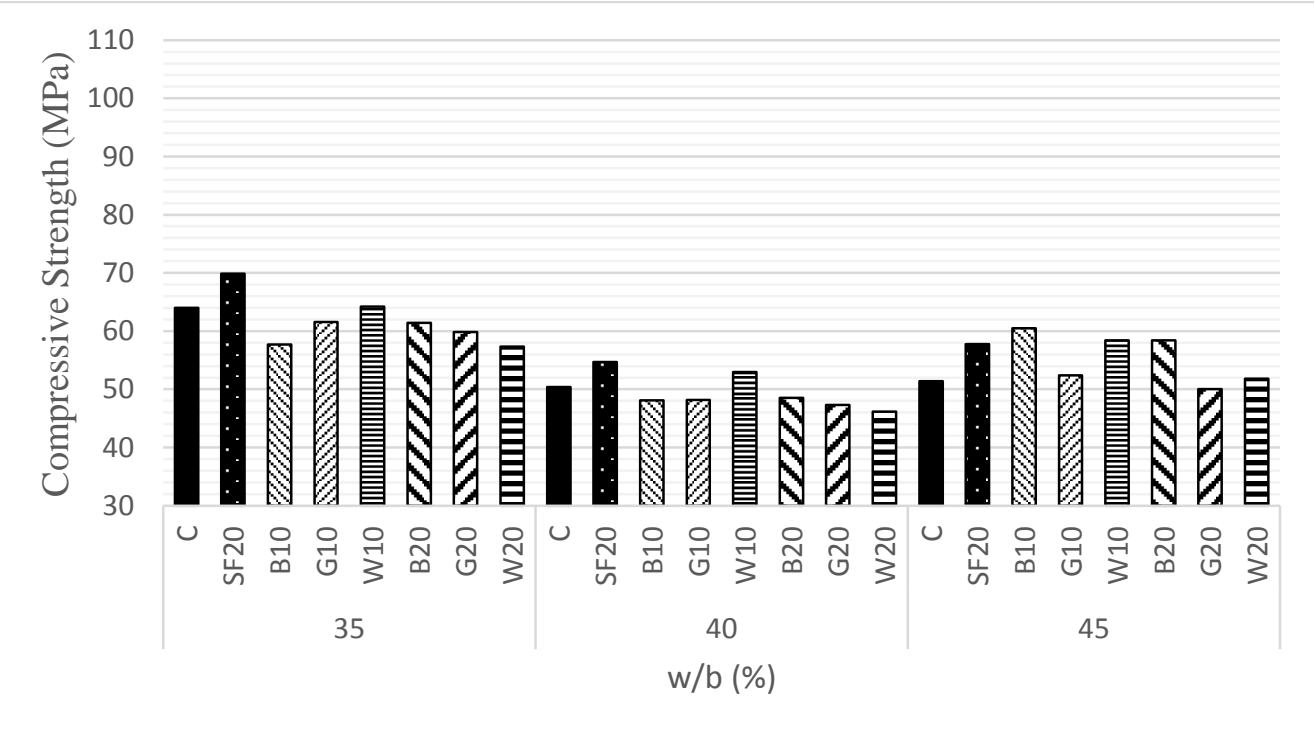

Figure 4.20: Effect of Different Colors and Quantities of GPs and w/b Ratios on 28-days Compressive Strength for Curing Temperature of $55^{\circ} \mathrm{C}$ 
The compressive strength of control, SF20, G10, G20 and W20 decreased by increasing the w/b from 0.35 to 0.45 , at curing temperature of 80 in early and later ages(Fig4.21,Fig4.22). However, the compressive strength of B10, B20, and W10 decreased by increasing the $w / b$ to 0.40 then increased by increasing the w/b to 0.45 .

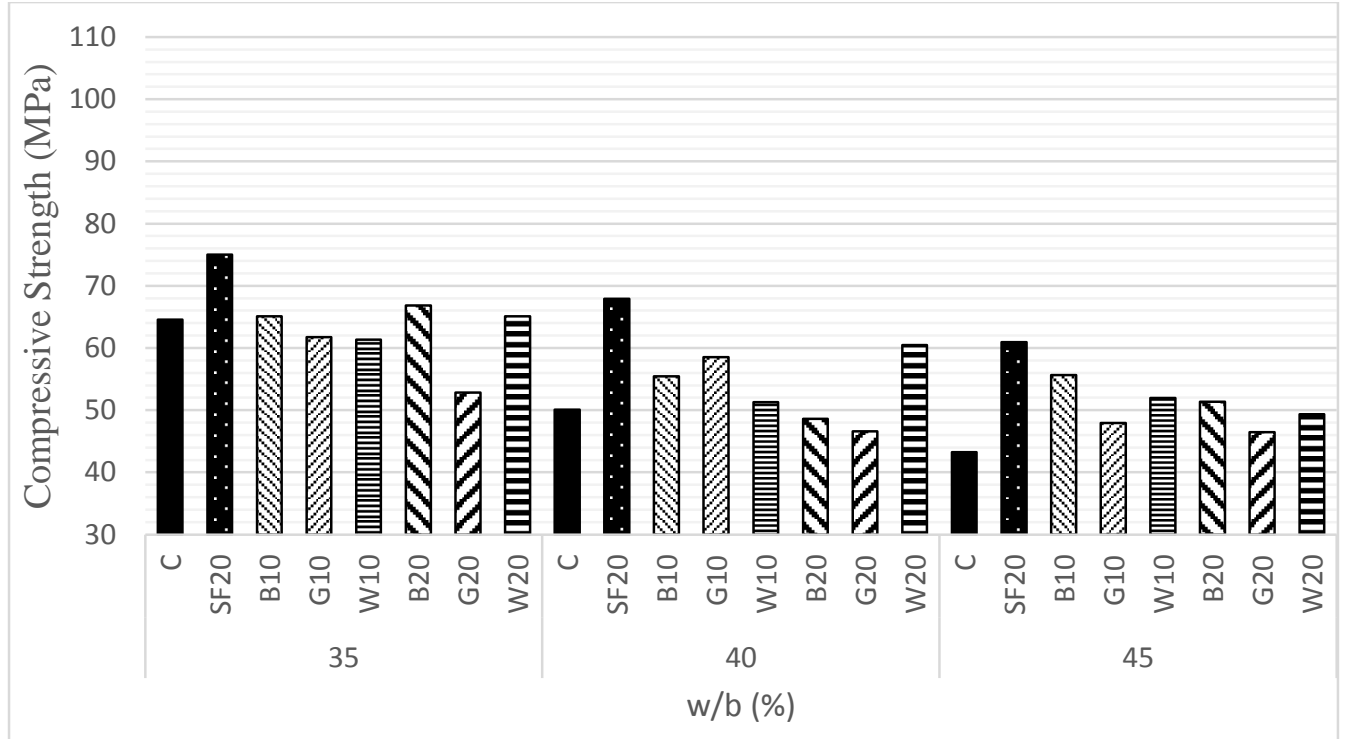

Figure 4.21: Effect of Different Colors and Quantities of GPs and w/b Ratios on 7-days Compressive Strength for Curing Temperature of $80^{\circ} \mathrm{C}$

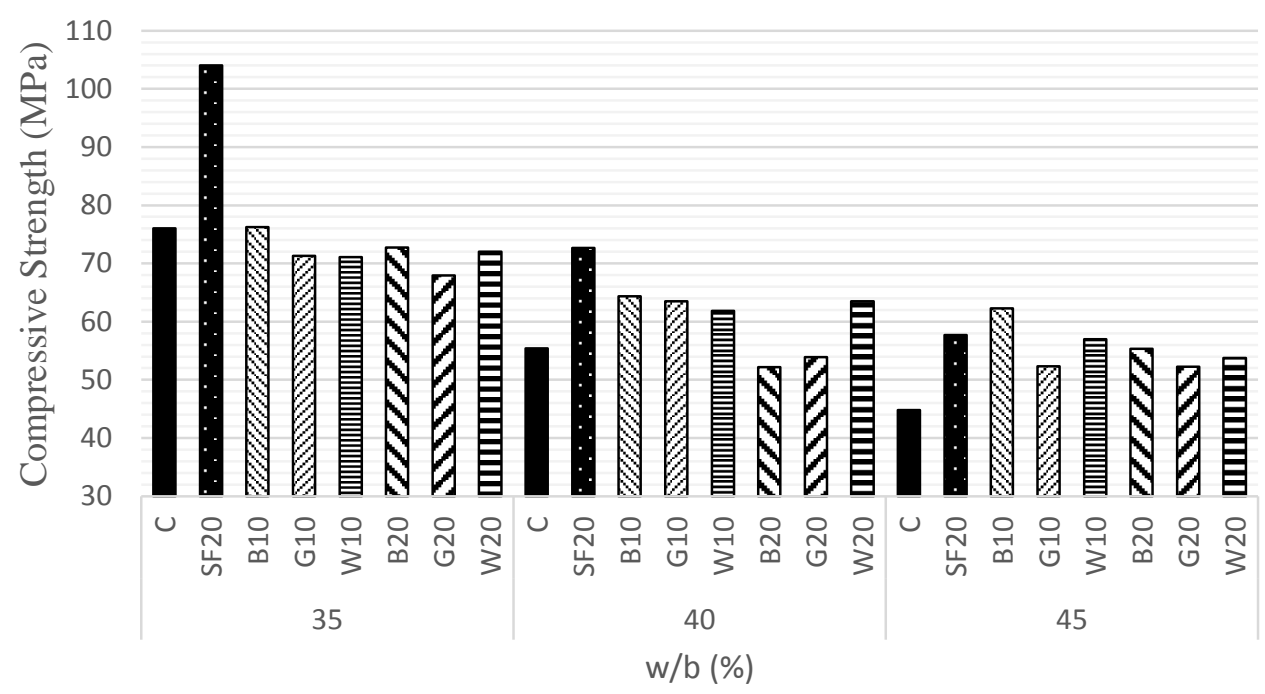

Figure 4.22: Effect of Different Colors and Quantities of GPs and w/b Ratios on 28-days Compressive Strength for Curing Temperature of $80^{\circ} \mathrm{C}$ 


\subsection{Effects of GP Type and Quantity, w/b Ratio, and Curing Temperature on Flexural Strength of HSM}

Flexural strength of mortars was tested at $7^{\text {th }}$ and $28^{\text {th }}$ days of curing. Then results were compared to investigate effects of GP type and quantity, curing temperature, and amount of water (w/b ratio) on flexural strength of HSM. Then, the results compared with control mix and SF20 as they are prepared by replacing $20 \%$ of silica fume with cement.

Comparison between $7^{\text {th }}$ and $28^{\text {th }}$ of flexural test results showed that, mortars modified with glass powder at w/b of 0.35 and standard curing temperature had lower flexural strength than control or SF20. Among these mortars, B10, G10 and W10 revealed higher flexural strength than others at the early age. However, B20 exhibited higher flexural strength among the rest in the later age (Fig 4.23).

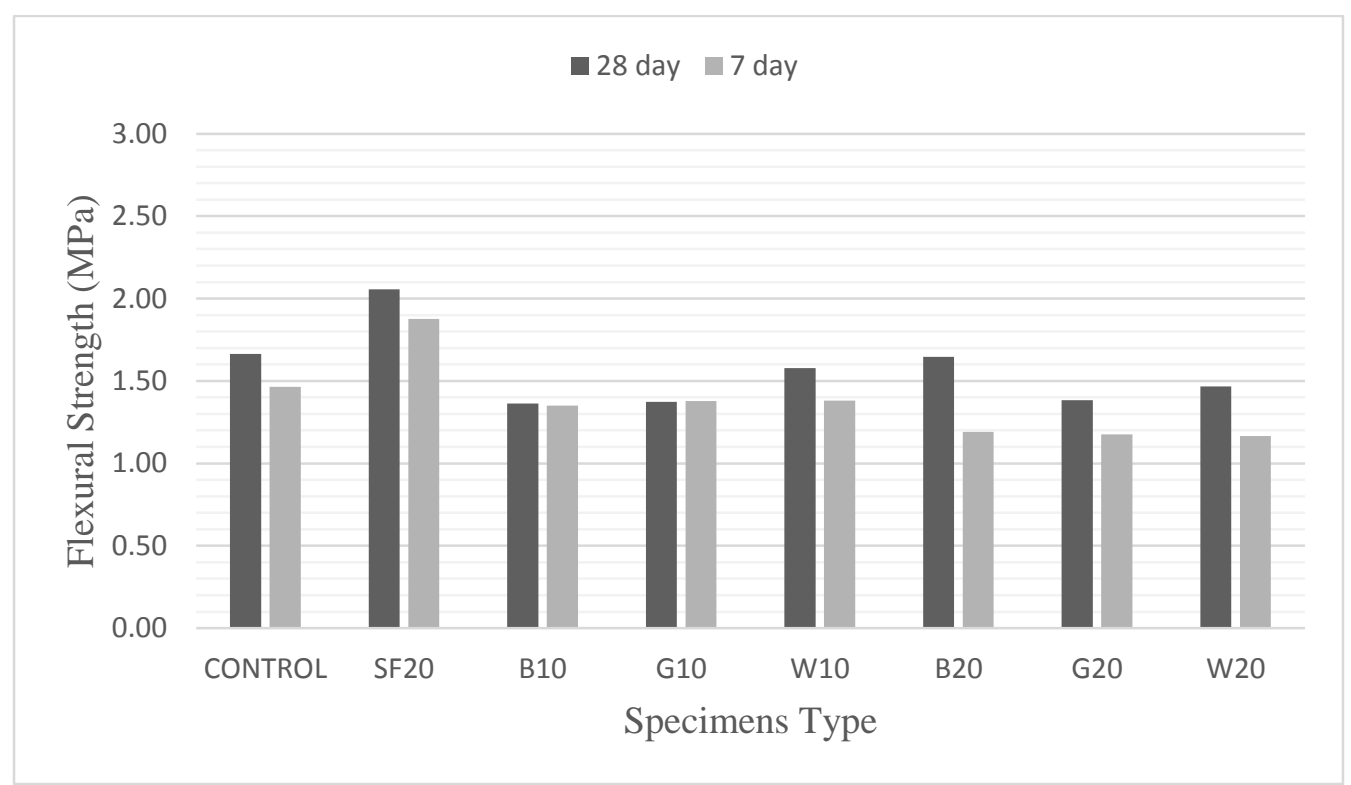

Figure 4.23: Effect of Different Colors and Quantities of GPs on 7 and 28 Days Flexural Strength for w/b 0.35 under $22^{\circ} \mathrm{C}$ Curing Temperature 
As the temperature increases to $55^{\circ} \mathrm{C}$, the flexural strength of $\mathrm{B} 10, \mathrm{G} 10, \mathrm{~B} 20$ and $\mathrm{G} 20$ will become higher than control. The $28^{\text {th }}$ day's flexural strength of SF20, W10 and W20 decreased by passing the time, which might be due to increasing of shrinkage in these mortars and propagation of micro cracks trough specimens (Fig 4.24).

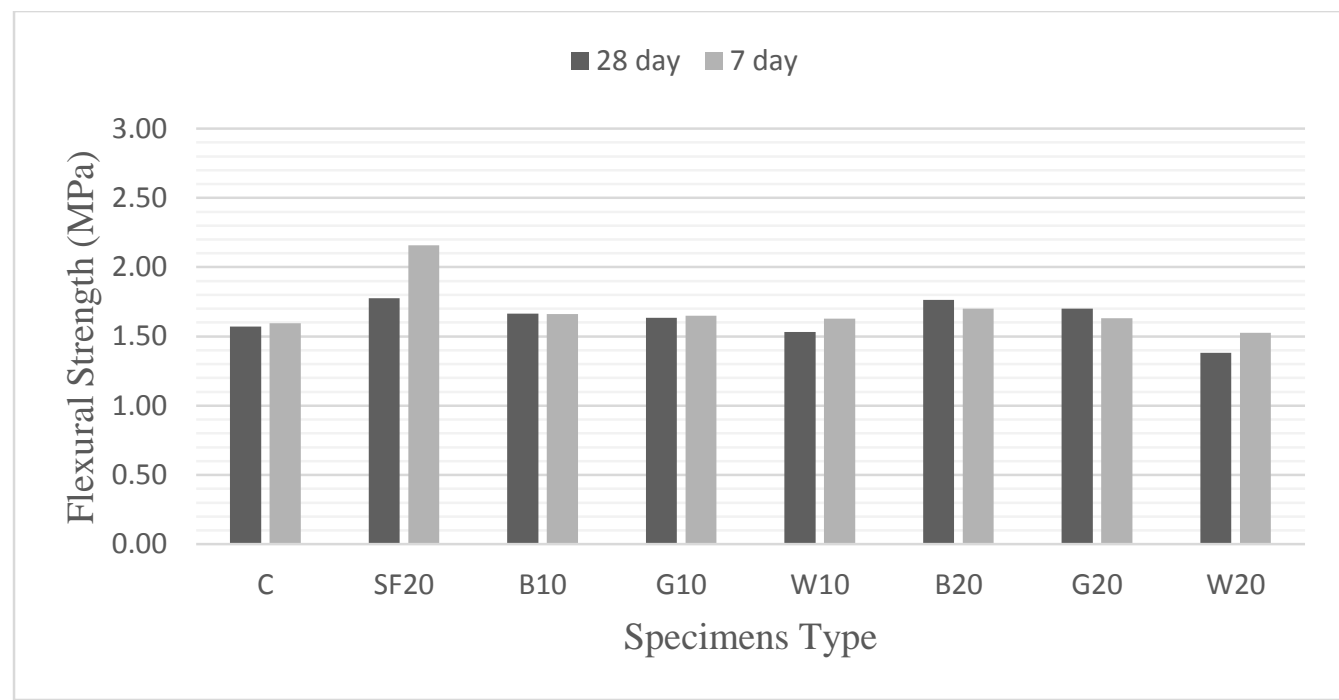

Figure 4.24: Effect of Different Colors and Quantities of GPs on 7 and 28 Days Flexural Strength for w/b 0.35 under $55^{\circ} \mathrm{C}$ Curing Temperature

At $80^{\circ} \mathrm{C}$ and w/b of 0.35 , the flexural strength of all mortars was nearly the same as its property on $28^{\text {th }}$ day. Besides, control mix exhibited the highest flexural strength among the others. However, SF20 showed higher flexural strength among the others on $7^{\text {th }}$ day of curing. But, its flexural strength decreased as it reached to $28^{\text {th }}$ day (Fig4.25). 


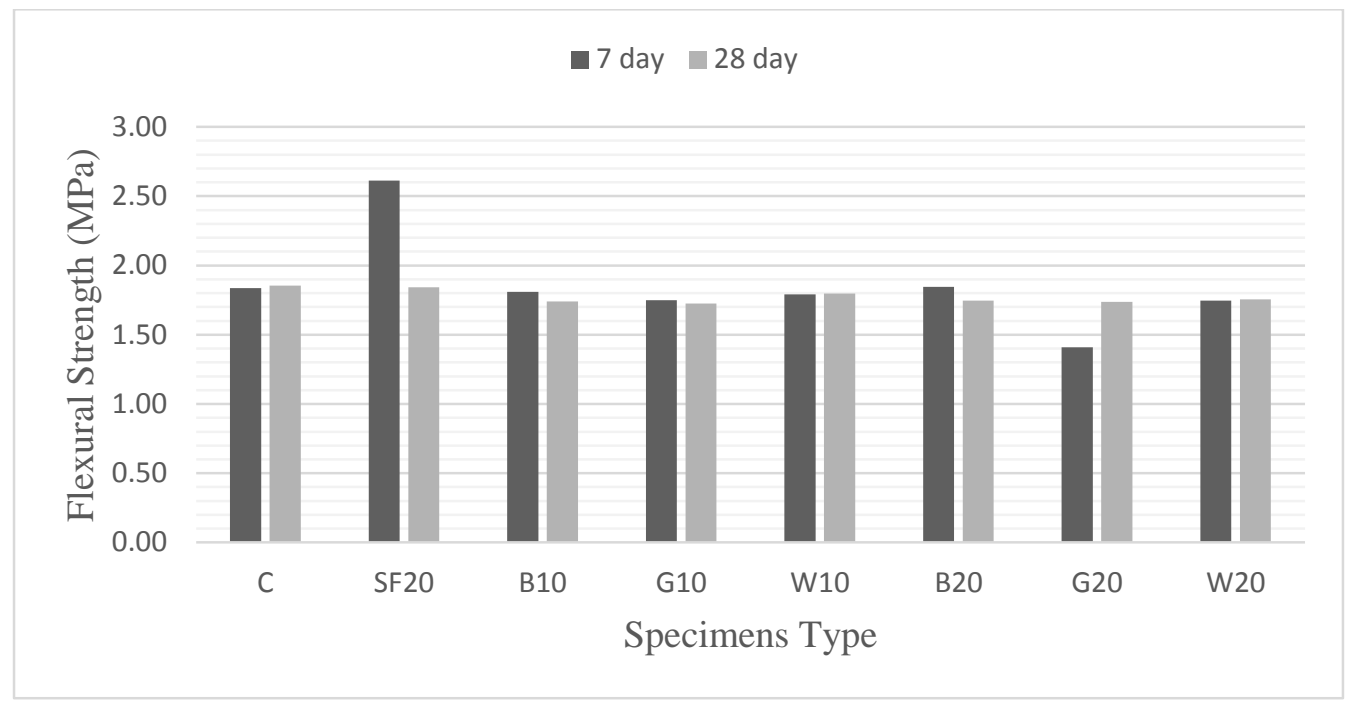

Figure 4.25: Effect of Different Colors and Quantities of GPs on 7 and 28 Days Flexural Strength for w/b 0.35 under $80^{\circ} \mathrm{C}$ Curing Temperature

The decrease rate in flexural strength of SF20 might be the result of propagation of microcracks due to shrinkage of hardened paste. Unlike the others, Flexural strength of G20 increased in these conditions by passing the time (Fig 4.25).

Comparisons between all samples that prepared at $\mathrm{w} / \mathrm{b}$ of 0.35 at different temperatures showed that, the early flexural strength increased by increasing the temperature of curing for all samples, which might be because of accelerating effect of high temperature on the hydration of binder (Fig 4.26). 


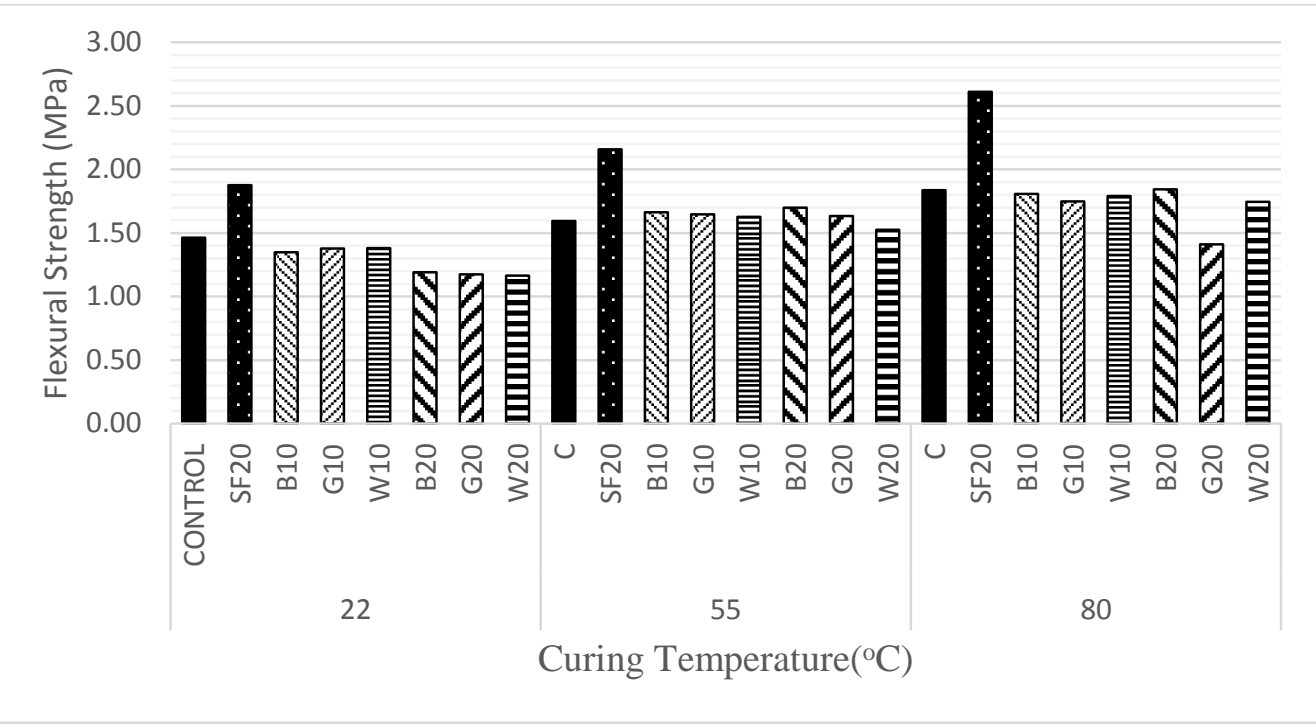

Figure 4.26: Effect of Different Colors and Quantities of GPs and Curing Temperatures on 7-Days Flexural Strength for w/b 0.35

At later ages, the rate of increase in flexural strength of mortars decreased by increasing the temperature of curing (Fig4.27). On the other hand, the flexural strength of samples increased at standard temperature except for B10 and G10. This increase rate can be seen in temperature of 55, except for W20, W10 and SF20. However, the rate of this increase was lower than standard temperature (Fig4.28).

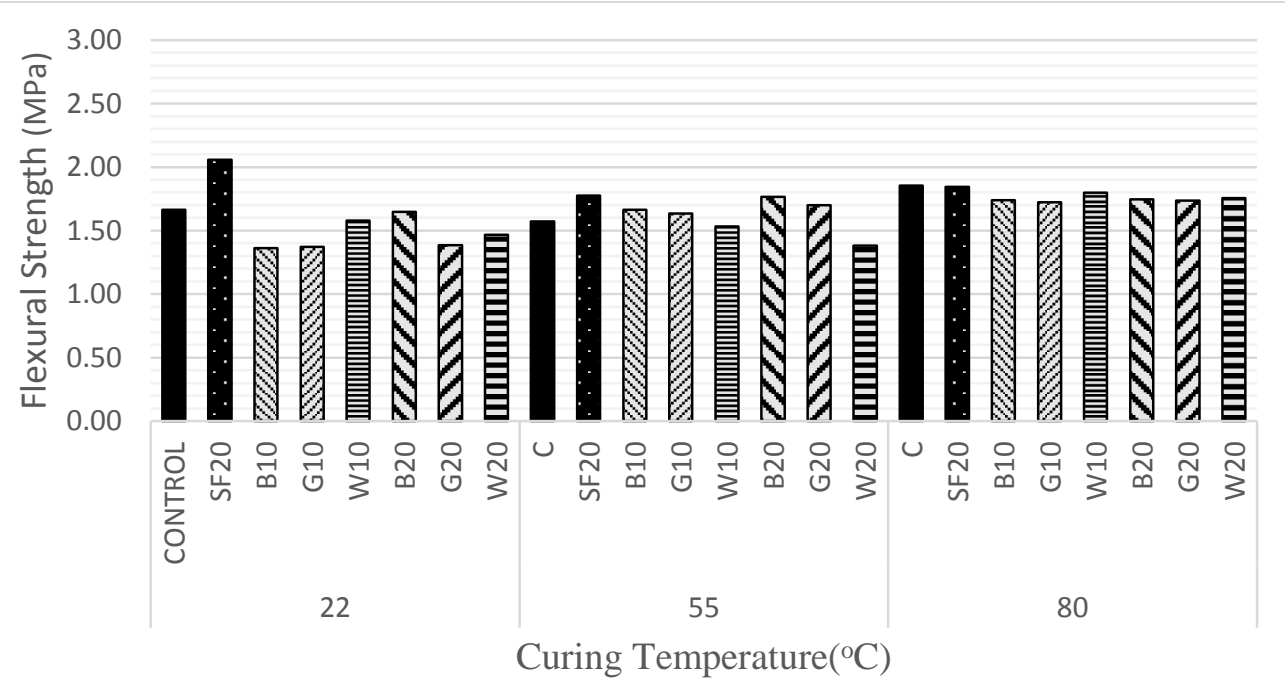

Figure 4.27: Effect of Different Colors and Quantities of GPs and Curing Temperatures on 28-Days Flexural Strength for w/b 0.35 


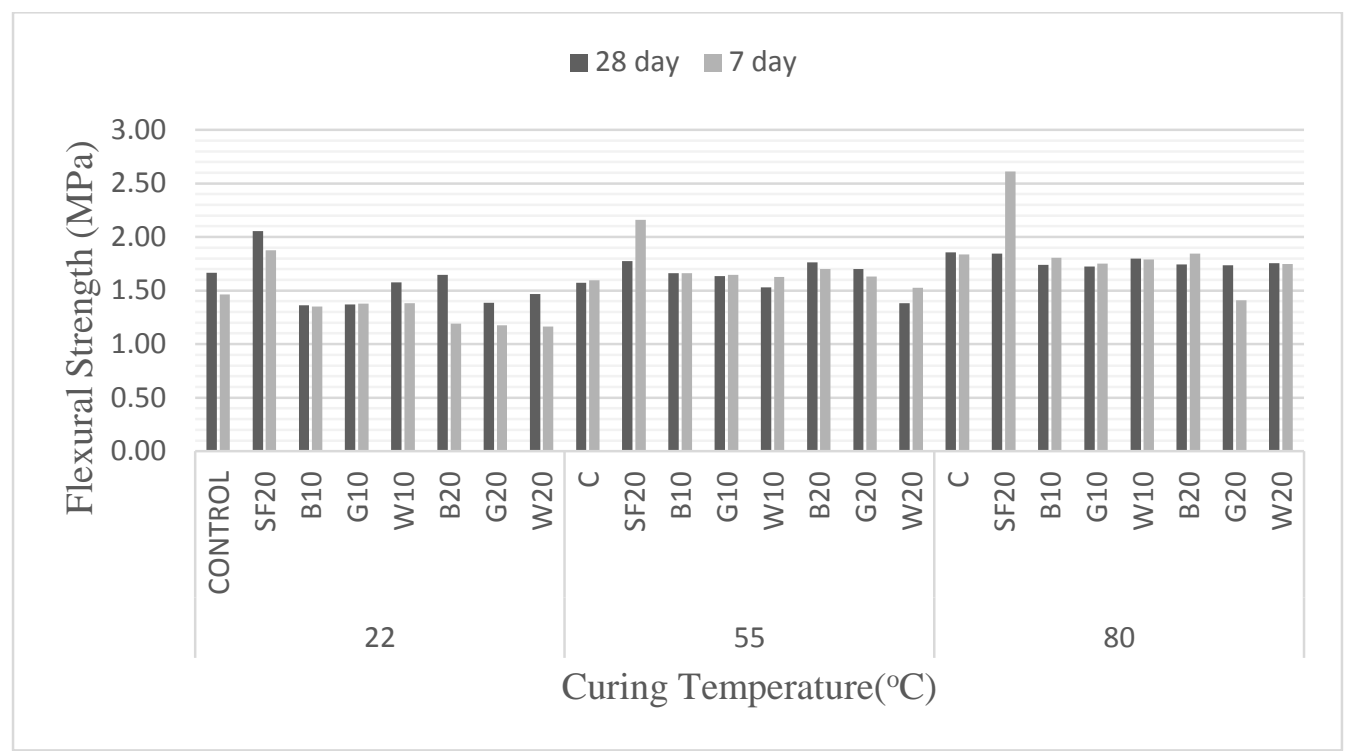

Figure 4.28: Effect of Different Colors and Quantities of GPs and Curing Temperatures on 7 and 28-Days Flexural Strength for w/b 0.35

Anomalously, flexural strength started to decline through time by raising the temperature to $80^{\circ} \mathrm{C}$. It might be because of the increase rate in initial micro-cracks due to higher shrinkage of mortar in this temperature rather than other temperatures (Fig4.28).

Flexural strength of G10, W10, W20 and SF20 was slightly higher than control mix at $\mathrm{w} / \mathrm{b}$ of 0.40 and standard curing temperature in early age, but other mortars except for W20, which were modified by GP and SF, exhibited higher flexural strength than control mix in later age (Fig 4.29). 


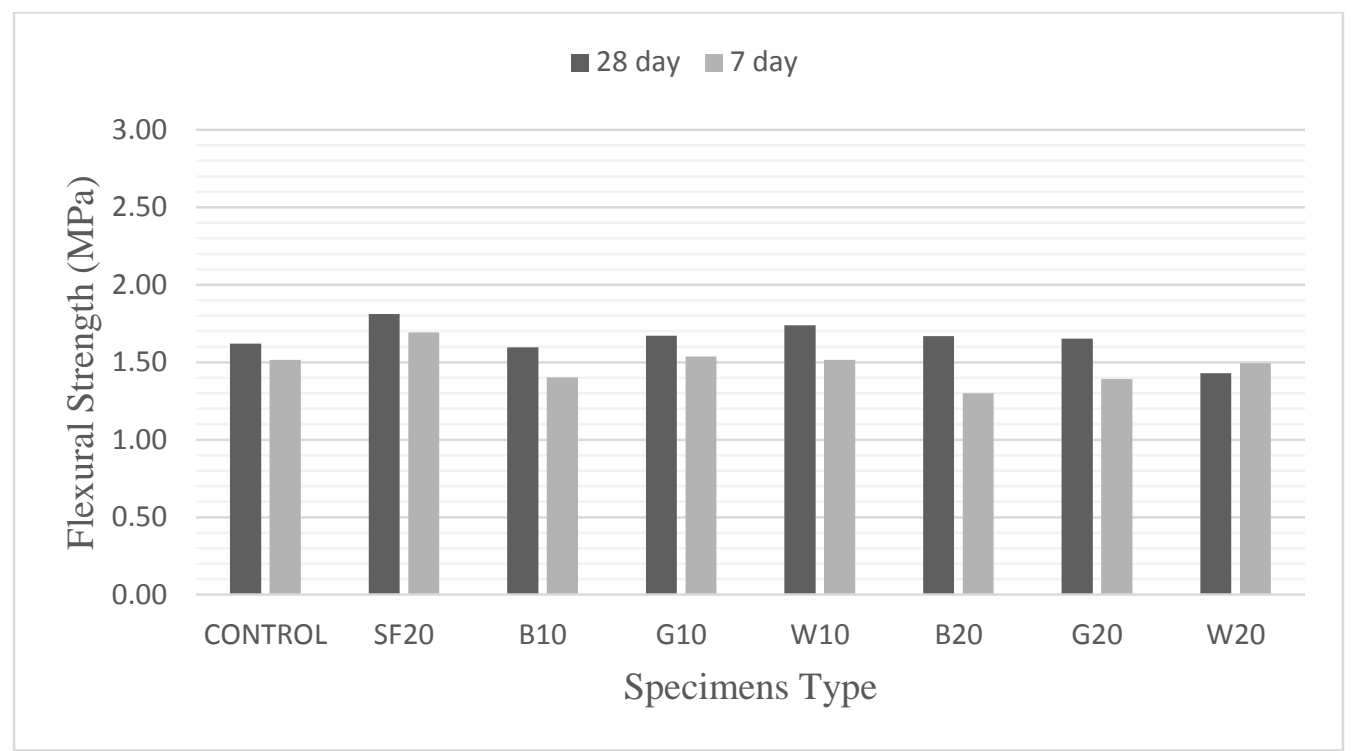

Figure 4.29: Effect of Different Colors and Quantities of GPs on 7 And 28 Days Flexural Strength for w/b 0.40 under $22^{\circ} \mathrm{C}$ Curing Temperature

The flexural strength of all mortars at curing temperature of 55 and w/b of 0.40 was slightly higher than control mix in early age. However, B10 and G10 showed the same flexural strength as the control mix in later ages, while SF20, G20 and B20 exhibited higher flexural strength than control mix. W10 and W20 showed lower flexural strength at later ages than control. It can be seen that the flexural strength of W10, W20 and SF20 decreased by increasing in age as it is illustrated in Fig 4.30.

Figure 4.31 illustrates the flexural strength of mortars at curing temperature of 80 and w/b of 0.40 . Obviously, all samples except for W10 showed slightly higher flexural strength than control mix in the early age. But, other samples except for B20 exhibited slightly higher flexural strength at later ages. 


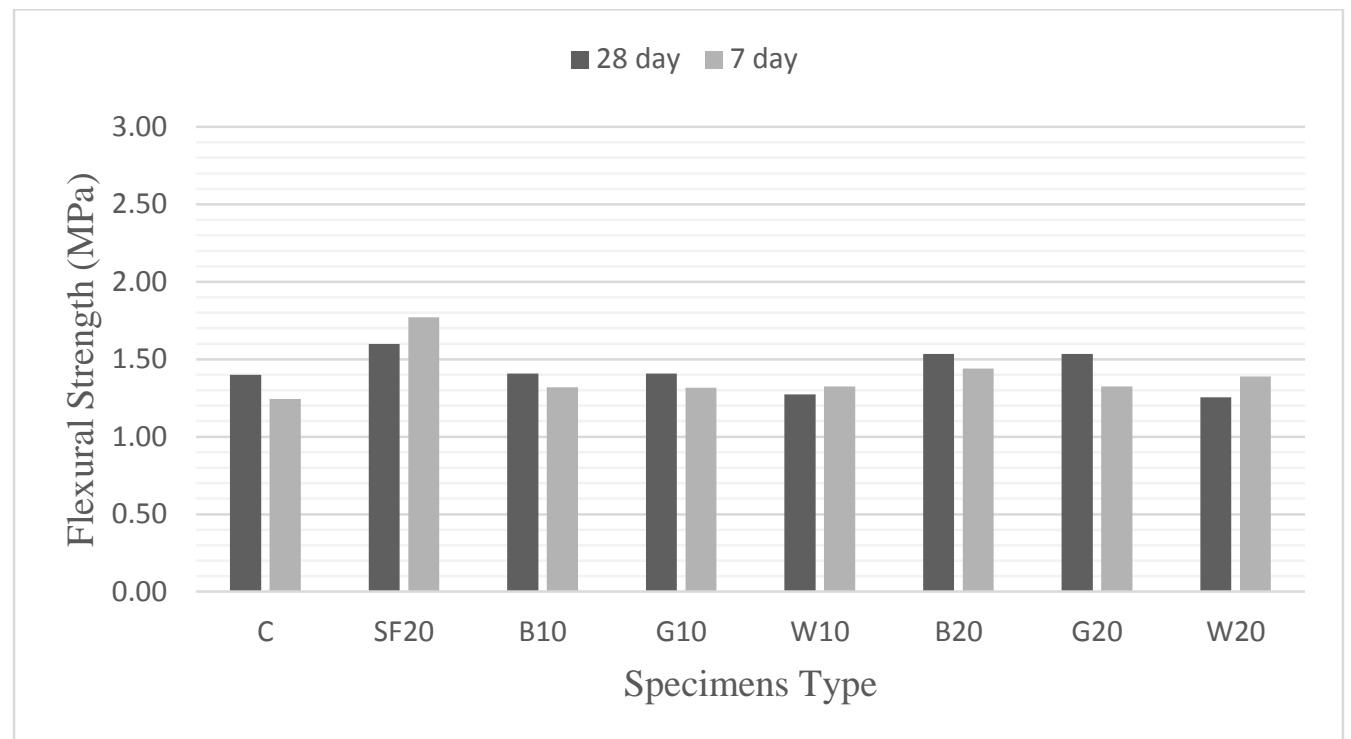

Figure 4.30: Effect of Different Colors and Quantities of GPs on 7 and 28 Days Flexural Strength for w/b 0.40 under $55^{\circ} \mathrm{C}$ Curing Temperature

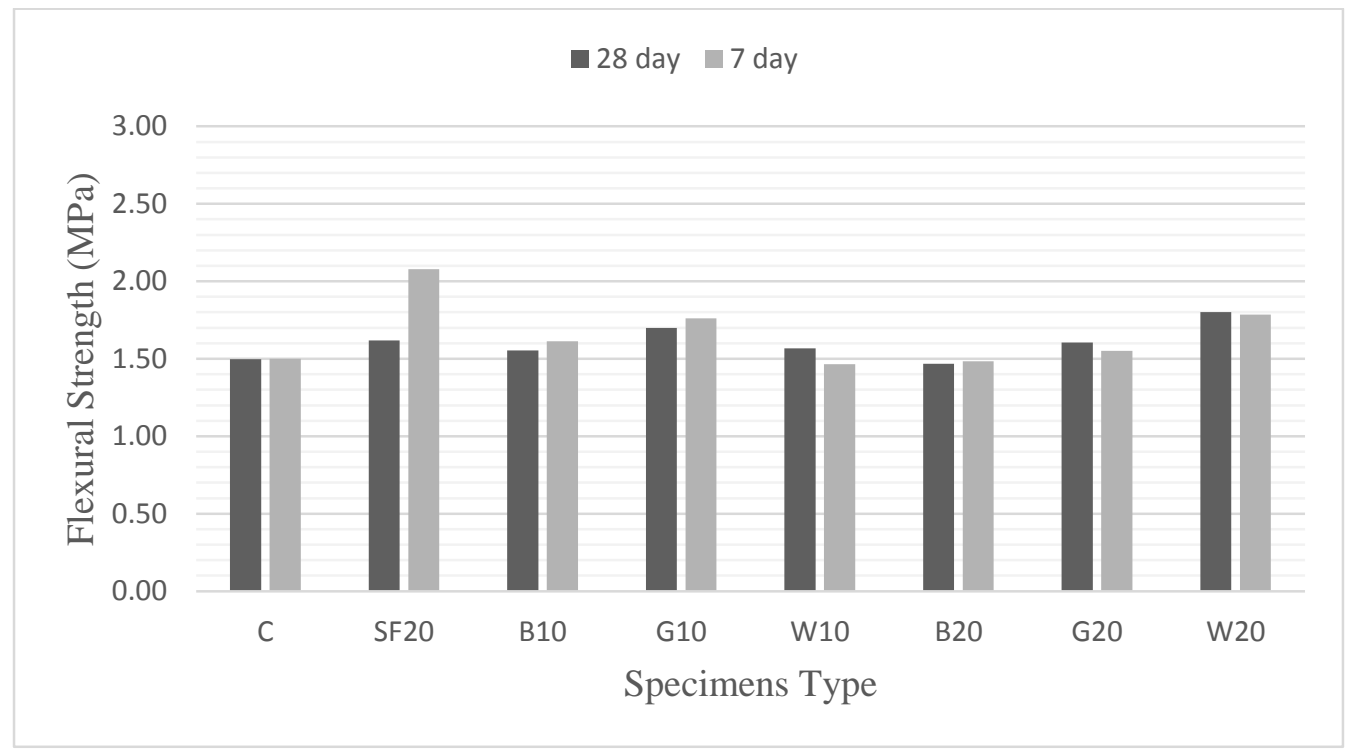

Figure 4.31: Effect of Different Colors and Quantities of GPs on 7 and 28 Days Flexural Strength for w/b 0.40 under $80^{\circ} \mathrm{C}$ Curing Temperature

The early and later flexural strength of mortars in different curing temperatures and w/b of 0.40 were compared together. Results showed that, the early age flexural strength of SF20 and B20 increased as the temperature increased in this water binder ratio. Flexural strength of control mix showed no change between $22^{\circ} \mathrm{C}$ and $80^{\circ} \mathrm{C}$ but it decreased in $55^{\circ} \mathrm{C}$. Early age flexural strength of B10, G10, W10, G20 and W20 
decreased at $55^{\circ} \mathrm{C}$ and then increased by increasing the temperature to $80^{\circ} \mathrm{C}$ as it illustrated in Fig 4.32. In later ages, the flexural strength of control, SF20, B10, G10, G20 and W20 decreased at curing temperature of 55 then increased at $80^{\circ} \mathrm{C}$. However, the highest flexural strength belongs to standard curing temperature for all specimens except for G10. The flexural strength of B20 decreased as the temperature increased. Somehow, the lowest amount of flexural strength belongs to the curing temperature of 55 for all samples at w/b of 0.40 as it is shown in Fig 4.33.

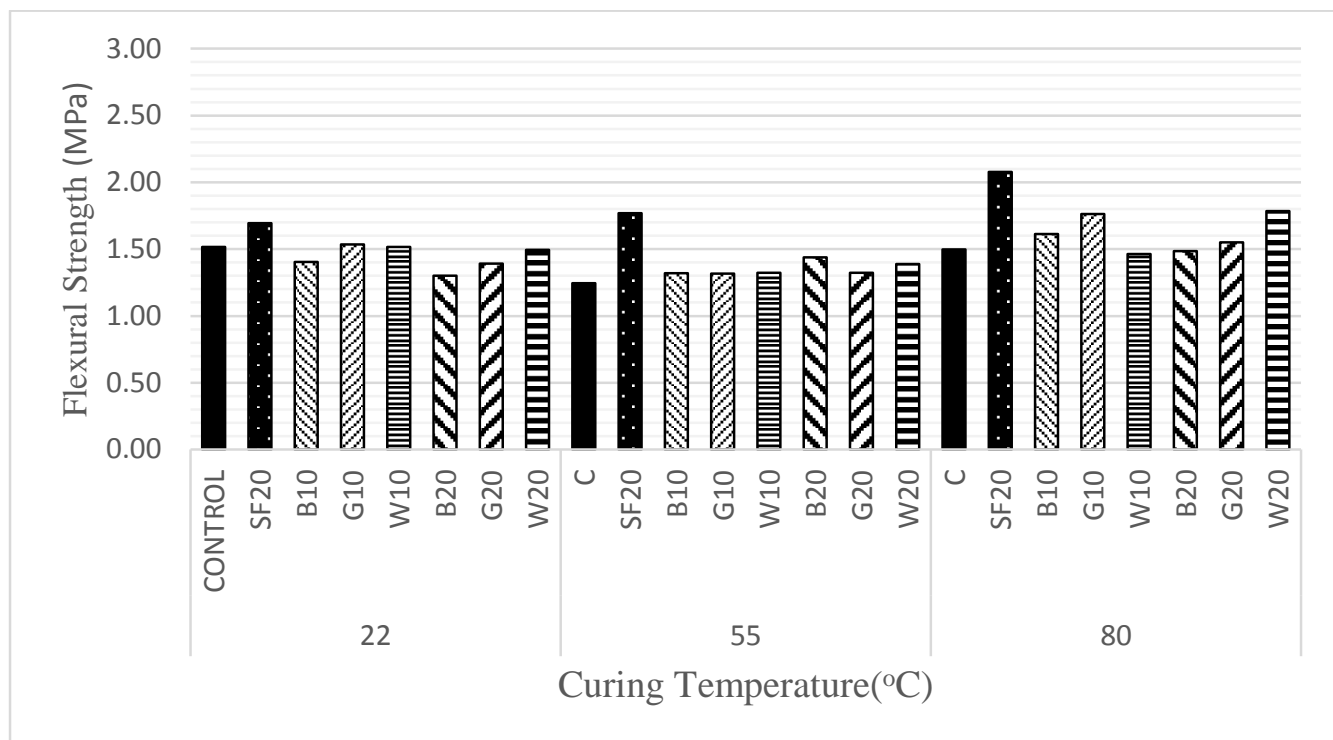

Figure 4.32: Effect of Different Colors and Quantities of GPs and Curing Temperatures on 7-Days Flexural Strength for w/b 0.40

As the water binder ratio increased to 0.45 , all samples except for G20 exhibited higher flexural strength in early and later ages than control mixture at standard temperature. In addition, B10 and W10 showed higher later flexural strength among other mortars which are modified with GP. G10 exhibited the highest early flexural strength among all other samples in this condition as it is illustrated in Fig 4.35. All modified mortars with SF or GP exhibited higher flexural strength than control mix at w/b of 0.45 and higher curing temperature of 55. It is obvious that, the flexural strength of G10 and 
G20 will not increase yet remained approximately constant by passing time. Also, control mix and samples except for W20 showed a reduction in flexural strength in the later age as it is shown in Figure 4.36.

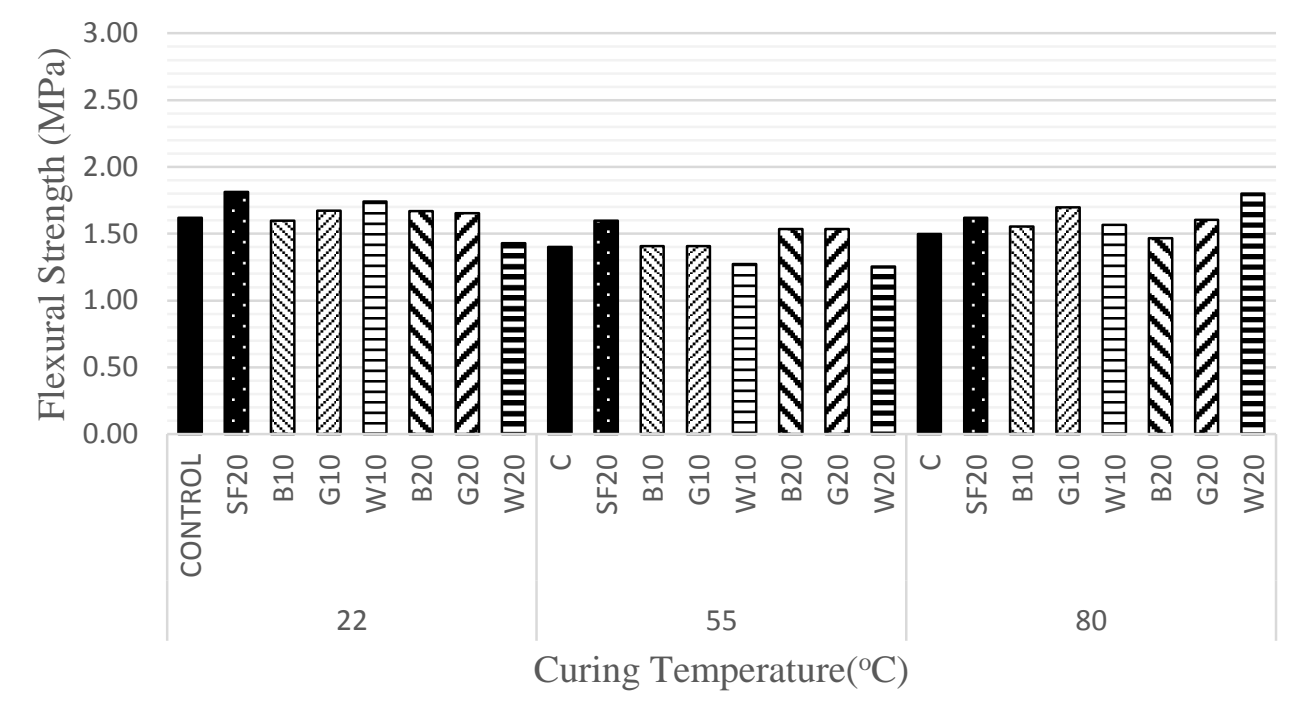

Figure 4.33: Effect of Different Colors and Quantities of GPs and Curing Temperatures on 28-Days Flexural Strength for w/b 0.40

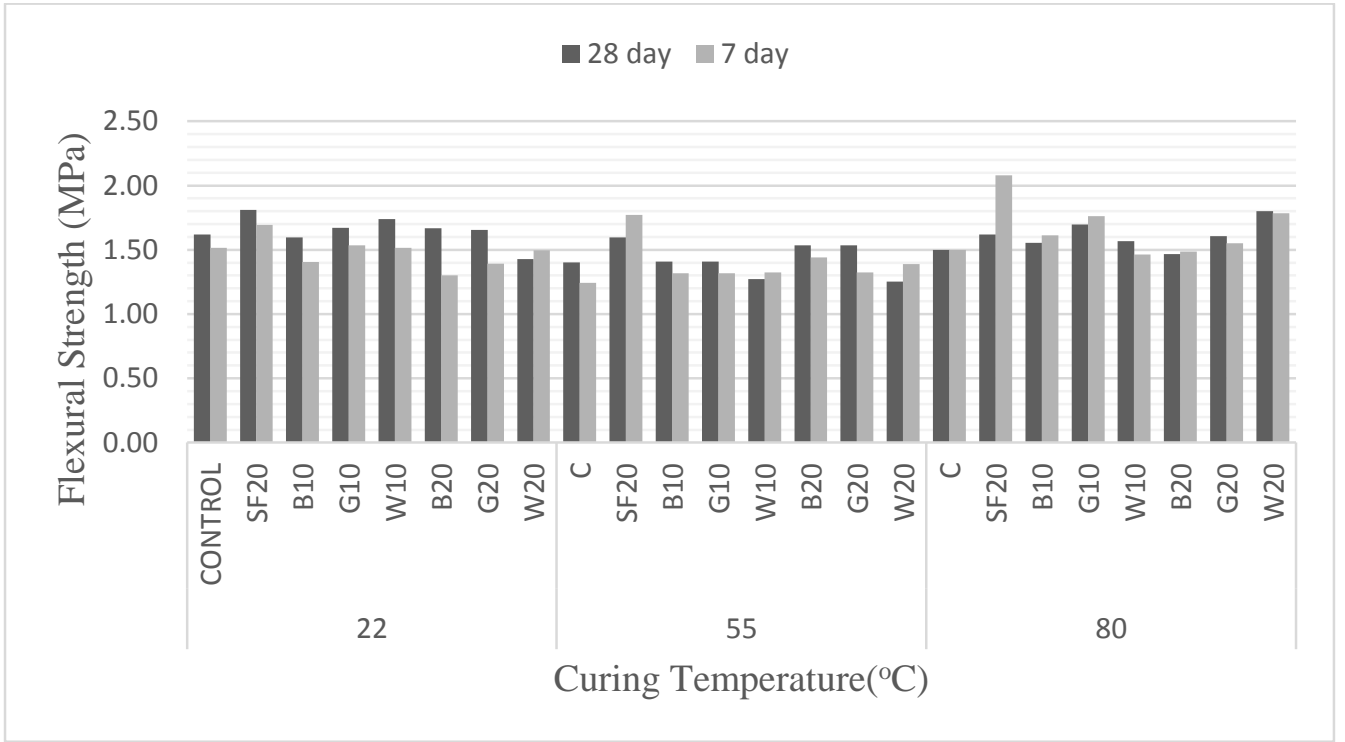

Figure 4.34: Effect of Different Colors and Quantities of GPs and Curing Temperatures on 7 and 28-Days Flexural Strength for w/b 0.40 
As the curing temperature increased up to $80^{\circ} \mathrm{C}$, the flexural strength of all mortars became higher than control mix in early and later ages of curing. The increase rate in flexural strength was stopped in B10 and it remained constant on $7^{\text {th }}$ and $28^{\text {th }}$ day (Fig 4.37).

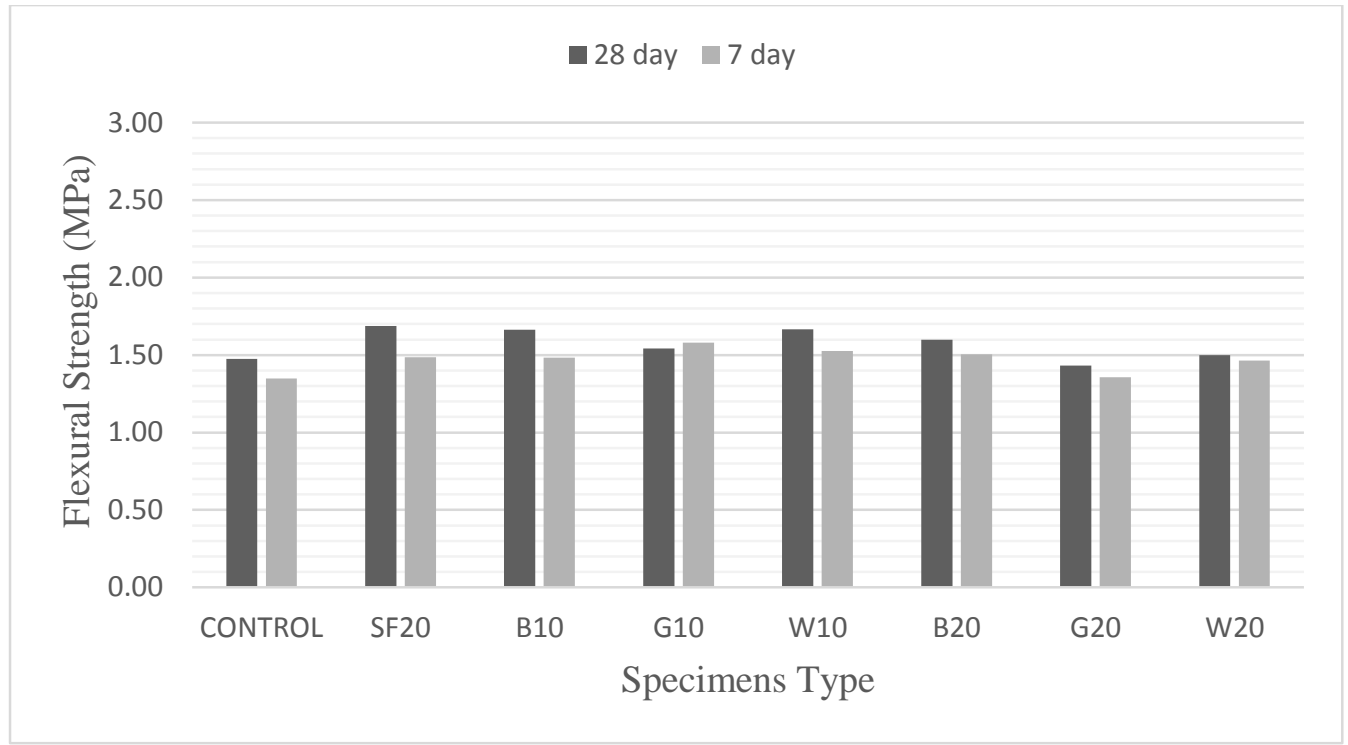

Figure 4.35: Effect of Different Colors and Quantities of GPs on 7 and 28Days Flexural Strength for w/b 0.45 under $22^{\circ} \mathrm{C}$ Curing Temperature

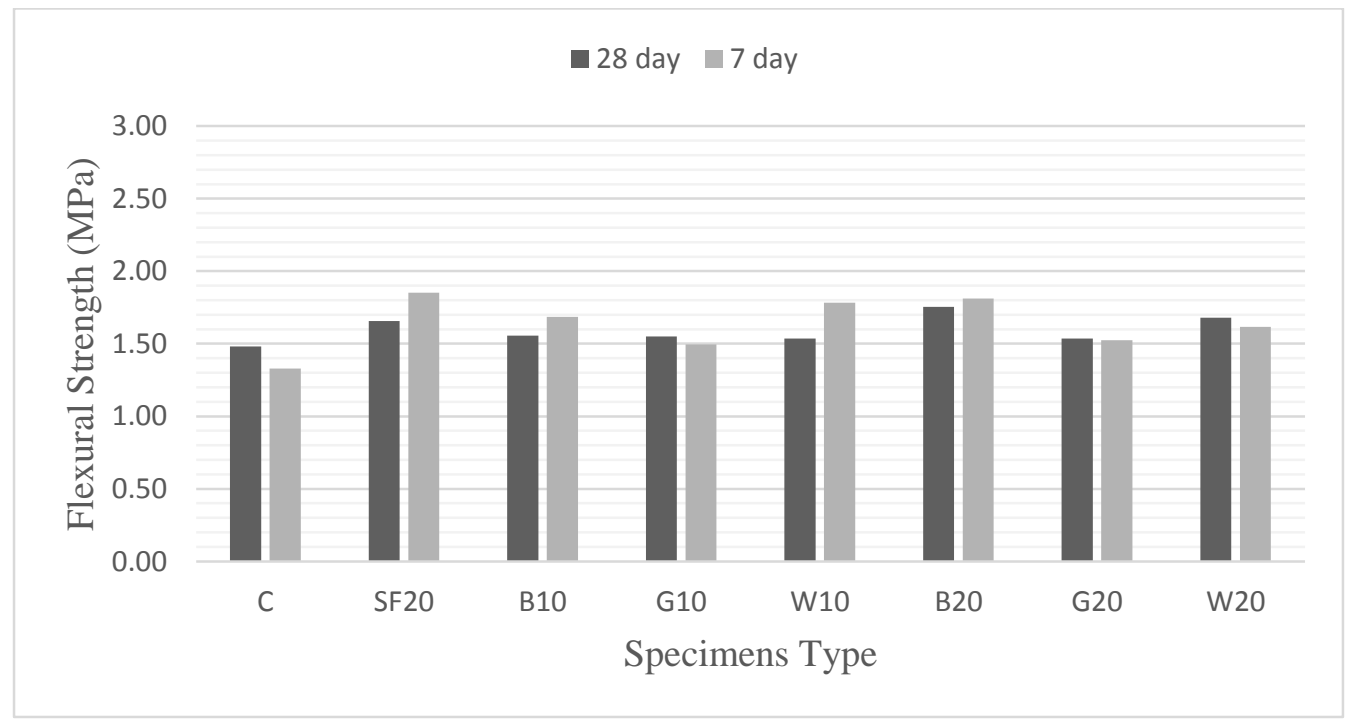

Figure 4.36: Effect of Different Colors and Quantities of GPs on 7 and 28 Days Flexural Strength for w/b 0.45 under $55^{\circ} \mathrm{C}$ Curing Temperature 
In addition, the rest of samples except for control mixture and W10 indicate a decline in flexural strength, as the age increased at this temperature. It can be seen that, all mortars modified by glass powder except for G10 and G20 exhibit higher flexural strength than SF20 in this temperature as it is demonstrated in (Fig 4.37).

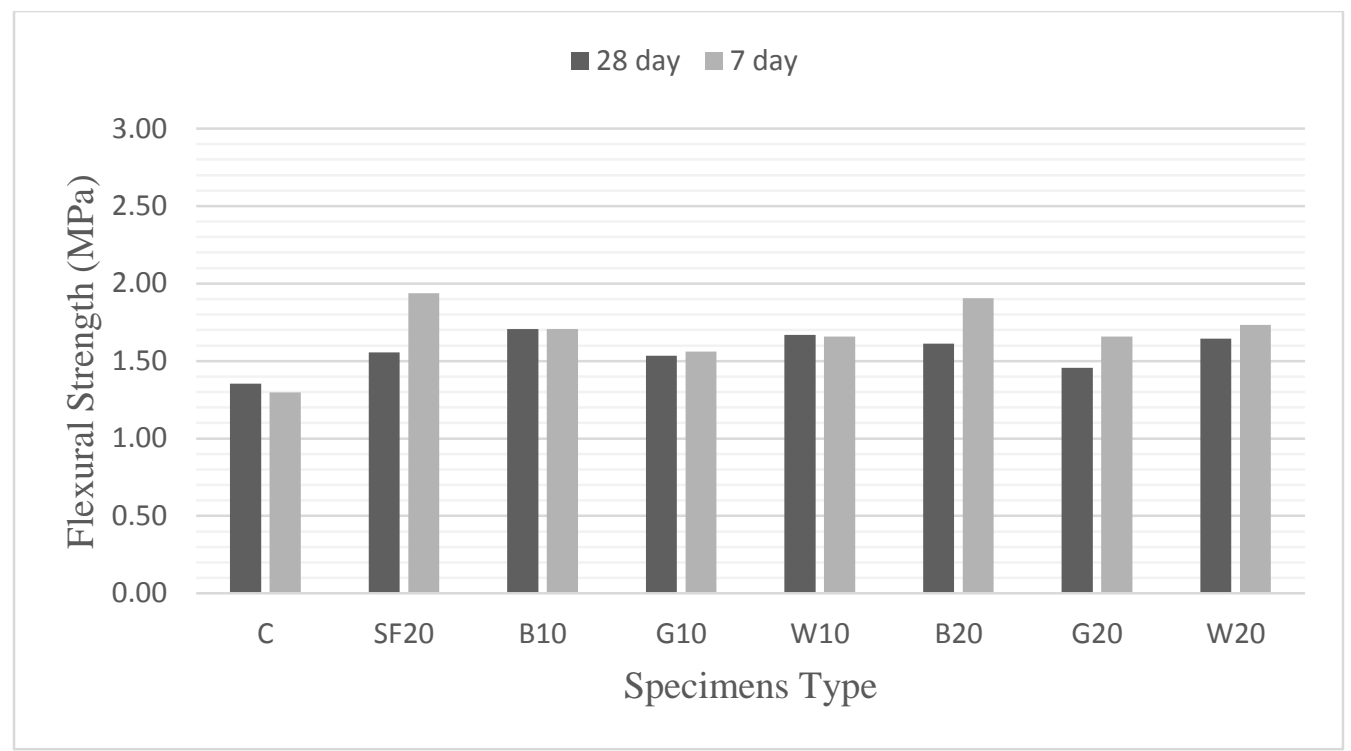

Figure 4.37: Effect of Different Colors and Quantities of GPs on 7 and 28 Days Flexural Strength for w/b 0.45 under $80^{\circ} \mathrm{C}$ Curing Temperature

Figure 4.38 shows the flexural strength of all mortars at w/b of 0.45 . Early and later flexural strength of control decreased by increasing the temperature in this level. Comparison between the early and later flexural strength of mortars in standard temperature showed a slight increase by passing the time. On the other hand, the later flexural strength decreased comparing to $7^{\text {th }}$ day flexural strength at higher temperatures. Besides, the rate of reduction of flexural strength increased as the temperature increased. Raising the temperature increases the rate of hydration and accelerates the pozzolanic reaction of SF and GP, which leads to hardened mortar exhibiting higher strength at early ages. On the other hand, high temperature curing 
conditions lead to the creation of larger pores in the paste, which affects the microstructure of paste and mortar and decreases the later strength of mortars.

Also, the early flexural strength of mortars modified with GP and SF except for G10 and W10 increased slightly by increasing the temperature up to 80 (comparing to other samples at different curing temperatures) (Fig 4.39).

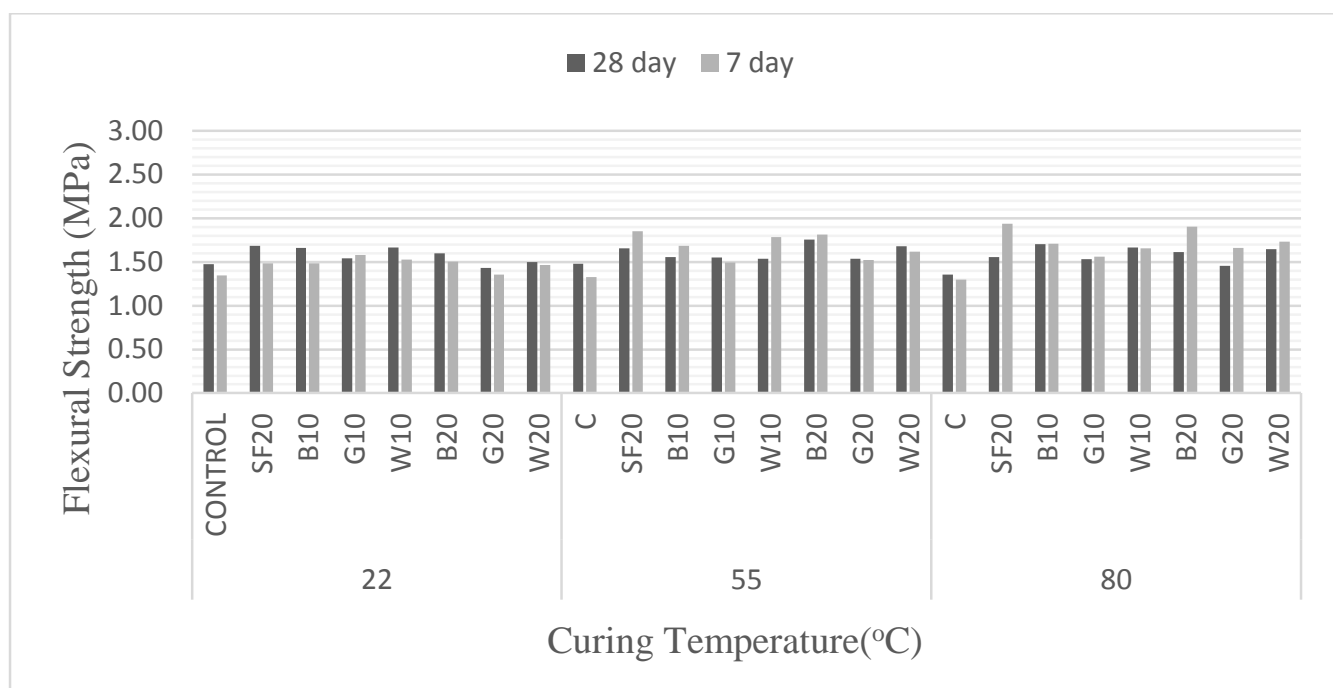

Figure 4.38: Effect of Different Colors and Quantities of GPs and Curing Temperatures on 7and 28-Days Flexural Strength for w/b 0.45

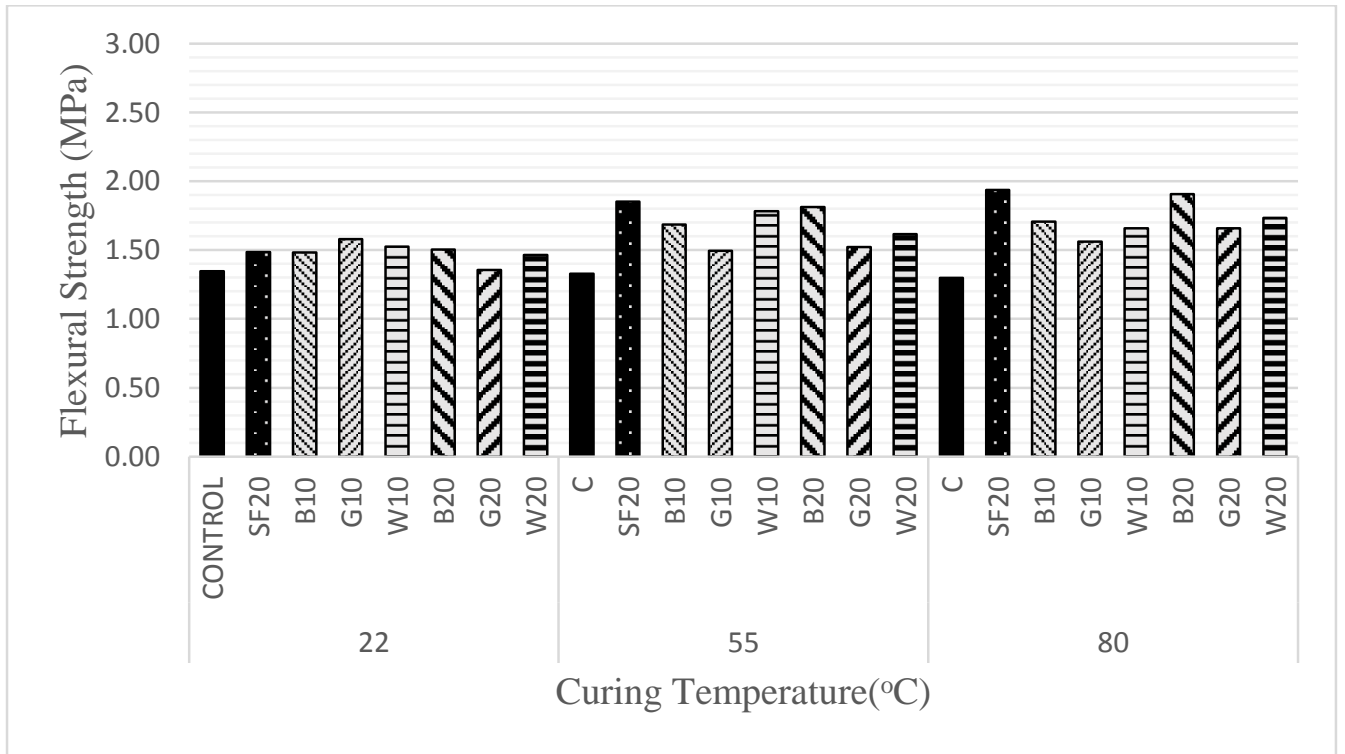

Figure 4.39: Effect of Different Colors and Quantities of GPs and Curing Temperatures on 7-Days Flexural Strength for w/b 0.45 
While, raising temperature from standard to 55 increased the flexural strength of B20, G20 and W20 in later age, while increasing more to 80 degrees decreased the flexural strength of these samples. However, the flexural strength of SF20, B10 and W10 at 55 degree of curing temperature exhibited the lowest amount between two other curing temperatures. The later age's flexural strength of G10 showed no change by changing temperature as it is shown in Fig 4.40.

As the effect of different $\mathrm{W} / \mathrm{b}$ ratios at standard temperature, the early and later flexural strength of control and SF20 reduced by increasing the water binder ratio from 0.35 to 0.40 and 0.45 . Increasing the $w / b$ from 0.35 to 0.40 for all mortars modified with GP except for W20 increase the flexural strength, and increasing the amount of water to 0.45 decrease the flexural strength in early and later ages as it is shown in Fig 4.41. It can be concluded that, the amount of water required to complete hydration for GP binders is higher than control and SF mortars at this temperature (Fig 4.41).

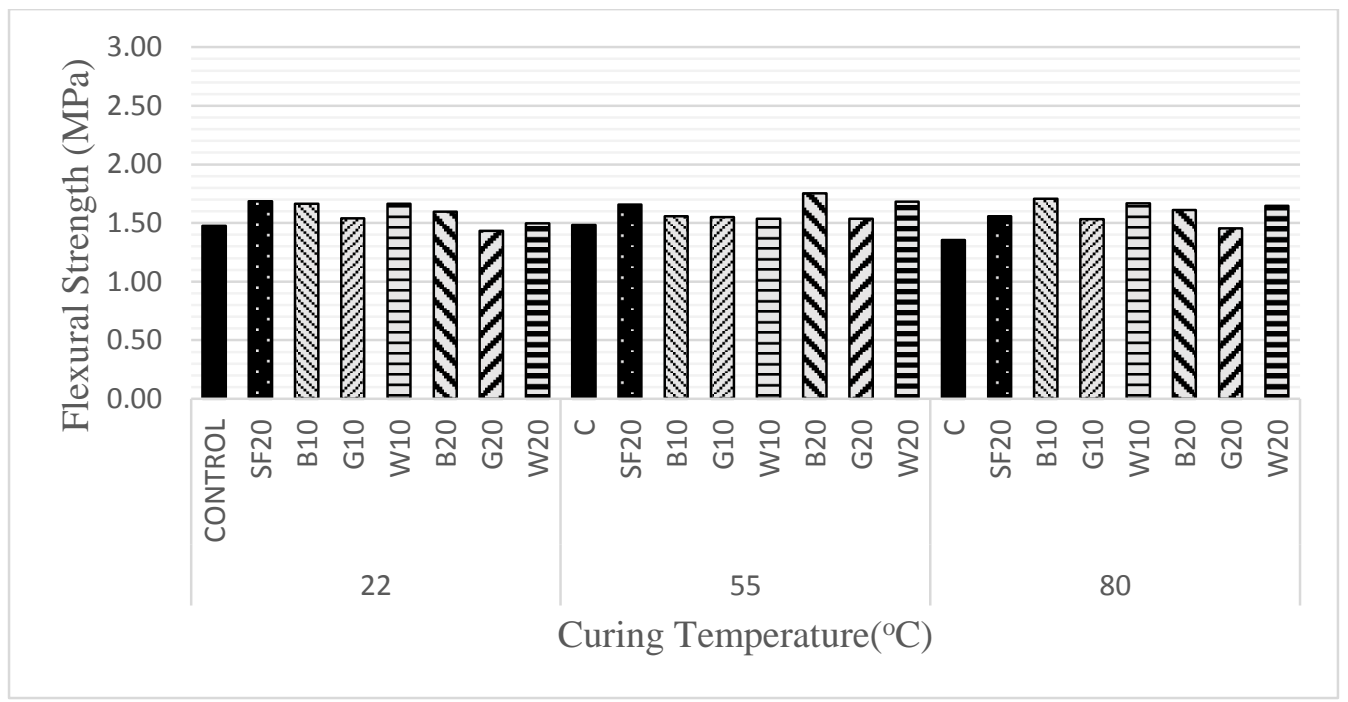

Figure 4.40: Effect of Different Colors and Quantities of GPs and Curing Temperatures on 28-Days Flexural Strength for w/b 0.45 


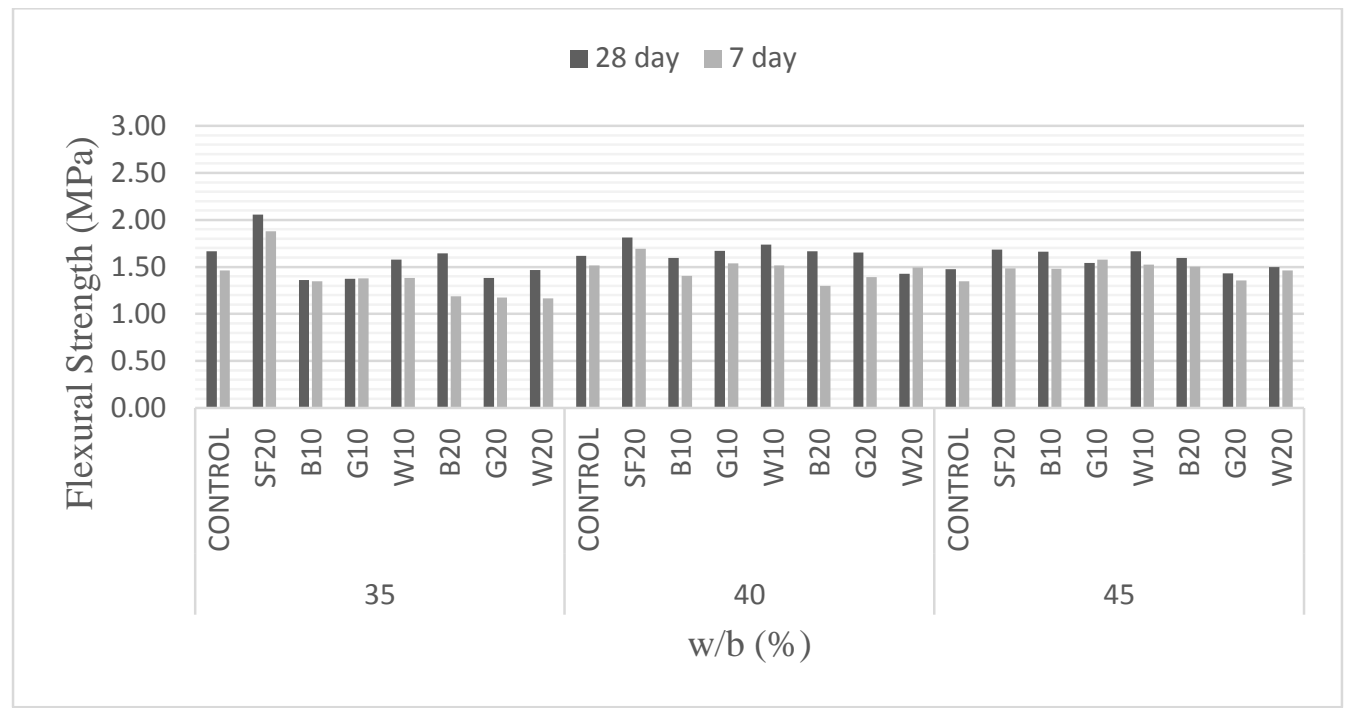

Figure 4.41: Effect of Different Colors and Quantities of GPs and w/b Ratios on 7 and 28-Days Flexural Strength for Curing Temperature of $22^{\circ} \mathrm{C}$

The flexural strength of all samples decreased as the water to binder increased to 0.40 and the temperature raised to 55 in early and later ages. However, the flexural strength of mixtures increased as the w/b increased from 0.40 to 0.45 in early and later ages. Comparison between 0.35 and 0.45 showed that, mortars exhibited higher flexural strength in w/b of 0.35 in later age as it shown in Fig 4.42.

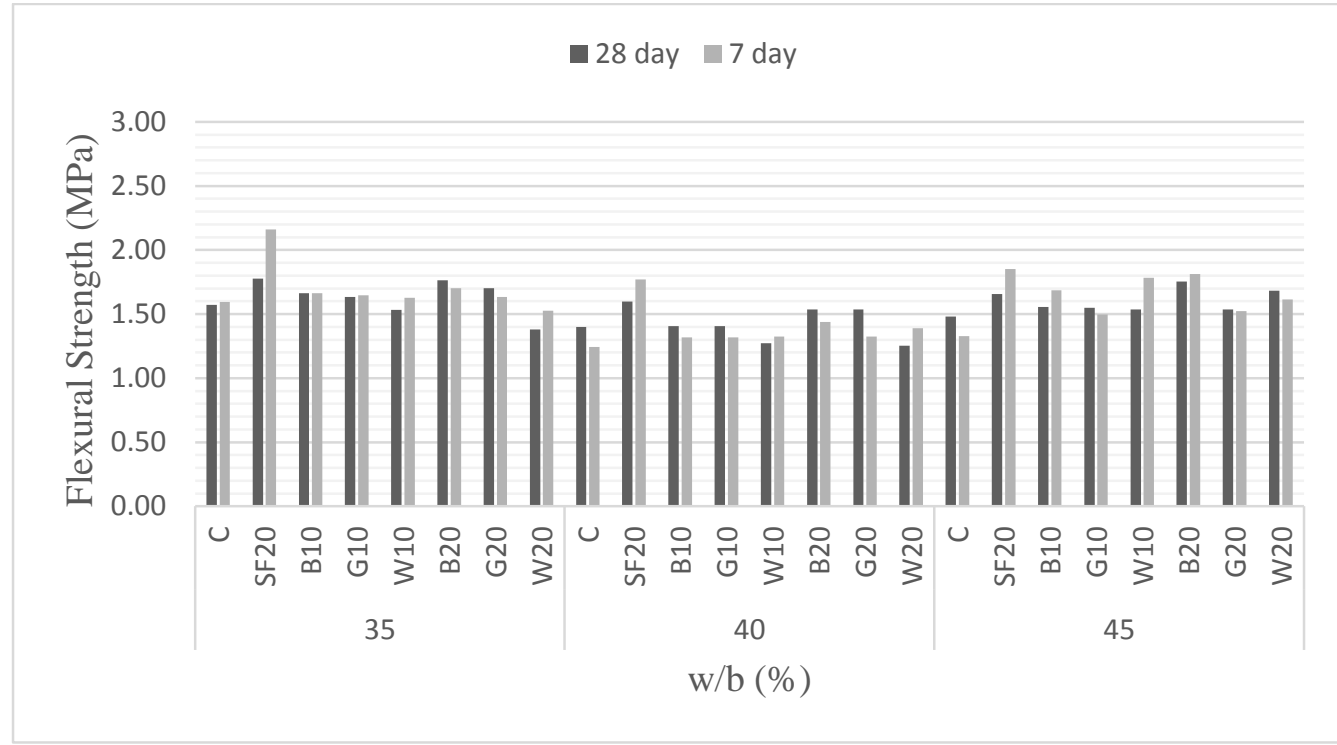

Figure 4.42: Effect of Different Colors and Quantities of GPs and w/b Ratios on 7 and 28-Days Flexural Strength for Curing Temperature of $55^{\circ} \mathrm{C}$ 
SF20 and W10, showed a reduction in flexural strength with passing time in later age comparing to early age within all different $\mathrm{w} / \mathrm{b}$ ratios. This drop in flexural strength also happened in w/b of 0.45 for all mortars modified with GP except for W20 and G10. It can be concluded that, the higher the water content increases, production of pores in paste increases more in high curing temperature (Fig 4.42).

The comparison between different water-binder ratios showed that, early flexural strength of all mortars except for G20 decreased as w/b increased from 0.35 to 0.40 at high temperature of $80^{\circ} \mathrm{C}$, (Fig 4.42). B10, B20, W10 and G20 exhibited higher early strength while the flexural strength of control, SF20, G10 and W20 decreased as the $\mathrm{w} / \mathrm{b}$ ratio raised from 0.40 to 0.45 . Generally, mortars with w/b ratio of 0.35 exhibited higher flexural strength in early and later ages. It can be noted that, reduction rate due to the increase of age was more significant in 80 degree of curing temperature than $55^{\circ} \mathrm{C}$.

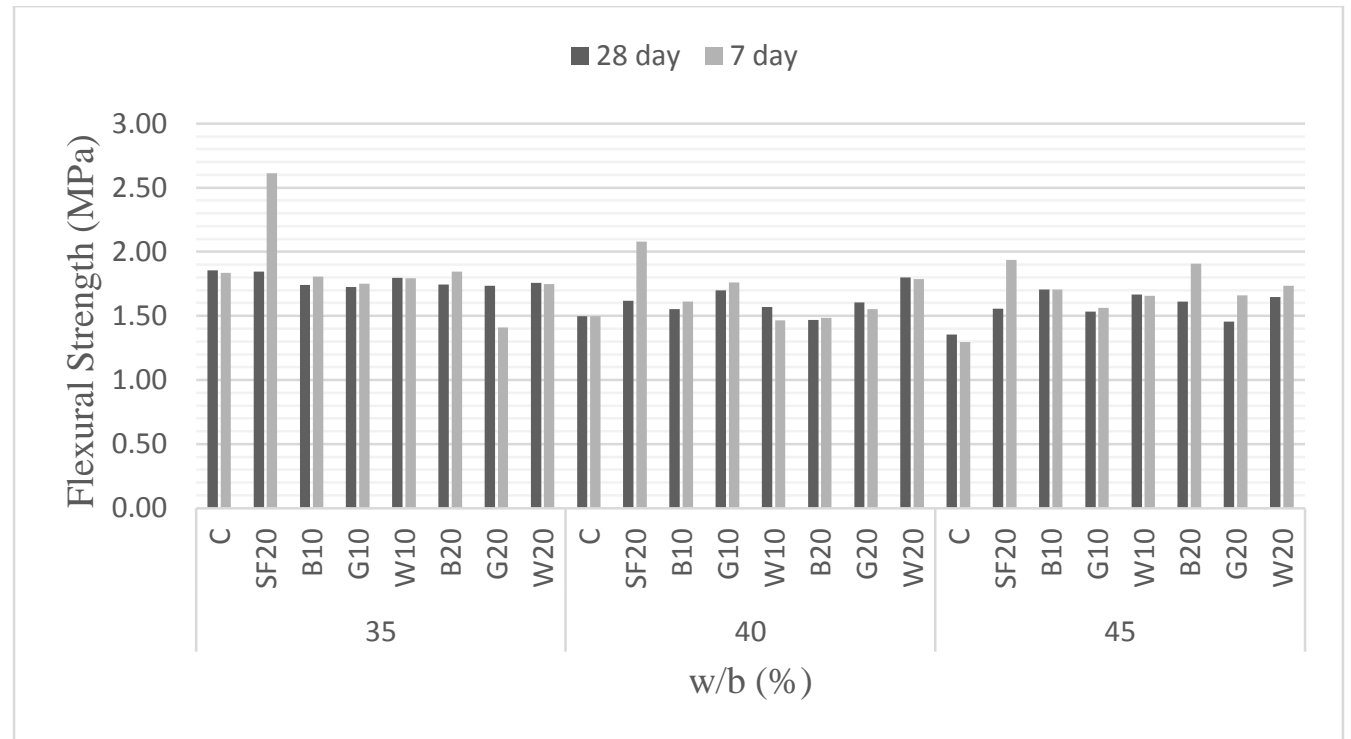

Figure 4.43: Effect of Different Colors and Quantities of GPs and w/b Ratios on 7 and 28-Days Flexural Strength for Curing Temperature of $80^{\circ} \mathrm{C}$ 


\subsection{Effect of GP Type and Quantity, w/b Ratio, and Curing Temperature on Modulus of Elasticity of HSM}

Effects of glass powder with different types, amounts, temperatures and water-binder ratios were investigated and results were compared with control mixture.

In water binder of 0.35 mortars which modified with $10 \%$ of BGP and cured at standard temperature (22) exhibited the highest modulus of elasticity among the others in this range of w/b. Comparison between specimens which cured at standard temperature showed that, all samples except for B10, B20 and W20 exhibited a lower modulus of elasticity than control mixture. In addition, increasing the amount of GGP and BGP decreased the modulus of elasticity while increasing the amount of WGP increased it. Modifications by SF or GPs showed negative effects on the modulus of decreasing elasticity at curing temperature of $55^{\circ} \mathrm{C}$ as it is shown in Fig 4.44. Comparisons between mortars except for WGP, which modified by GP showed that, increasing the amount of glass powder from $10 \%$ to $20 \%$ decreased the modulus of elasticity (Fig 4.44).

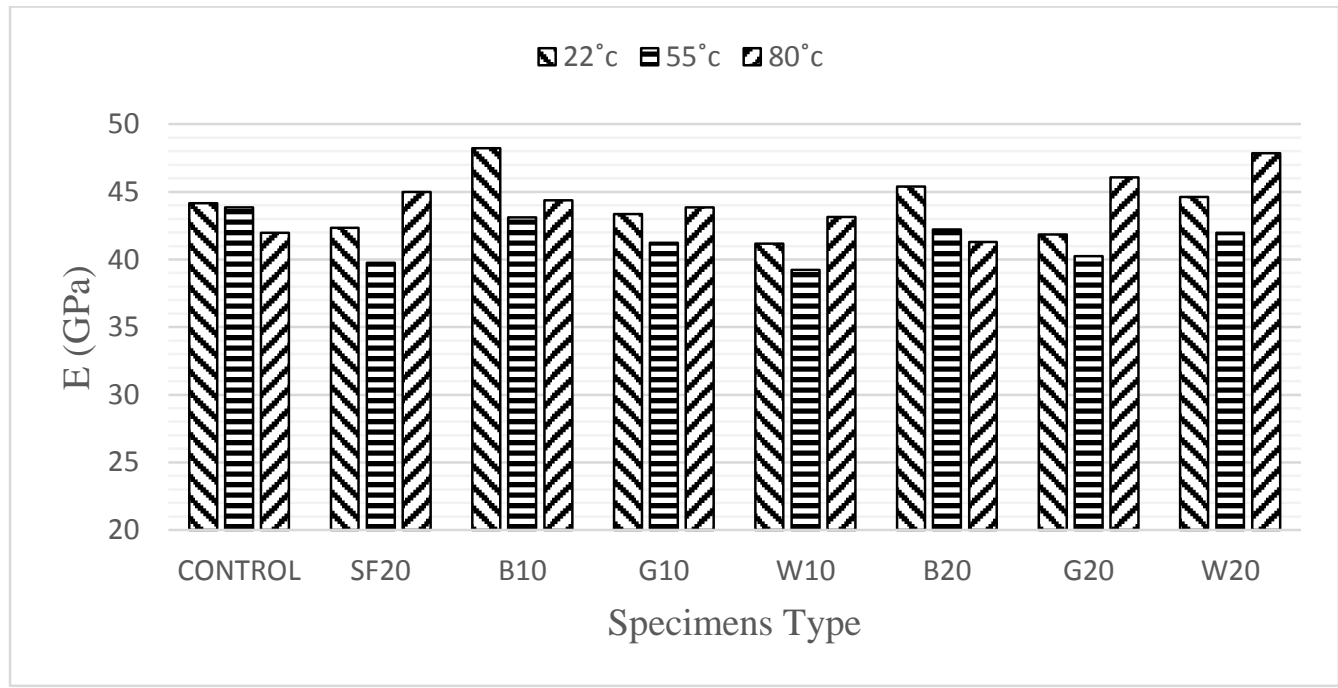

Figure 4.44: Effect of Different Colors and Quantities of GPs and Curing Temperatures on $\mathrm{E}$ for $\mathrm{w} / \mathrm{b} 0.35$ 
Modifications with glass powder and silica fume had some advantages on the modulus of elasticity at curing temperature of $80^{\circ} \mathrm{C}$ and all modified mortars except $\mathrm{B} 20$ exhibited a higher modulus of elasticity than control mixture (Fig 4.44).

As the temperature increased, the modulus of elasticity decreased at w/b of 0.40 in comparison to standard temperature. In addition, the lowest modulus of elasticity was at temperature of 55 except for control and W20. The E of all modified mortars was lower than E of control mixture and WGP at this temperature (55). Mortars, which were improved by BGP and WGP, showed higher modulus of elasticity than control and SF20 at $80^{\circ} \mathrm{C}$. Comparisons between curing temperatures of 55 and 80 showed that, within the process that modulus of elasticity of control decreased with increasing the temperature, mortars that were modified with GPs and SF except W20 showed higher modulus of elasticity by increasing the temperature as it is illustrated in Fig4.45.

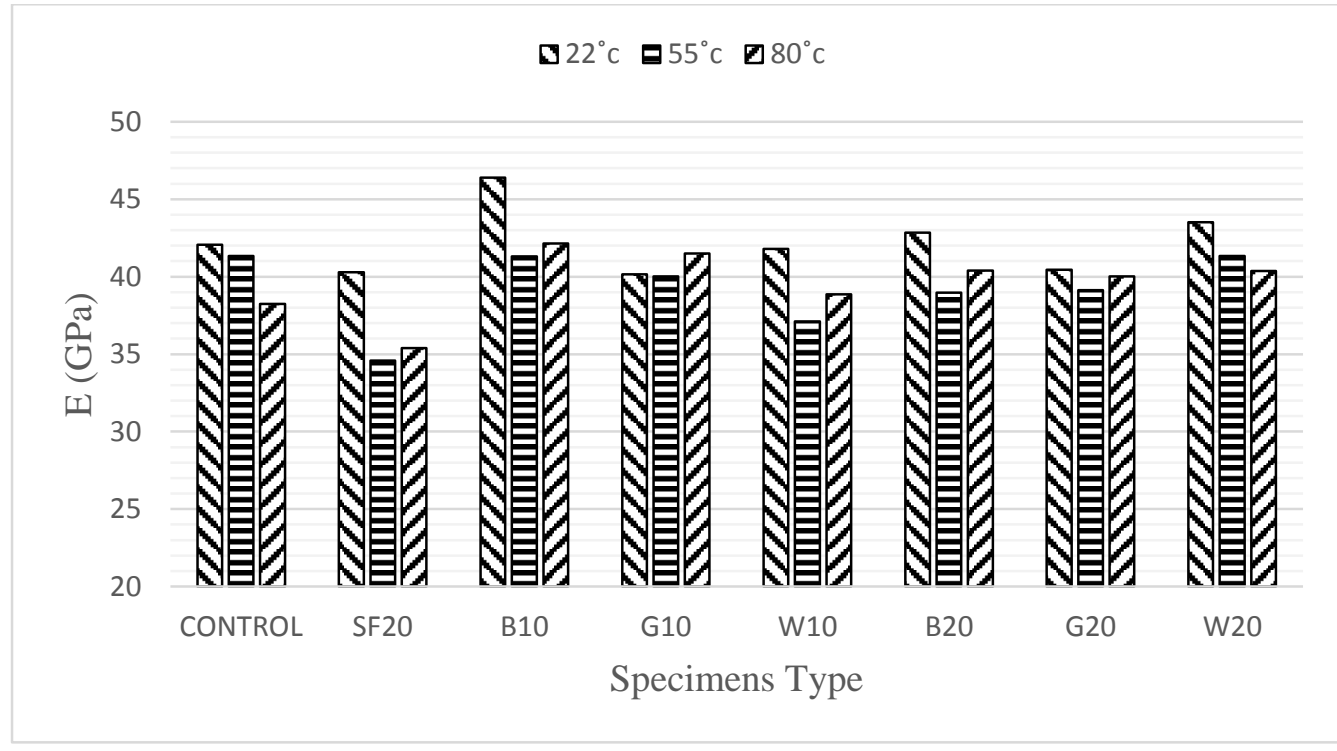

Figure 4.45: Effect of Different Colors and Quantities of GPs and Curing Temperatures on E for w/b 0.40

Fig 4.46 shows the amount of E-modulus for samples at w/b of 0.45 . B20 exhibited slightly higher modulus of elasticity than control mix at this water to binder ratio and 
at standard temperature, but the other mixtures showed lower E-modulus than control mix. The modulus of elasticity of mortars increased as the amount of GP increased at this temperature. As the fact of matter, the addition of GP have positive effects on E. Modulus of elasticity of B10, B20 and W20 were higher, while the rest especially SF20 showed lower modulus of elasticity than control mix at curing temperature of 55 . However, all mortars, which were modified with GP, exhibited a higher amount of Emodulus than control mix at $80^{\circ} \mathrm{C}$. The contrast among all mortars modified with glass powder at this temperature showed that, increasing the amount of GPs had positive effects of increasing of the E.

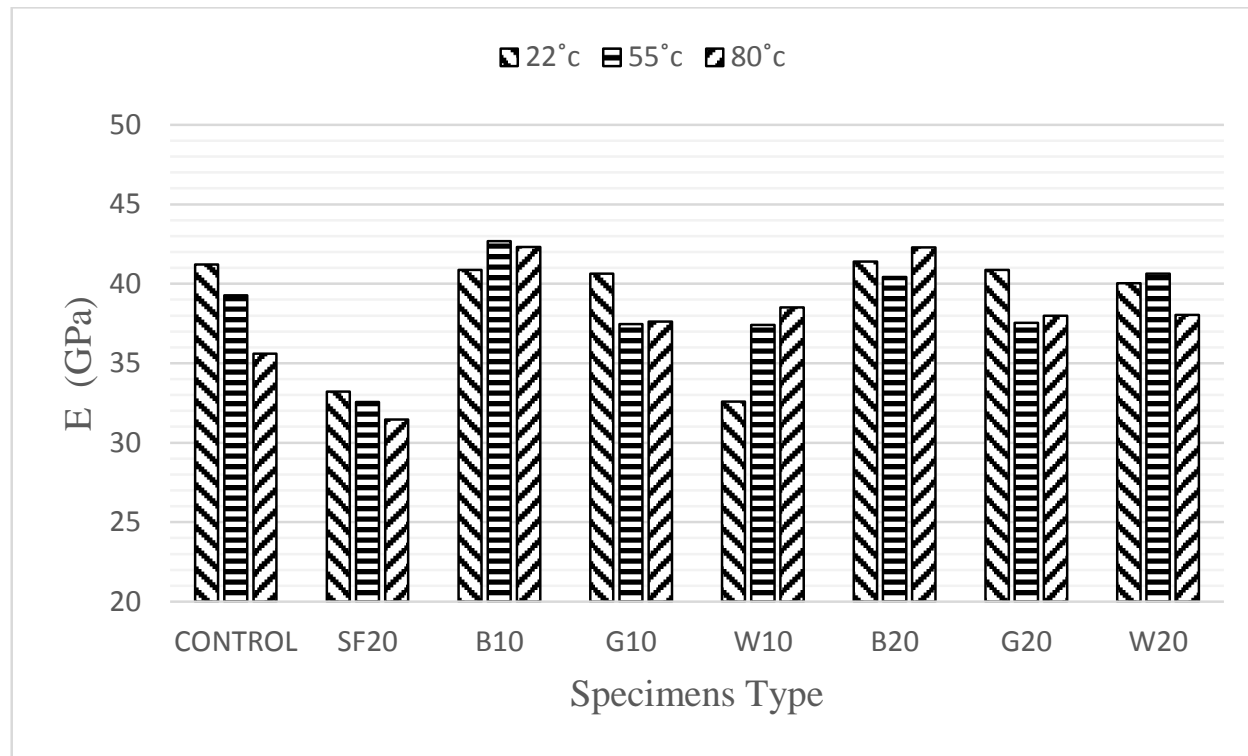

Figure 4.46: Effect of Different Colors and Quantities of GPs and Curing Temperatures on $\mathrm{E}$ for $\mathrm{w} / \mathrm{b} 0.45$

Fig 4.47 shows the comparison among the modulus of elasticity of all specimens that are prepared at standard curing temperature. Generally, as the w/b increased the E decreased. B10, B20 and W20 showed higher modulus of elasticity than control at w/b of 0.35 . This difference is also valid for $w / b$ ratio of 0.40 . But, only B20 showed higher amount of E-modulus than control mixture at w/b of 0.45. The increase BGP and GGP 
at w/b of 0.35 had negative effects on E-modulus, in fact decreased it, while increasing the amount of WGP increased the E. Addition in the amount of BGP decrease the modulus of elasticity at w/b of 0.40 , while increasing the GGP and WGP increases it slightly. The increase in the amount of all GPs showed to have positive effects on increasing of E-modulus at w/b of 0.45 .

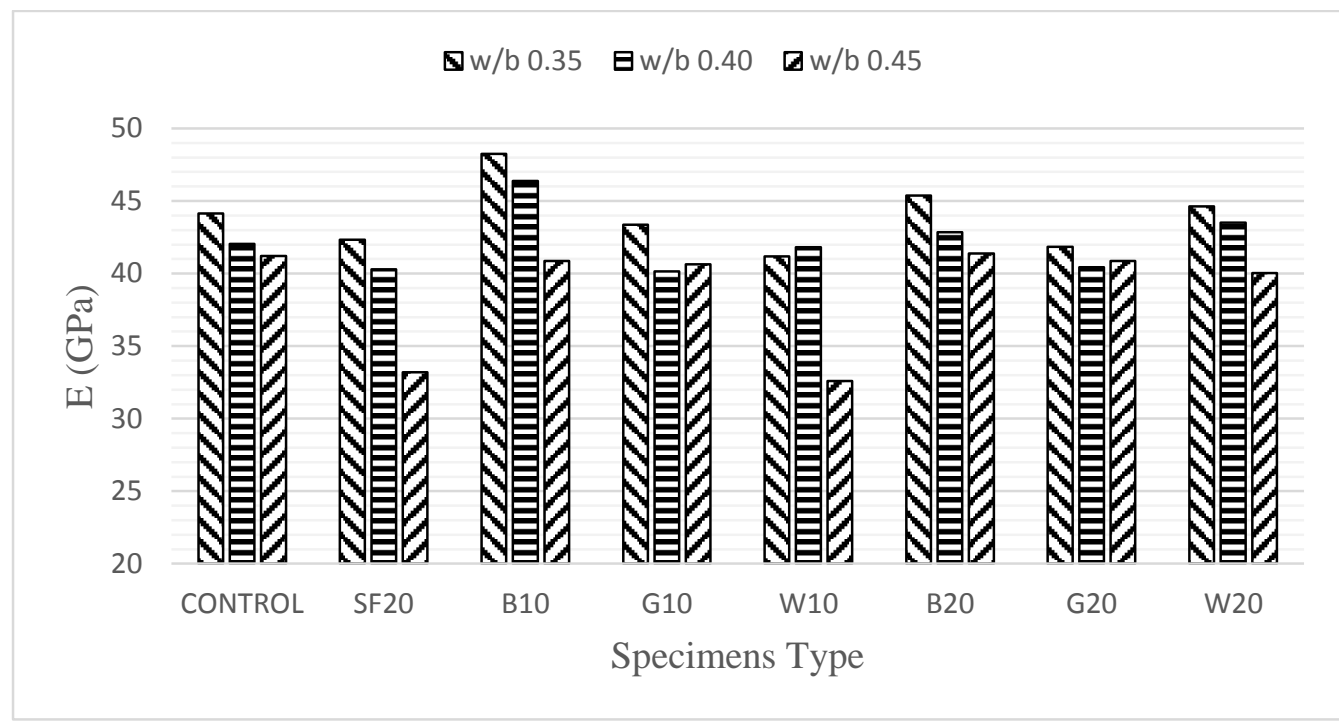

Figure 4.47: Effect of Different Colors and Quantities of GPs and w/b Ratios on $\mathrm{E}$ at Curing Temperature of $22^{\circ} \mathrm{C}$

E of all samples decreased as the w/b of increased from 0.35 to 0.40 at the curing temperature of 55 , but increasing the w/b more from 0.40 to 0.45 increased the $\mathrm{E}$ of B10, B20 and W10 and decreased the E-modulus of the rest. Increasing the amount of BGP and GGP increased the E, while addition in quantity of WGP decreased it in all w/b ratios as it is shown in Fig 4.48. 


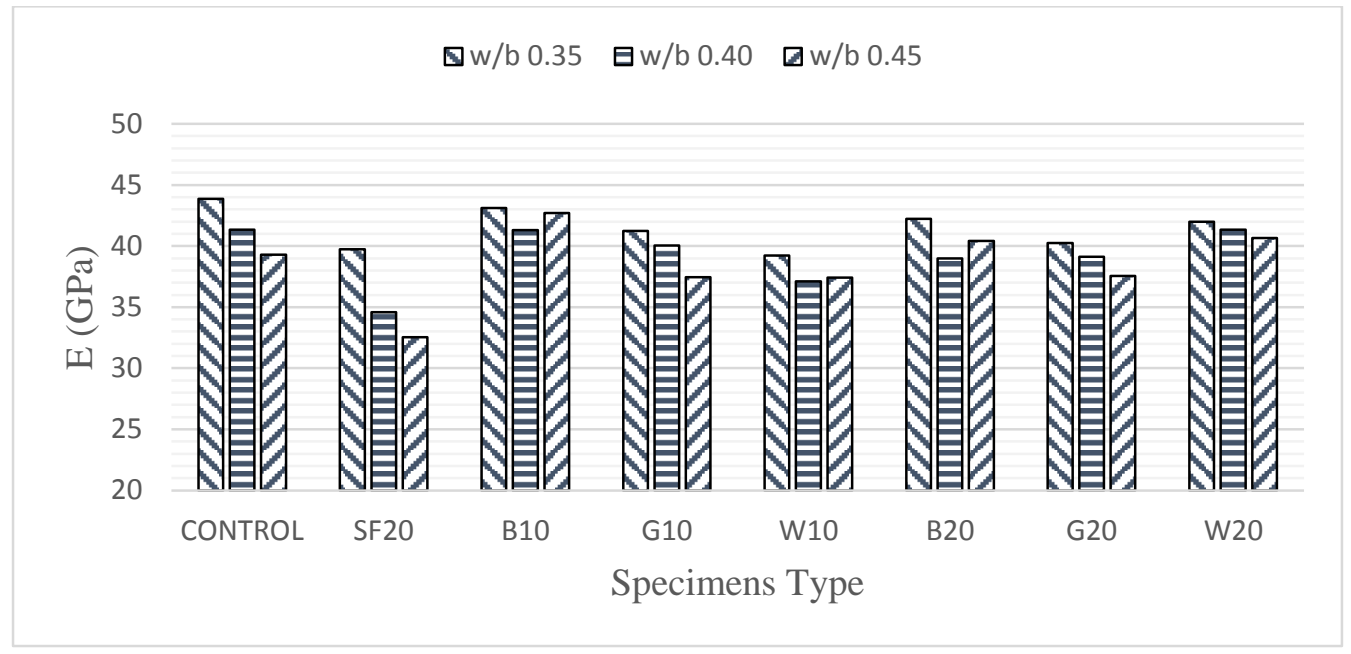

Figure 4.48: Effect of Different Colors and Quantities of GPs and w/b Ratios on $\mathrm{E}$ at Curing Temperature of $55^{\circ} \mathrm{C}$

Fig 4.49 illustrates modulus of elasticity of mortars, which cured in high temperature of $80^{\circ} \mathrm{C}$. Other samples except B20 exhibited a higher amount of E-modulus than control mix at w/b of 0.35 . Increasing the amount of glass powder increased the $\mathrm{E}$ of mortars in this w/b except for BGP. All mortars, which were modified with GP, showed higher E-modulus than control at w/b of 0.40 and 0.45 . Increasing the BGP and GGP decreased the $\mathrm{E}$ at w/b of 0.40 , but increasing the WGP increased it. Different amount of glass powders had no significant effect on $\mathrm{E}$ of mortars at w/b of 0.45 .

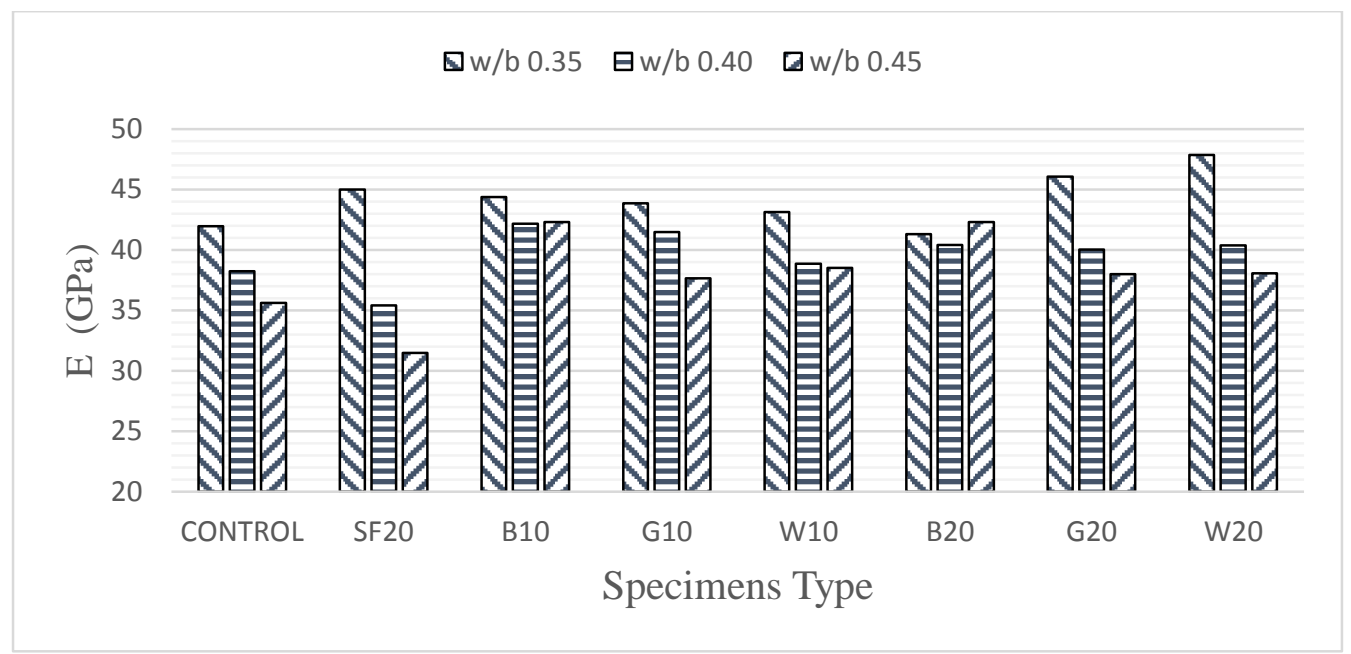

Figure 4.49: Effect of Different Colors and Quantities of GPs and w/b Ratios on $\mathrm{E}$ at Curing Temperature of $80^{\circ} \mathrm{C}$ 


\subsection{Rapid Chloride Permeability}

Rapid chloride permeability test is performed on brown glass powder at different proportions, normal curing condition and fixed w/b ratio of 0.45 . Results of RCPT showed that, the resistance of mortars modified with GP toward ionic penetration is increased as the amount of GP increased up to $10 \%$ and it is compared with control mix which is enlisted in table 4.1. However increasing the amount of GP from $10 \%$ to $20 \%$ decreased the resistance of mortar against chloride ions penetration. Generally, more amount of glass powder benefits the resistance of mortars toward ionic penetration. The reason can be found in glass powder particles size, which is smaller than cement particles and fills empty voids. With respect to pozzolanic reactivity of glass powder, the production of C-S-H components in the paste of mortar increased which filled empty voids due to expansion nature of $\mathrm{C}-\mathrm{S}-\mathrm{H}$ within production and decreased the permeability of mortars. It should be noted that, the amount of coulombs passed from SF20 was the lowest among the rest samples.

Table 4.1: Amount of charge passed from mortars at w/b of 0.45 and standard curing temperature

\begin{tabular}{lll}
\hline SPECIMEN & CHARGED & CLASSIFICATION \\
& PASSED $(M A)$ & \\
\hline C2245 & 2024 & Moderate \\
SF2245 & 378 & Very low \\
B102245 & 1033 & Low \\
B202245 & 1530 & Low \\
\hline
\end{tabular}

\subsection{Pozzolanic Activity Index of Glass Powders}

According to ASTM standard tests, pozzolanic /strength activity index of all glass powders and silica fume is investigated in this study to see whether all three types of GP are approved or not. The strength activity index of all samples compared and results 
are shown in Fig 4.50. Obviously, the strength activity of silica fume was higher than control mix and all other specimens. On the other hand, activity index of GPs was lower than control mix as they gained the minimum amount of activity index of $75 \%$, however all three samples are acceptable by ASTM standard. Comparison among all three samples that containing glass powder indicated that, the GGP and BGP exhibited highest and lowest strength activity index respectively.

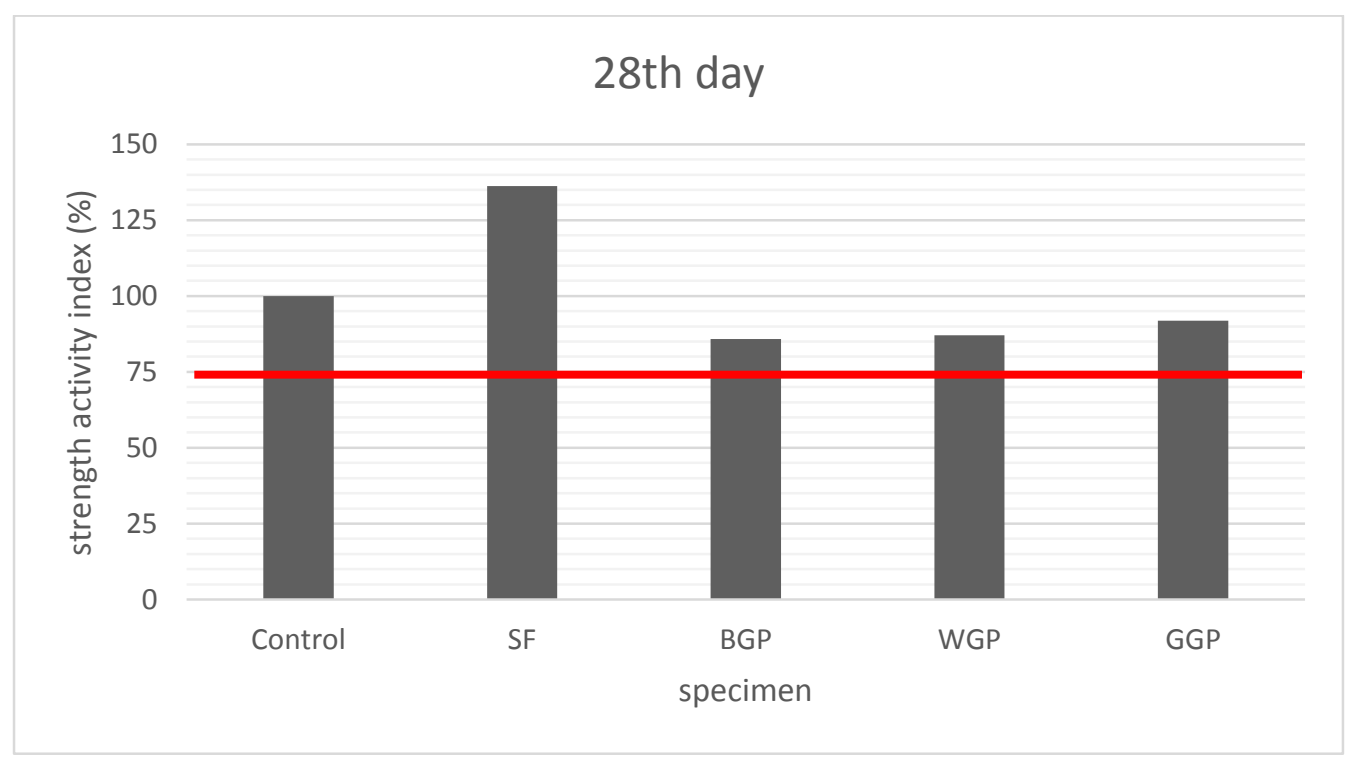

Figure 4.50: Strength Activity Index of GPs and SF at the Age of 28 Day 


\section{Chapter 5}

\section{CONCLUSION AND RECOMMENDATION}

\subsection{Conclusions}

In this study Effects of four independent variables, such as w/b, curing temperature, different types and quantities of glass powder on fresh and hardened properties of high strength mortars were investigated. The most significant outcomes are given below:

- Replacement of all types (colors) of glass powder, with quantities varying from $10 \%$ to $20 \%$ increased the workability. On the other hand, both the control and SF specimens showed lower workability than the glass powder ones. Silica fume achieving the lowest workability.

- Pozzolanic reactivity of glass powder increases with increase in curing temperature and decreases with increase in $\mathrm{w} / \mathrm{b}$ ratio.

- The lower the $\mathrm{w} / \mathrm{b}$ ratio and the higher the curing temperature, the higher is the $7^{\text {th }}$ day and $28^{\text {th }}$ day compressive strength. This condition is more obvious at 28 days compressive strength.

- Addition of glass powder decreased the flexural strength of mortars both at early and later ages at $0.35 \mathrm{w} / \mathrm{b}$ ratio and standard curing temperature. On the other hand, replacement of GGP and BGP increased the flexural strength of mortars at $55^{\circ} \mathrm{C}$ curing temperature. Generally, the early and later age flexural 
strength of mortars modified with glass powders increases by increasing the temperature of curing.

- The pozzolanic reactivity of all modified mortars with SF and GPs increased as the curing temperature increased.

- Raisin the temperature increased the rate of hydration and accelerates the pozzolanic reaction of SF and GP pozzolans.

- At low w/b ratio (0.35), increasing the glass powder replacement from $10 \%$ to $20 \%$ decreased the modulus of elasticity of GGP and BGP modified specimens, but increased the modulus of elasticity (E) of WGP ones under all three different curing temperatures.

- On the other hand, 0.40 and $0.45 \mathrm{w} / \mathrm{b}$ ratios mortars modified with all types and quantities of GP showed higher $\mathrm{E}$ than the control specimen under $80^{\circ} \mathrm{C}$ curing temperature.

- The value of young's modulus of mortars modified with all types and quantities of glass powders is close to the values of the control under $22^{\circ} \mathrm{C}$ but lower than control at $55^{\circ} \mathrm{C}$ curing temperature.

- The resistance of mortars modified with GP towards ionic penetration is increased when $10 \%$ of GP is used (comparing with control mix). However increasing the amount of GP from $10 \%$ to $20 \%$ decreased the resistance of mortar against chloride ions penetration. 
- Strength Activity index of GPs was lower than control mix. However all three samples are acceptable by ASTM standard as they gained the minimum amount of activity index of $75 \%$. In addition, comparison between all three samples that contained glass powder indicated that, the GGP and BGP exhibited highest and lowest strength activity index respectively.

\subsection{Recommendations}

1. Further experiments by using different quantities of glass powder could be examined with different $\mathrm{w} / \mathrm{b}$ ratios for normal and low strength mortars.

2. Effects of glass powders could be examined for longer ages than 28 days and curing temperature. 


\section{REFERENCES}

A.M Neville, J. B. (1987). concrete technology. london: pearson.

A.M.neville. (1995). properties of concrete. london: longman.

Aboshama, A. A. (2016). Utilization of waste glass powder in the production of cement and concrete. Construction and Building Materials, 124, 866-877.

ACI (American Concrete Institute). (2000). Report on High-Strength Concrete. Farmington Hill,: American Concrete Institute.

Ansari Ismail, S. S. (2015). utilization of glass powder as a partial replacement of cement and its effect on concrete strength. IRF InternationalConference, 1-5.

Bingol, F. A. (2013). Effects of different curing regimes on the compressive strength properties of self compacting concrete incorporating fly ash and silica fume. Mater Des, 51, 8-12.

Boubekeur, T. K. (2014). Estimation of mortars compressive strength at different curing temperature by the maturity method. construction and building materials(71), 299-307.

Bouzoubaa, N. (2002). Mechanical properties and durability of concrete made with high volume fly ash blended cement produced in cement plant. ACI Material Journal, 99(7), 560-567. 
Caijun Shia, Y. W. (2005). Characteristics and pozzolanic reactivity of glass powders. Cement and Concrete Research, 35, 987-993.

Chikhalikar, S. (2012). An experimental investigation on characteristics properties of fibre reinforced concrete containing waste glass powder as pozzolan. 37th Conference on Our World in Concrete and Structures. Singapore.

Chini, A. L. (2003). Determination ofmaximum placement and curing temperatures in mass concrete to avoid durability problems and DEF. Florida: Department of Transportation.

Cwirzen, A. (2007). The effect of the heat-treatment regime on the properties ofreactive powder concrete. Adv. Cem. Res, 25-34.

Dali, J. S. (2012). Performance of concrete containing mineral admixtures subjected to high temperature. 37th Conference on Our World in Concrete and Structures. Singapore.

Derabla, R. (2014). Characterization of heat-treated self-compacting concrete containing mineral admixtures at early age and in the long term. Construction and Building Materials(66), 787-794.

Elkhadiri, I. M. (2009). Effect of curing temperature on cement hydration. Silikaty, 2(53), 65-75. 
Grace. (2006). Understanding AASHTO T277 and ASTM C1202 Rapid Chloride Permeability Test. Ajax, Ontario.

Hani H. Nassif, H. N. (2005). Effect of pozzolanic materials and curing methods on the. Cement \& Concrete Composites(27 ), 661-670.

Haranki, B. (2009). strength, modulus of elasticity, creep and shrinkage of concrete. florida: university of florida.

Idir R, C. M.-H. (2010). Use of fine glass as ASR inhibitor in glass aggregate mortars. Construction Building Materials, 24(13), 9-12.

Ismail Ansari, S. S. (2015). Utilization Of Glass Powder As A Partial Replacement Of Cement And Its Effect On Concrete Strength. IRF International Conference, 1-5.

Johnston, C. (1974). Waste glass as coarse aggregate for concrete. ASTM j test eval, 44-50.

Jos Olivier, G. J.-M. (2015). Trends in global CO2 emissions. Den Haag: PBL Publishers.

joseph F.lamond, j. H. (2006). significans of tests and properties of concrete and concrete making materials. west conshohoken: astm international. 
Kamali, m. A. (2016). An investigation into the hydration and microstructure of cement pastes modified with glass powders. Construction and Building Materials, $112,915-924$.

Khatib, J. ,. (2012). Glass powder utilization in concrete production. Eur. J. Appl. Sci,, 4(4), 173-176.

Kumarappan, N. (2013). Partial replacement cement in concrete using waste glass. Eng. Res. Technol, 10(2), 34-41.

Larrard, F. d. (1999). Concrete Mixture proportioning, A scientific approach. Taylor \& Francis. New York.

Limbachiya, M. (2009). Bulk engineering and durability properties of washed glass sand concrete. Constr Build Material, 23(10), 78-83.

Lothenbach, B. W. (2007). Effect of temperature on the pore solution, microstructure and hydration products of Portland cement pastes. cement and concrete research, $4,483-491$.

Mesbah H, L. M. (2002). Determination of elastic properties of high-performance concrete at early age. ACI Material journal, 1(99), 37-41.

Meyer C. (1999). Use of recycled glass and fly ash for precast concrete. Material Civil engineering, 11, 89-90. 
Meyer, C. X. (1999). Use of recycled glass and fly ash for precast concrete. Mater Civ eng, 11, 89-90.

Miguel Ángel Sanjuán, C. A. (2015). Effect of silica fume fineness on the improvement of Portland cement strength performance. Construction and Building Materials, 96, 55-64.

Mirzahosseini, M. K. (2014). Effect of curing temperature and glass type on the pozzolanic reactivity of glass powder. Cement and Concrete Research, 58, 103111.

Mirzahosseini, M. K. (2015). Influence of different particle size on reactivity of finely ground glass as supplementary cementitious material (SCM). Cement \& Concrete Composites, 56, 95-105.

Nassif H., S. N. (2002). Effect of curing methods on durability of concrete pavements. Journal of the Transportation Research Board, 2, 31-39.

Neithalath, N. J. (2009). Hydration in high-performance cementitious systems containing vitreous calcium aluminosilicate or silica fume. cement and concrete research, 39, 473-481.

Nishikawa, T. ,. (1995). fracture behavior of hardened cement paste incorporation mineral additions. Cement and concrete Research, 14(8), 1218-1224. 
Pade, C. M. ( 2007). The CO2 uptake of concrete in a 100 year perspective. Cement concrete research, 37(9), 1348-1356.

Paillère, A. B. (1989). Effect of fiber addition on the autogenous shrinkage of silica fume concrete. ACI Materials Journal, 2(86), 139-144.

Patil, D. K. (2013). Experimental investigation of waste glass powder as partial replacement of cement in concrete. Advanced Technology in Civil Engineering., 2(1).

Pereira de Oliveira, L. (2005). Optimization of pozzolanic reaction of ground waste glass incorporated in cement mortars. Cement \& Concrete Composites(27), 319327.

Sarıdemir, M. ( 2013). Effect of silica fume and ground pumice on compressive strength and modulus of elasticity of high strength concrete. Construction and Building Materials, 49, 484-489.

Schwarz. (2008). Influence of a fine glass powder on cement hydration: comparison to fly ash and modeling the degree of hydration. Cem. Concr. Res., 38, 429-436.

Schwarz N, C. H. ( 2008). Influence of a fine glass powder on the durability characteristics of concrete and its comparison to fly ash. Cem Concr Compos, 30(4), 86-96. 
Serdar, A. B. (2007). Effect of pumice and fly ash incorporation on high temperature resistance of cement based mortars. Cement and Concrete Research, 24(7), 988995.

Shao Y, L. T. (2000). Studies on concrete containing ground waste glass. cement concrete research, 30, 91-100.

Shao Y, L. T. (2000). Studies on concrete containing ground waste glass. Cement and Concrete Research, 30, 91-100.

Shayan, A. X. (2006). Performance of glass powder as a pozzolanic material inconcrete: a field trial on concrete slabs. Cement concrete research, 24(5), 45768.

Shi C, W. Y. (2005). Characteristics and pozzolanic reactivity of glass powders. cement concrete research, 35(9), 87-93.

Siddique, R. (2008). Waste Materials and By-products in Concrete. Springer Verlag, $18(15), 50-62$.

Siddique, R. (2008). Waste Materials and By-products in Concrete. Springer-Verlag.

Soliman, N. A. (2016). Development of ultra-high-performance concrete using glass powder toward ecofriendly concrete. Construction and Building Materials, 125, 600-612. 
Soroushian, P. (2012). Strength and durability of recycled aggregate concrete containing milled glass as partial replacement for cement. Constr. Build. Material, 29, 368-377.

standard, A. (2016). ASTM International. Retrieved from www.astm.org

Vandhiyan, R. K. (2013). Experimental study on replacement of cement by glass powder. Int. J. Eng. Res. Technol,, 2(5), 234-238.

Vijayakumar, G. H. (2013). Studies on mechanical properties of concrete containing waste glass powder as a partial replacement of cement in concrete. Int. J. Emerg. Technol. Adv. Eng, 2(3), 153-157.

Wang, Z. C. (2009). Effect of glass powder on chloride ion transport and alkaliaggregate reaction expansion of lightweight aggregate concrete. Wuhan University of Technology and Science, 24, 312-317.

William Henry glanville, A. R. (1947). The Grading of Aggregates and Workability of Concrete. London: Pl. 23.

Yanzhou, P. Z. (2015). Properties and microstructure of reactive powder concrete having a high content of phosphorous slag powder and silica fume. Construction and Building Materials, 34(5), 482-487. 
Yue Wang, M. A. (2016). Impacts of various factors on the rehydration of cementbased materials with a low water-binder ratio using mathematical models. Construction and Building Materials, 125, 160-167. 


\section{APPENDICES}


Appendix A: Effect of Different Gradients on Compressive Strength of mortars
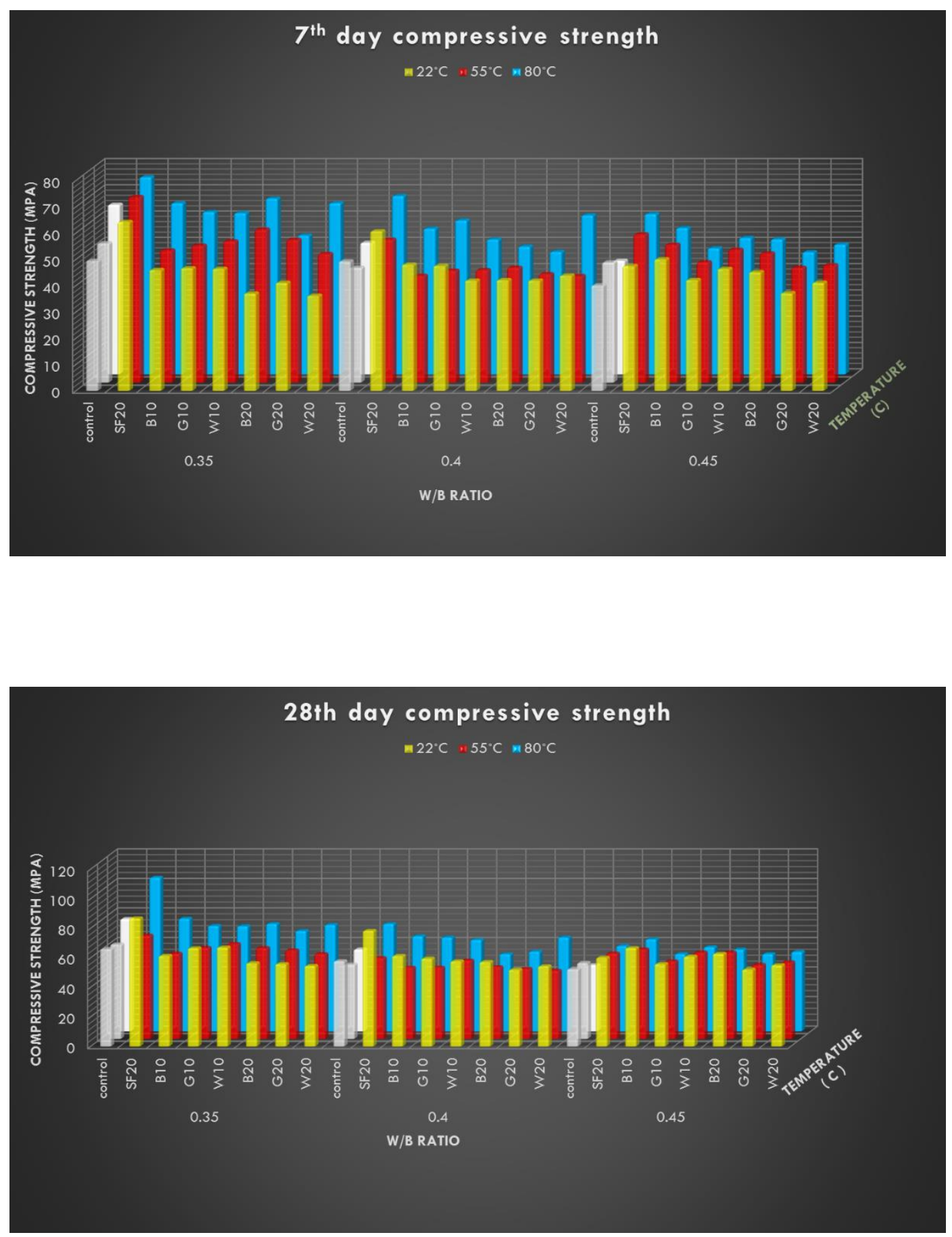
Appendix B: Effect of Different Gradients on Flexural Strength of Mortars
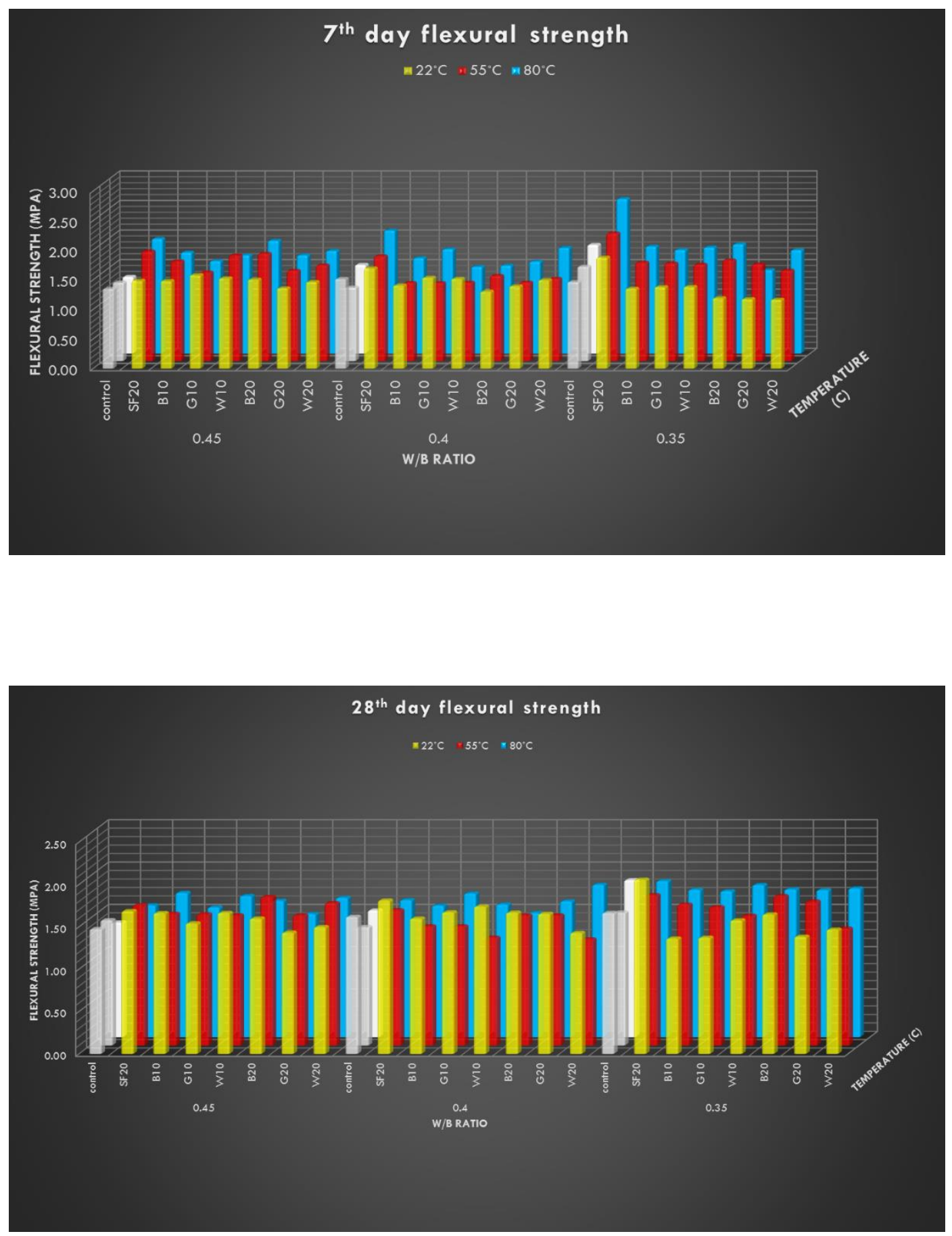
Appendix C: Effect of Different Ingredients on Modulus of Elasticity of Mortars

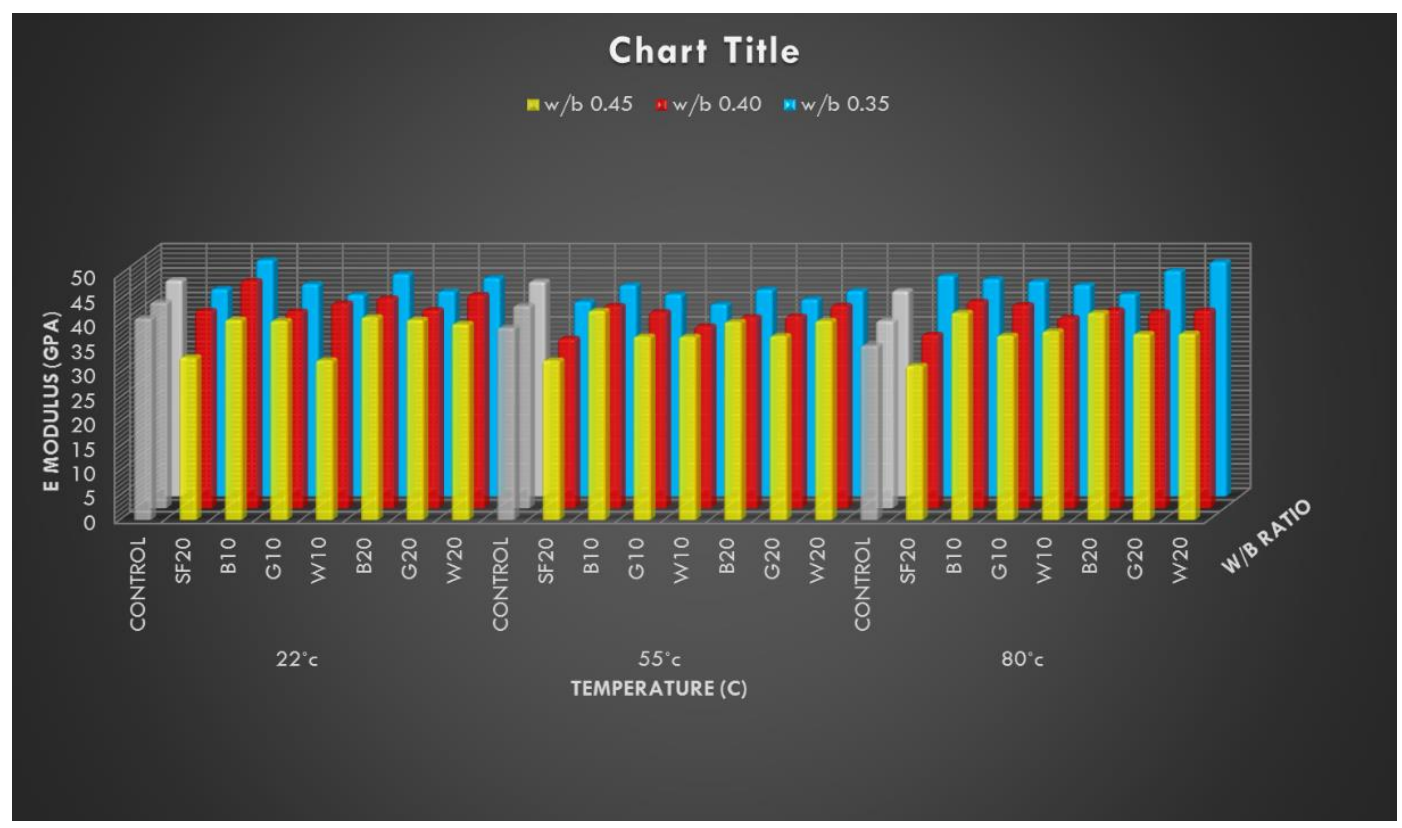

